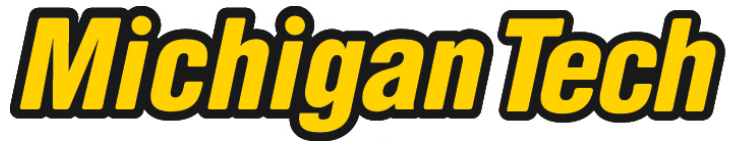 \\ Michigan Technological University Create the Future Digital Commons @ Michigan Tech
}

Experimental results on gravity driven fully condensing flows in vertical tubes, their agreement with theory, and their differences with shear driven flows' boundary-condition sensitivities

Jorge H. Kurita

Michigan Technological University

Follow this and additional works at: https://digitalcommons.mtu.edu/etds

Part of the Mechanical Engineering Commons

Copyright 2011 Jorge H. Kurita

Recommended Citation

Kurita, Jorge $\mathrm{H}_{\text {., " }}$ "Experimental results on gravity driven fully condensing flows in vertical tubes, their agreement with theory, and their differences with shear driven flows' boundary-condition sensitivities", Dissertation, Michigan Technological University, 2011.

https://doi.org/10.37099/mtu.dc.etds/379

Follow this and additional works at: https://digitalcommons.mtu.edu/etds

Part of the Mechanical Engineering Commons 


\title{
EXPERIMENTAL RESULTS ON GRAVITY DRIVEN FULLY CONDENSING FLOWS IN VERTICAL TUBES, THEIR AGREEMENT WITH THEORY, AND THEIR DIFFERENCES WITH SHEAR DRIVEN FLOWS' BOUNDARY-CONDITION SENSITIVITIES
}

\author{
By \\ Jorge H. Kurita

\begin{abstract}
A DISSERTATION
Submitted in partial fulfillment of the requirements for the degree of DOCTOR OF PHILOSOPHY (Mechanical Engineering-Engineering Mechanics)
\end{abstract}

MICHIGAN TECHNOLOGICAL UNIVERSITY

2011

Copyright $^{\circledR}$ Jorge H. Kurita 
This dissertation, "Experimental Results on Gravity Driven Fully Condensing Flows in Vertical Tubes, their Agreement with Theory, and their Differences with Shear Driven Flows' Boundary-Condition Sensitivities," is hereby approved in partial fulfillment of the requirements for the degree of DOCTOR OF PHILOSOPHY in MECHANICAL ENGINEERING-ENGINEERING MECHANICS.

Department of Mechanical Engineering-Engineering Mechanics

Signatures:

Dissertation Advisor

Dr. Amitabh Narain, Professor

Department Chair

Dr. William W. Predebon, Professor

Date 


\section{Table of contents}

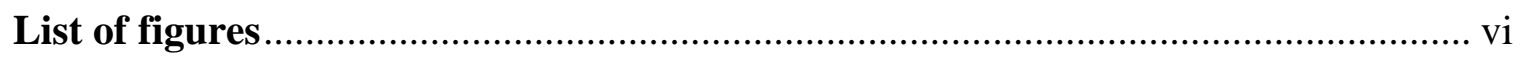

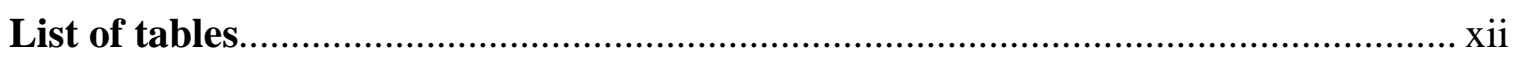

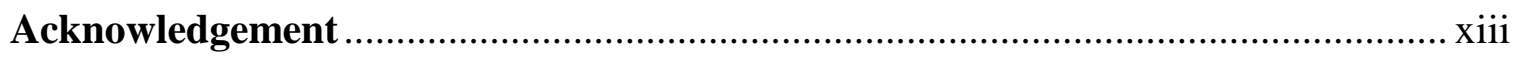

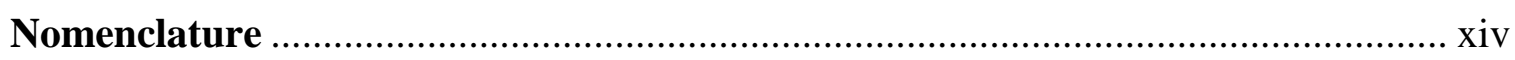

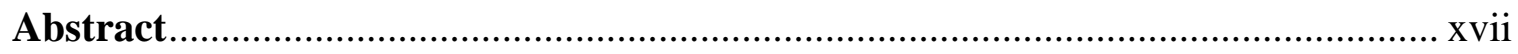

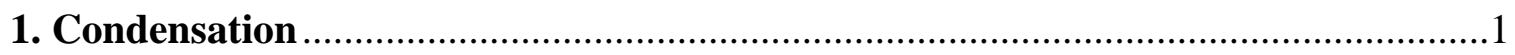

1.1 Dimensionless Parameters in Condensation ........................................................1

1.1.1 Nusselt Condensation............................................................................ 1

1.1.2 Gravity Driven Flow Condensation ......................................................... 2

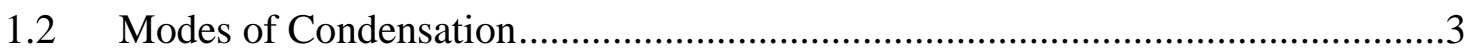

1.3 Laminar Film Condensation on a Vertical Plate (Nusselt Analysis) .....................5

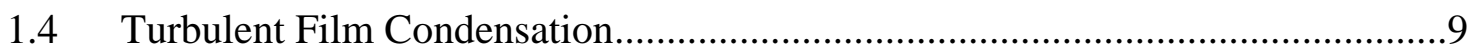

1.5 Other Models for Laminar Wavy Region with Interfacial Waves ......................12

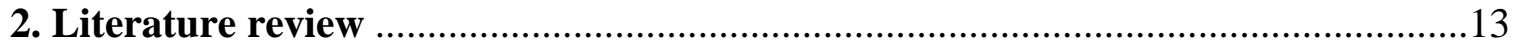

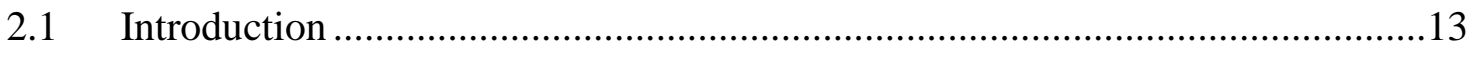

2.2 Analytical Studies ...............................................................................

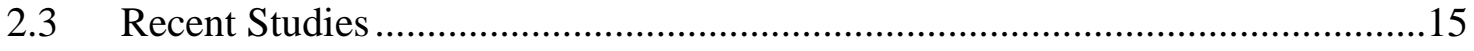

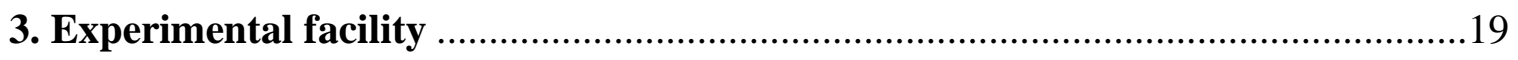

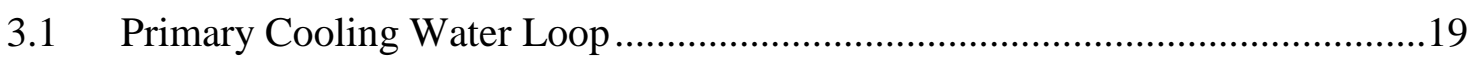

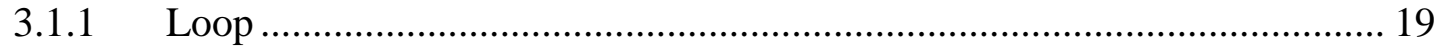

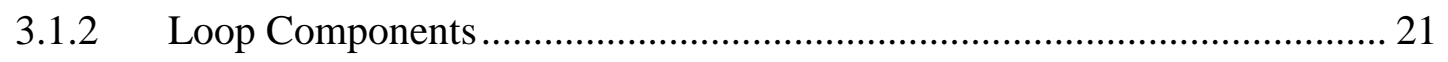

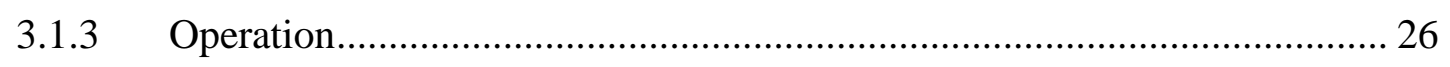

3.1.4 Recommendations on the Primary Loop...................................................... 26

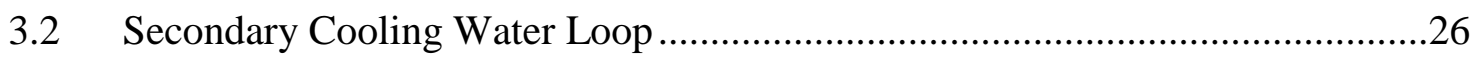

3.2.1 Koolant Water Chiller Loop Components .................................................. 27 


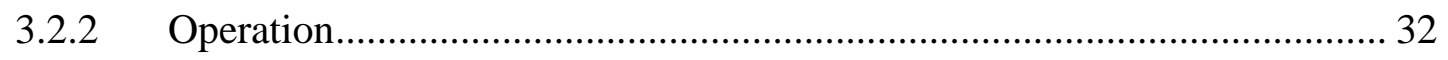

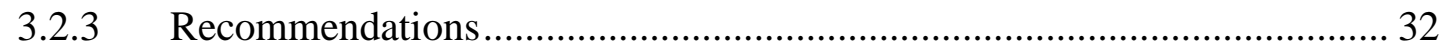

3.2.4 Teca Secondary Cooling Water Loop ........................................................ 32

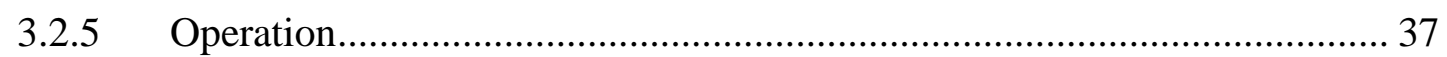

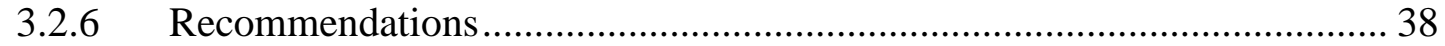

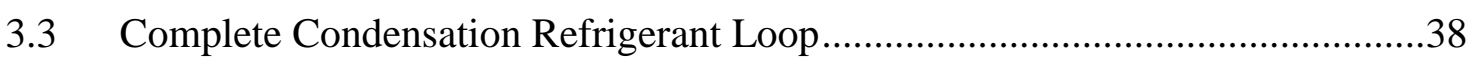

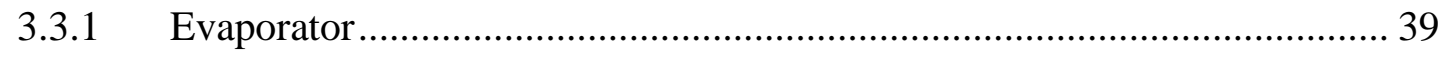

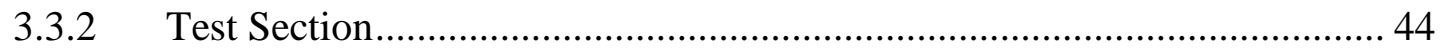

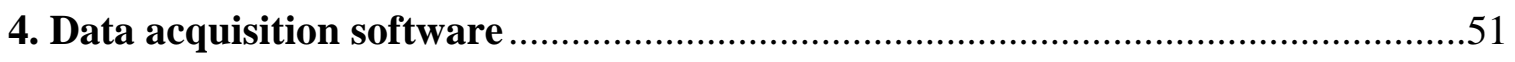

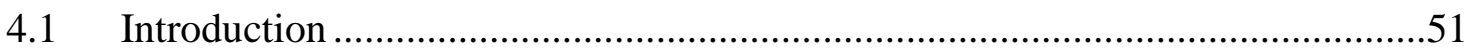

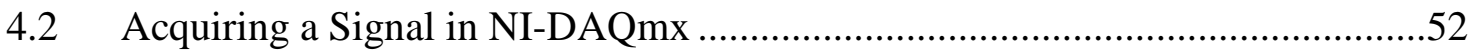

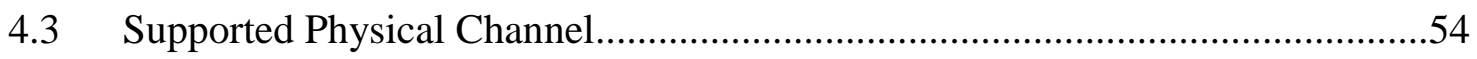

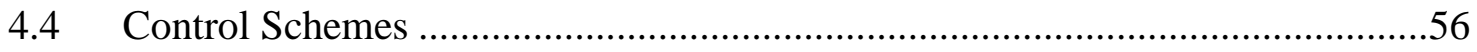

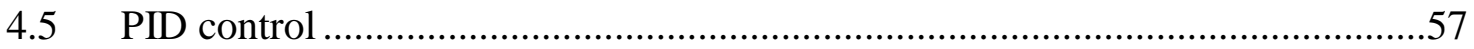

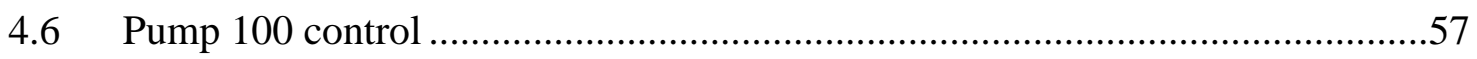

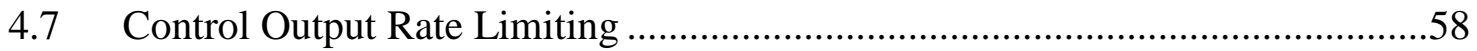

4.8 Evaporator power control.......................................................................5

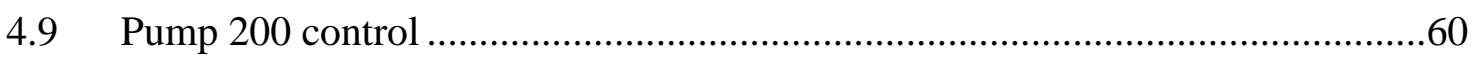

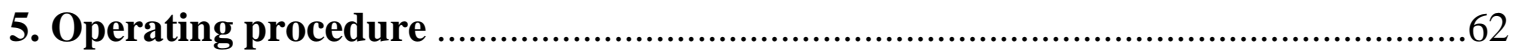

5.1 Procedure for "Natural/Unspecified" Exit Condition Cases for Fully Condensing Gravity Driven Flows .....................................................................62

5.2 Error Analysis, Repeatability, and Flow Morphology for the

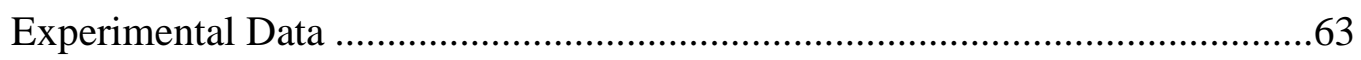

6. Experimental results for vertical tube and comparisons with theory ……..............69

6.1 Notations Used for Reporting Experimental Results .........................................69

6.2 Experimental Range and Results ................................................................

7. Effects of interactions between near-interface vapor flow and condensate

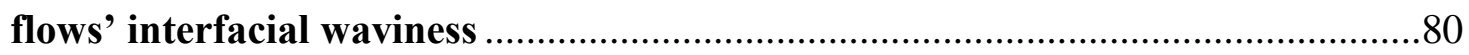

7.1 Observed Deviations between Experimental and Theoretical Results.................80

7.2 Reasons for Deviations and Suggested Modeling for Wavy and Turbulent Annular Flows 
8. Remarks on comparisons with well known correlations and recommendations ...91

9. Experimental results on differences between gravity and shear driven flows'

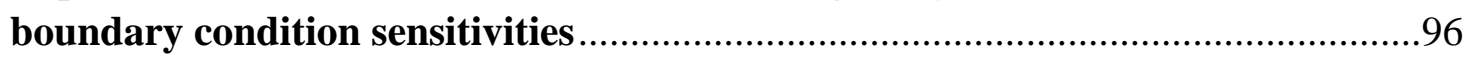

9.1 Background for Boundary-Condition Sensitivity Results...............................96

9.2 Procedure for Imposition of "Non-Natural” Pressure-difference for

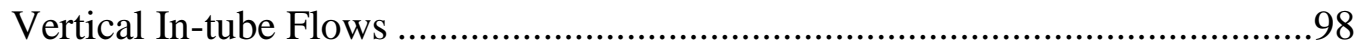

9.3 The Inability to Impose Quasi-steady “Non-natural” PressureDifferences at a Fixed Quasi-steady Mass Flow Rate for Gravity Dominated Flows

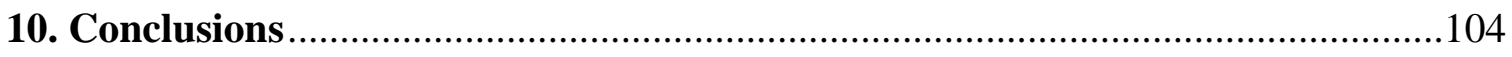

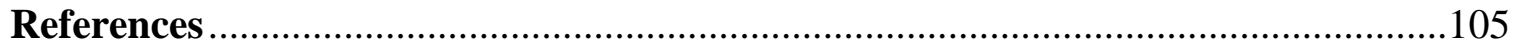

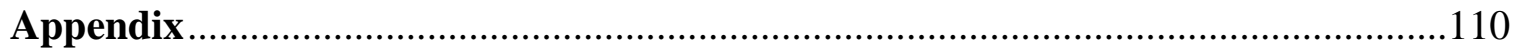




\section{List of figures}

\section{Condensation}

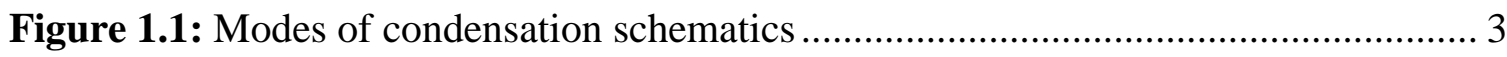

Figure 1.2: Homogeneous condensation schematics................................................... 4

Figure 1.3: Laminar film condensation on a vertical plate............................................. 5

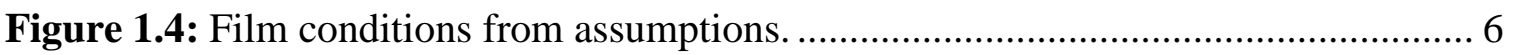

Figure 1.5: Schematic of a turbulent film............................................................... 10

\section{Literature review}

Figure 2.1: (a) Partial condensation. (b) Full condensation............................................ 13

\section{Experimental facility}

Figure 3.1: Schematic of the primary cooling loop................................................... 20

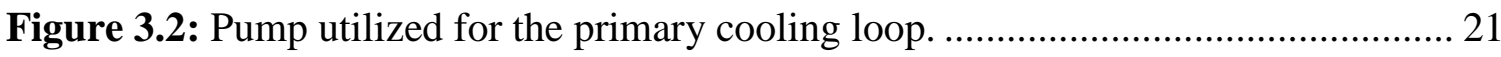

Figure 3.3: Water filter used in the primary cooling loop........................................... 22

Figure 3.4: Water flow meter installed in the primary cooling loop. ............................ 23

Figure 3.5: Water tank mounted at the highest point of the primary cooling loop.......... 23

Figure 3.6: Heat exchanger used at the cooling loops............................................... 24

Figure 3.7: Pressure gauge installed at the exit of the pump........................................ 25

Figure 3.8: A typical ball type valve utilized in this loop............................................. 25

Figure 3.9: Schematic of the Koolant secondary cooling water loop............................. 27

Figure 3.10: A picture of the Koolant water chiller installed in the secondary cooling

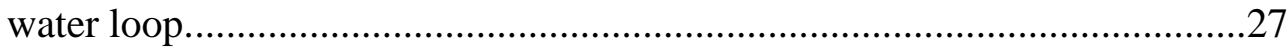

Figure 3.11: A picture of the customized three way valve. ......................................... 28

Figure 3.12: Water flow meter used in the secondary cooling loop............................... 29

Figure 3.13: Typical rope heater used at the exit of the evaporator. .............................. 30

Figure 3.14: Picture of a variable transformer used to control heating power. ............... 31

Figure 3.15: Schematic of the Teca secondary cooling water loop................................ 33

Figure 3.16: Picture of the Teca chiller installed in the secondary water loop................ 33

Figure 3.17: Needle valve used for accurate and repeatable flow control....................... 34

Figure 3.18: Water flow meter located at the exit of the Teca chiller. ........................... 35

Figure 3.19: Water filter at the secondary cooling water loop. ..................................... 35

Figure 3.20: Diaphragm pump for the Teca chiller loop.............................................. 36 
Figure 3.21: Water tank installed at the highest point of the secondary cooling loop.... 37

Figure 3.22: Schematic of the complete condensation refrigerant loop. ........................ 39

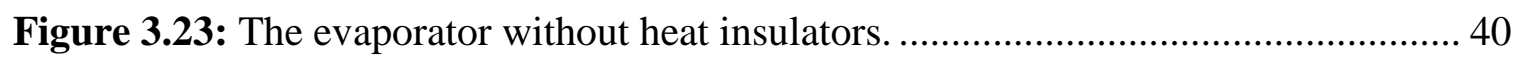

Figure 3.24: Solid state relay used for current control. .......................................... 41

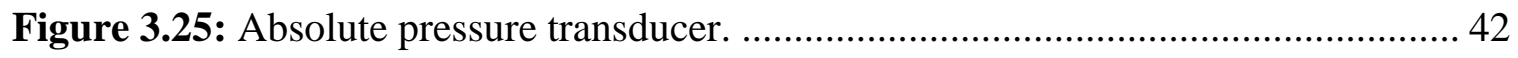

Figure 3.26: The three cable Resistive Thermal Device (RTD) picture......................... 43

Figure 3.27: (a) The photograph of condenser test-section. (b) The test-section schematic (diameters in (a) and (b) are not to the same scale). The condensing surface covers the zone $\mathrm{x}_{0} \leq \mathrm{x} \leq \mathrm{x}_{10}$.

Figure 3.28: The schematic of the flow loop for achieving unspecified exit condition flows for partial or full condensation cases. For full condensation cases, valve $\mathrm{V}_{3}$ is closed and the auxiliary condenser is not in use. .....................46

Figure 3.29: Borescope with video camera mounted on top of the test section............. 48

\section{Data acquisition software}

Figure 4.1: DAQ assistant windows showing parameters to set................................. 52

Figure 4.2: LabVIEW block diagram showing DAQ wiring for Thermocouples, RTD's, APT's, DPT, Peristaltic pump outputs and flowmeters. .................53

Figure 4.3: LabVIEW block diagram showing the pump control strategy..................... 58

Figure 4.4: LabVIEW block diagram showing the control output rate limiting............. 59

Figure 4.5: LabVIEW block diagram showing the evaporator power control using

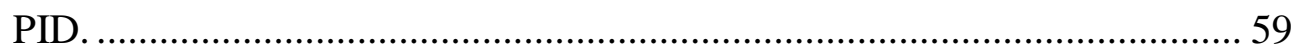

Figure 4.6: LabVIEW block diagram showing the evaporator power control. ............... 60

Figure 4.7: LabVIEW block diagram showing the pump 200 (P2) control strategy....... 60

Figure 4.8: LabVIEW block diagram showing the pump 200 (P2) tracking mode strategy.

Figure 4.9: LabVIEW block diagram showing the limiting output strategy for pump 100 (P1)

\section{Operating procedure}

Figure 5.1: These time histories of inlet mass flow rate, inlet saturation temperature, and average wall temperature are nearly the same for three separate steady realizations over three separate time intervals. They are termed unspecified ("natural") exit condition cases - namely Natural-1, Natural2, and Natural-3.

Figure 5.2: Time histories of $p_{i n}, p_{\text {exit, }}$ and $\Delta p$ for the three unspecified pressuredifference runs shown in Figure 5.1. The first time-segment's steady flow realization was by procedure- 1 and the steady realizations in the 
second and the third time segments were by procedure-2. Though $\mathrm{p}_{\text {in }}$ in the first segment is different, the natural pressure-difference $\Delta \mathrm{p}$ values are seen to be equal for all the three runs because Min and $\Delta \mathrm{T} \equiv$ $T_{\text {Sat }}\left(p_{\text {in }}\right)-T_{W}$ values are approximately the same for all the three cases...67

Figure 5.3: The light reflected from the interface depicts typical wavy annular flows realized in vertical tube experiments. The borescope views are taken from the top of the test-section and the blue/green lights are vertically down at a location below the test-section. The blue light picture on the left is for a representative partial condensation case and the green light picture on the right is for a representative full condensation case.

\section{Experimental results for vertical tube and comparisons with theory}

Figure 6.1: The figure shows two different condensing-surface temperature variations $\mathrm{T}_{\mathrm{w} 1}(\mathrm{x})$ and $\mathrm{T}_{\mathrm{w} 2}(\mathrm{x})$ corresponding to runs 12 and 13 in Table 5.1. It also shows corresponding non-dimensional temperatures $\theta_{\mathrm{W}}(\tilde{\mathrm{x}})$ with respect to non-dimensional $\mathrm{x}=\mathrm{x} / \mathrm{D}$

Figure 6.2: The investigated full and partial condensation flow cases cover the parameter space $\left\{\mathrm{Re}_{\mathrm{in}}, \mathrm{Gp}, \mathrm{Ja} / \mathrm{Pr}_{1}\right\}$ above

Figure 6.3: The investigated full and partial condensation flow cases cover the parameter space $\left\{\rho_{2} / \rho_{1}, \mu_{2} / \mu_{1}\right\}$ space above.

Figure 6.4: For a representative case (run 14 in Table 5.1), the plot shows testsectional pressure variation with distance $\mathrm{x}$. The measurements are at locations $\mathrm{x}_{0}, \mathrm{x}_{3}, \mathrm{x}_{6}$, and $\mathrm{x}_{9}$ marked in Figure 3.27. The value of $\mathrm{x}_{\mathrm{FC}}$ is marked to indicate its estimated value.

Figure 6.5: The comparison of theoretically and computationally obtained values of $\mathrm{X}_{\mathrm{FC}}$ as a function of $\dot{\mathrm{M}}_{\mathrm{in}}$. Here the the dashed lines indicates the simulation results and the solid lines indicate the experimental results. .... 77

Figure 6.6: The comparison of theoretically and computationally obtained values of $\mathrm{x}_{\mathrm{FC}}$ as a function of $\Delta \mathrm{T}$. Here the dashed lines indicate the simulation results and the solid lines indicate the experimental results.

Figure 6.7: Comparison of experimentally and computationally obtained values of average heat transfer coefficients for fully condensing flows. 


\section{Effects of interactions between near-interface vapor flow and condensate flows' interfacial waviness}

Figure 7.1: The plot shows deviation levels (between theory and experiments) with respect to the variables $\mathrm{Ja} / \operatorname{Pr}_{1}$ (representing $\Delta \mathrm{T}$ ) and the inlet Reynolds number $\operatorname{Re}_{\text {in }}$ (representing $\dot{\mathrm{M}}_{\mathrm{in}}$ ). The solid black diamond points show less than $15 \%$ deviation from the idealized theory. The hollow diamond points show experimental heat transfer coefficient values higher by $15 \%$ - 30\% and hollow circular points show that the experimental heat transfer values were greater than $30 \%$ with respect to the idealized theoretical estimates.

Figure 7.2: The plot shows deviation levels (between theory and experiments) with respect to the variables $\mathrm{Ja} / \mathrm{Pr}_{1}$ (representing $\Delta \mathrm{T}$ ) against the condensate film's Reynolds number $\operatorname{Re}_{\delta}$ at $\mathrm{x}=\mathrm{x}_{\mathrm{FC}}$. The solid black diamond points show less than $15 \%$ deviation from the idealized theory. The hollow diamond points show experimental heat transfer coefficient values higher by $15 \%$ - $30 \%$ and hollow circular points show that the experimental heat transfer values were greater than $30 \%$ with respect to the idealized theoretical estimates.

Figure 7.3: Plot of deviation against inlet parameter $\mathrm{Re}_{\mathrm{in}} /\left(\mathrm{Ja} / \mathrm{Pr}_{1}\right)^{0.2718}$. The solid black diamond points show less than $15 \%$ deviation from the idealized theory. The hollow diamond points show experimental heat transfer coefficient values higher by $15 \%-30 \%$ and the hollow circular points show that the experimental heat transfer values were greater than $30 \%$ with respect to the idealized theoretical estimates.

Figure 7.4: Plot of discrepancy against inlet parameter $\left(\left.\operatorname{Re}_{\delta}\right|_{\mathrm{x}}=\mathrm{x}_{\mathrm{FC}}\right) /(\mathrm{Ja} /$ $\left.\operatorname{Pr}_{1}\right)^{0.1145}$ at $\mathrm{x}=\mathrm{x}_{\mathrm{FC}}$. The solid black diamond points show less than $15 \%$ deviation from the idealized theory. The hollow diamond points show experimental heat transfer coefficient values higher by $15 \%-30 \%$ and the hollow circular points show that the experimental heat transfer values were greater than $30 \%$ with respect to the idealized theoretical estimates.

Figure 7.5: For modeling heat transfer enhancement greater than $15 \%$, the figure shows the schematic of variations, with distance $\mathrm{x}$, for the near interface vapor turbulence parameter $\operatorname{Re}_{\mathrm{VL}}(\mathrm{x})$, vapor flow Reynolds number $\operatorname{Re}_{\mathrm{V}}(\mathrm{x})$, and the condensate Reynolds number $\operatorname{Re}_{\delta}(\mathrm{x})$. 


\section{Remarks on comparisons with well known correlations and recommendations}

Figure 8.1: The figure shows a comparison of experimentally obtained heat transfer coefficient with heat transfer coefficients obtained from evaluating different correlations with the help of our simulation tool's predictions. The figure limits itself to assessing the efficacy of various correlations for the gravity dominated flows considered here

\section{Experimental results on differences between gravity and shear driven flows' boundary condition sensitivities}

Figure 9.1: Flow loop arrangement for investigation of various boundary-condition sensitivities of internal partially or fully condensing flows (gravity or shear driven).

Figure 9.2: Representative experimental time histories for test-section and flow-loop pressures demonstrating inability of gravity driven internal condensing flows to achieve steady state (at a fixed inlet mass flow rate) under imposition of "non-natural" pressure-difference values.

Figure 9.3: Representative experimental time histories for test-section and flow-loop temperatures, inlet flow rate, and compressor speed demonstrating inability of gravity driven internal condensing flows to achieve steady state (at a fixed inlet mass flow rate) under imposition of "non-natural" pressure-difference values. This data corresponds to the same periods of time over which the data in Figure 9.2 were obtained.

\section{Appendix}

Figure A.1: In this chart, data from a particular full or complete condensation case is shown. Having the inlet mass flow rate actively fixed at 1.0 gram per second the inlet pressure was actively changed through a range of values. These changes of pressures effectively were describing different temperature differences or $\Delta \mathrm{T}$.

Figure A.2: In this chart, data from a particular full or complete condensation case is shown. Having the inlet mass flow rate actively fixed at 1.75 grams per second the inlet pressure was actively changed through a range of values. These changes of pressures effectively were describing different temperature differences or $\Delta \mathrm{T}$.

Figure A.3: In this chart, data from a particular full or complete condensation case is shown. Having the inlet mass flow rate actively fixed at 0.25 grams per second the inlet pressure was actively changed through a range of 
values. These changes of pressures effectively were describing different temperature differences or $\Delta \mathrm{T}$.

Figure A. 4: In this chart, data from a particular full or complete condensation case is shown. Having the inlet mass flow rate actively fixed at 2.0 grams per second the inlet pressure was actively changed through a range of values. These changes of pressures effectively were describing different temperature differences or $\Delta \mathrm{T}$.

Figure A.5: In this chart, data from a particular full or complete condensation case is shown. Having the inlet mass flow rate actively fixed at 1.0 gram per second the inlet pressure was actively changed through a range of values. These changes of pressures effectively were describing different temperature differences or $\Delta \mathrm{T}$.

Figure A.6: In this chart, data from a particular full or complete condensation case is shown. Having the inlet vapor pressure actively fixed at $55 \mathrm{kPa}(8 \mathrm{psi})$ the inlet mass flow rate was actively changed through a range of values. 117

Figure A.7: In this chart, data from a particular full or complete condensation case is shown. Having the inlet vapor pressure actively fixed at $172 \mathrm{kPa}(25 \mathrm{psi})$ the inlet mass flow rate was actively changed through a range of values. 118

Figure A.8: In this chart, data from a particular full or complete condensation case is shown. Having the inlet vapor pressure actively fixed at $117 \mathrm{kPa}(17 \mathrm{psi})$ the inlet mass flow rate was actively changed through a range of values. 119

Figure A.9: In this chart, data from a particular full or complete condensation case is shown. Having the inlet vapor pressure actively fixed at $41 \mathrm{kPa}(6 \mathrm{psi})$ the inlet mass flow rate was actively changed through a range of values. 120

Figure A.10: In this chart, data from a particular full or complete condensation case is shown. Having the inlet vapor pressure actively fixed at $72 \mathrm{kPa}(10$ psi) the inlet mass flow rate was actively changed through a range of values.

Figure A.11: In this chart, data from a specific set of full or complete condensation cases are shown. Having the inlet mass flow rate actively fixed from 0.25 to 2.0 grams per second, the inlet vapor pressure was actively changed from $30 \mathrm{kPa}$ to $155 \mathrm{kPa}$ (4 psia to $22 \mathrm{psia}$ ).

Figure A.12: In this chart, data from a specific set of full or complete condensation cases are shown. Having the inlet vapor pressure actively fixed from 6 to 25 psia (41 to $172 \mathrm{kPa}$ ) the inlet mass flow rates were actively changed from 0.25 to 2.75 grams per second. 


\section{List of tables}

\section{Experimental facility}

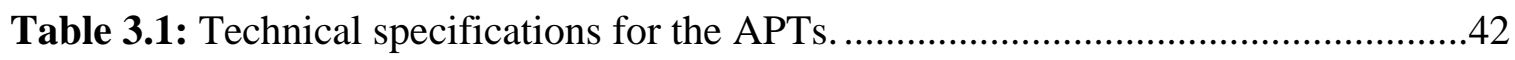

Table 3.2: Technical specification for RTDs.............................................................43

\section{Data acquisition software}

Table 4.1: Physical channel labeling where TCT stands for $T$ type thermocouples, RTD stands for Resistive Thermal Devices, TS for Test Section, BH for Bulk Head, LV for Liquid/Vapor Separator, AC for Accumulator, P for Peristaltic Pump and HEX for Heat Exchanger.

Table 4.2: Physical channel labeling where FLC stands for Coriolis Flow Meter, FLR for Rotameter, PSP for Peristaltic Pump, DPT for Differential Pressure Transducer, PCV for Pneumatic Controlable Valve, TEC for Thermoelectric Controller and CMP for Compressor.

\section{Operating procedure}

Table 5.1: Representative experimentally measured data and some key calculated and computed variables for natural fully condensing steady flows.

\section{Remarks on comparisons with well known correlations and recommendations}

Table 8.1: Representative coverage of the parameter space under different well known empirical or semi-empirical correlations. 


\section{Acknowledgement}

Parts of this research were supported by NASA grants NNC04GB52G and NNX10AJ59G and parts through NSF grant NSF-CBET-1033591.

To my advisor Dr. Amitabh Narain from who I received support and encouragement throughout my entire doctoral program.

To my parents, Kaoru and Yuko, who taught me the importance of education for life fulfillment and provided me with all education opportunities without any condition or impediments.

And last but not least to my wife, Rocio Garcia who supported me in accomplishing this degree even as a condition to marry her. 


\section{Nomenclature}

\begin{tabular}{|c|c|}
\hline $\mathrm{C}_{\mathrm{p} 1}$ & Specific heat of the liquid condensate, $\mathrm{J} /(\mathrm{kg}-\mathrm{K})$ \\
\hline $\mathrm{D}$ & Inner diameter of the test-section, $\mathrm{m}$ \\
\hline Fr & Froude number $\mathrm{U}^{2} / \mathrm{gD}$ \\
\hline $\mathrm{h}_{\mathrm{fg}}\left(\mathrm{p}_{\mathrm{in}}\right)$ & Heat of vaporization at pressure $\mathrm{p}_{\mathrm{in}}, \mathrm{J} / \mathrm{kg}$ \\
\hline$\overline{\mathrm{h}}$ & Average heat transfer coefficient, $\dot{\mathrm{Q}}_{\mathrm{Out}} /(\pi \cdot \mathrm{D} \cdot \mathrm{L}), \mathrm{W} /\left(\mathrm{m}^{2}-\mathrm{K}\right)$ \\
\hline $\mathrm{Ja}$ & Condensate liquid Jakob number, $\mathrm{C}_{\mathrm{p} 1 .} \Delta \mathrm{T} / \mathrm{h}_{\mathrm{fg}}\left(\mathrm{p}_{\mathrm{in}}\right)$ \\
\hline $\mathrm{k}_{1}$ & Conductivity of condensate liquid, W/(m-K) \\
\hline $\mathrm{L}$ & Length of the test-section, $\mathrm{m}$ \\
\hline$\dot{\mathrm{M}}_{\mathrm{in}}$ & Vapor flow rate at test-section inlet, $\mathrm{g} / \mathrm{s}$ \\
\hline$\dot{\mathrm{M}}_{\mathrm{L}}$ & Liquid flow rate at test-section exit, $\mathrm{g} / \mathrm{s}$ \\
\hline$\dot{m}$ & Interfacial mass flux, $\mathrm{kg} / \mathrm{s} / \mathrm{m}^{2}$ \\
\hline $\mathrm{p}_{\mathrm{B}}$ & Evaporator (boiler) pressure, $\mathrm{kPa}$ \\
\hline $\mathrm{p}_{\mathrm{in}}$ & Pressure at the test-section inlet, $\mathrm{kPa}$ \\
\hline $\mathrm{p}_{\text {exit }}$ & Pressure at the test-section exit, $\mathrm{kPa}$ \\
\hline $\operatorname{Pr}_{1}$ & Condensate liquid Prandtl number, $\mu_{1} . \mathrm{C}_{\mathrm{p} 1} / \mathrm{k}_{1}$ \\
\hline $\mathrm{p}_{\mathrm{xP}-\mathrm{i}}$ & Test-section pressures at locations $x_{P}=x_{P-i}(i=1,2, \ldots), k P a$ \\
\hline$\overline{\mathrm{q}^{\prime \prime}}$ & Average convective heat flux, $\mathrm{W} / \mathrm{m}^{2}$ \\
\hline$\dot{\mathrm{Q}}_{\mathrm{b}}$ & Net heat rate into the evaporator, $\mathrm{W}$ \\
\hline$\dot{\mathrm{Q}}_{\text {total }}$ & Net heat rate out of the test-section, $\mathrm{W}$ \\
\hline $\mathrm{Re}_{\text {in }}$ & Inlet vapor Reynolds number, $\rho_{2} \mathrm{UL}_{c} / \mu_{2}$ \\
\hline
\end{tabular}




\begin{tabular}{|c|c|}
\hline $\mathrm{T}_{\mathrm{B}}$ & Evaporator fluid temperature, ${ }^{\circ} \mathrm{C}$ \\
\hline $\mathrm{T}$ & Non-dimensional time \\
\hline $\mathrm{T}_{\mathrm{sat}}(\mathrm{p})$ & Saturation temperature at pressure $\mathrm{p},{ }^{\circ} \mathrm{C}$ \\
\hline$\overline{\mathrm{T}}_{\mathrm{w}}$ & Mean condensing surface temperature, ${ }^{\circ} \mathrm{C}$ \\
\hline $\mathrm{T}_{\mathrm{w}}\left(\mathrm{x}_{\mathrm{P}-\mathrm{i}}\right)$ & Condensing surface temperatures at different locations $\mathrm{x}_{\mathrm{P}}=\mathrm{x}_{\mathrm{P}-\mathrm{i}}(\mathrm{i}=1,2, \ldots),{ }^{\circ} \mathrm{C}$ \\
\hline $\mathrm{T}_{\mathrm{V} \text {-in }}$ & Vapor temperature at test-section inlet, ${ }^{\circ} \mathrm{C}$ \\
\hline $\mathrm{u}_{\mathrm{f}}$ & Non-dimensional value of the $\mathrm{x}$-component of interfacial speed \\
\hline $\mathrm{U}$ & Average Inlet vapor speed, m/s \\
\hline $\mathrm{X}_{\mathrm{P}}$ & Physical distance along the test section, $\mathrm{m}$ \\
\hline $\mathrm{X}(\mathrm{x})$ & $\begin{array}{l}\text { Ratio of vapor mass flow rate to total mass flow rate at any location } \mathrm{x} \text { along the test } \\
\text { section }\end{array}$ \\
\hline$\tilde{\mathrm{X}}$ & Non-dimensional x (x/D) \\
\hline $\mathrm{x}_{\mathrm{FC}}$ & Approximate length needed for full condensation (estimted by computations), $\mathrm{m}$ \\
\hline$\Delta \mathrm{T}$ & $\mathrm{T}_{\mathrm{sat}}(\mathrm{p})-\overline{\mathrm{T}}_{\mathrm{W}},{ }^{\circ} \mathrm{C}$ \\
\hline$\Delta \mathrm{p}$ & $\mathrm{p}_{\mathrm{in}}-\mathrm{p}_{\mathrm{exit}}, \mathrm{kPa}$ \\
\hline $\mathrm{Z}(\mathrm{x})$ & Another name for $\mathrm{X}(\mathrm{x})$ \\
\hline$\Delta$ & Physical value of condensate thickness, $\mathrm{m}$ \\
\hline$\delta$ & Non-dimensional value of condensate thickness \\
\hline$\rho_{2}$ & Density of vapor, $\mathrm{kg} / \mathrm{m}^{3}$ \\
\hline$\rho_{1}$ & Density of liquid, $\mathrm{kg} / \mathrm{m}^{3}$ \\
\hline$\mu_{2}$ & Viscosity of vapor, kg/(m-s) \\
\hline$\mu_{1}$ & Viscosity of liquid, kg/(m-s) \\
\hline$\pi(\mathrm{x})$ & Non-dimensional pressure $\mathrm{p}$ \\
\hline
\end{tabular}




\section{Subscripts}

exit Test-section exit

in Test-section inlet

$\mathrm{Na}$ Natural steady case

exp Obtained from experiments

sim Obtained from computations/simulations 


\section{Abstract}

This doctoral thesis presents the experimental results along with a suitable synthesis with computational/theoretical results towards development of a reliable heat transfer correlation for a specific annular condensation flow regime inside a vertical tube. For fully condensing flows of pure vapor (FC-72) inside a vertical cylindrical tube of 6.6 $\mathrm{mm}$ diameter and $0.7 \mathrm{~m}$ length, the experimental measurements are shown to yield values of average heat transfer co-efficient, and approximate length of full condensation.

The experimental conditions cover: mass flux $\mathrm{G}$ over a range of $2.9 \mathrm{~kg} / \mathrm{m}^{2}-\mathrm{s} \leq \mathrm{G} \leq$ $87.7 \mathrm{~kg} / \mathrm{m}^{2}$-s, temperature difference $\Delta \mathrm{T}$ (saturation temperature at the inlet pressure minus the mean condensing surface temperature) of $5^{\circ} \mathrm{C}$ to $45^{\circ} \mathrm{C}$, and cases for which the length of full condensation $\mathrm{x}_{\mathrm{FC}}$ is in the range of $0<\mathrm{x}_{\mathrm{FC}}<0.7 \mathrm{~m}$.

The range of flow conditions over which there is good agreement (within 15\%) with the theory and its modeling assumptions has been identified. Additionally, the ranges of flow conditions for which there are significant discrepancies (between 15 -30\% and greater than $30 \%$ ) with theory have also been identified.

The paper also refers to a brief set of key experimental results with regard to sensitivity of the flow to time-varying or quasi-steady (i.e. steady in the mean) impositions of pressure at both the inlet and the outlet. The experimental results support the updated theoretical/computational results that gravity dominated condensing flows do not allow such elliptic impositions. 


\section{Condensation}

\subsection{Dimensionless Parameters in Condensation}

\subsubsection{Nusselt Condensation}

It is important we non-dimensionalized the governing equations to identify appropriate dimensionless groups. This will help our understanding of related physical mechanisms and later help us to propose a simplified procedure for processing experimentally obtained heat transfer results.

By applying the Buckingham pi theorem ${ }^{1}$ for condensing stagnant vapor in a vertical wall (Nusselt problem ${ }^{2}$ ) suitable dimensionless parameters are obtained. The convection coefficient $h$ can be considered to be a function of the temperature difference $\Delta \mathrm{T}=\mathrm{T}_{\text {sat }}-\mathrm{T}_{\text {wall }}$ between the working fluid saturation temperatures $\mathrm{T}_{\text {sat }}$ and the condensing surface temperature $T_{\text {wall }}$, the buoyancy force $g\left(\rho_{1}-\rho_{v}\right)$, resulting from the vapor and liquid density difference, the latent heat $\overline{\mathrm{h}}_{\mathrm{fg}}$, the characteristic length $\mathrm{L}$, the surface tension $\sigma$, and the thermodynamic properties (density $\rho$, specific heat $\mathrm{c}_{\mathrm{p}}$, thermal conductivity $k$, and viscosity $\mu$ ) of the condensate. This dependence is given as:

$$
h=f\left(\Delta \mathrm{T}, g\left(\rho_{1}-\rho_{\mathrm{v}}\right), \overline{\mathrm{h}}_{\mathrm{fg}}, \mathrm{L}, \sigma, \rho, \mathrm{c}_{\mathrm{p}}, \mathrm{k}, \mu\right)
$$

For $g$ equal to constant, separate acknowledgement of $\rho$ and specific heat $c_{p}$ (because sub cooled can be ignored) can be neglected. That is:

$$
h=f\left(\Delta \mathrm{T}, g\left(\rho_{1}-\rho_{\mathrm{v}}\right), \overline{\mathrm{h}}_{\mathrm{fg}}, \mathrm{L}, \sigma, \mathrm{k}, \mu\right)
$$

Since there are 18 variables and 4 fundamental dimensions/units (K, s, kg, m), represented by $\Delta \mathrm{T}, \mathrm{L}, \rho, \mu$, we have $(8-4)=4$ pi groups. Applying of pi theorem then yields: 


$$
\frac{h L}{k}=f\left[\frac{\rho g\left(\rho_{\mathrm{l}}-\rho_{\mathrm{v}}\right) \mathrm{L}^{3}}{\mu^{2}}, \frac{\mu_{\overline{\mathrm{h}}_{\mathrm{fg}}}}{\mathrm{k}}, \frac{\mathrm{g}\left(\rho_{1}-\rho_{2}\right) \mathrm{L}^{2}}{\sigma}\right]
$$

Where the dimensionless groups are:

$$
\begin{aligned}
& \frac{h L}{k}=\mathrm{Nu}_{\mathrm{L}} \text { (Nusselt number) } \\
& \frac{\mu \mathrm{c}_{\mathrm{p}}}{\mathrm{k}}=\operatorname{Pr} \text { (Prandtl number) } \\
& \frac{\mathrm{c}_{\mathrm{p}} \Delta \mathrm{T}}{\overline{\mathrm{h}}_{\mathrm{fg}}}=\mathrm{Ja} \text { (Jakob number) } \\
& \frac{\mu_{\overline{\mathrm{h}}_{\mathrm{fg}}}}{\mathrm{k}}=\mathrm{Ja} / \mathrm{Pr} \\
& \frac{\mathrm{g}\left(\rho_{1}-\rho_{2}\right) \mathrm{L}^{2}}{\sigma}=\text { Bo (Bond number) }
\end{aligned}
$$

Therefore, the Nusselt number can be a function of:

$$
N u_{L}=f\left[\frac{\rho g\left(\rho_{1}-\rho_{2}\right) \mathrm{L}^{3}}{\mu^{2}}, \mathrm{Ja}, \text { Pr, Bo }\right]
$$

As we can see in this reduced form, the Ja number is the ratio of the maximum sensible heat absorbed by liquid to the latent heat absorbed by the liquid during condensation. The Bo number is the ratio of the buoyancy force to the surface tension force.

\subsubsection{Gravity Driven Flow Condensation}

For gravity driven internal flow condensation, with average inlet duct speed U, are often modifies (1.1) as:

$$
h=f\left(\Delta \mathrm{T}, g\left(\rho_{1}-\rho_{\mathrm{v}}\right), \mathrm{L}, \sigma, \mathrm{k}, \mu, \mathrm{c}_{\mathrm{p}}, \rho_{\mathrm{v}}, \mu_{\mathrm{v}}\right)
$$

and obtains: 


$$
\frac{h L}{k}=f\left[\frac{\rho g\left(\rho_{1}-\rho_{\mathrm{v}}\right) \mathrm{L}^{3}}{\mu^{2}}, \mathrm{Ja}, \operatorname{Pr}, \operatorname{Re}_{\mathrm{in}}, \frac{\mu_{\mathrm{v}}}{\mu}, \frac{\rho_{\mathrm{v}}}{\rho}\right]
$$

\subsection{Modes of Condensation}

If the vapor temperature is reduced to below its saturation temperature, condensation occurs. In the industry, this process is achieved from contact between the vapor and a cool surface (Figure 1.1a and 1.1b). The latent heat of the vapor is released, it is transferred to the cool surface, and the condensate is produced. An alternative mode is the homogeneous condensation (Figure 1.2), where vapor condenses as droplets suspended in the gas phase and therefore fog is formed.

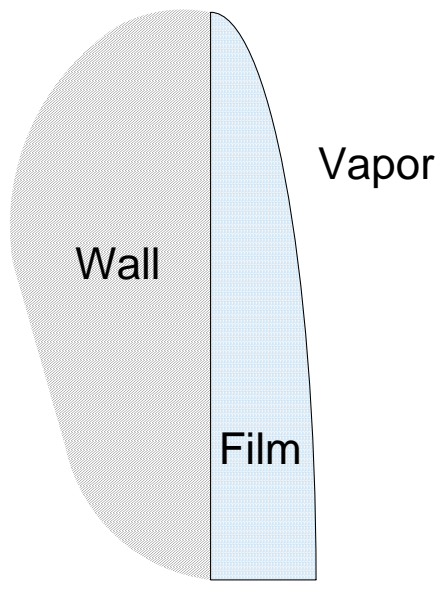

(a)

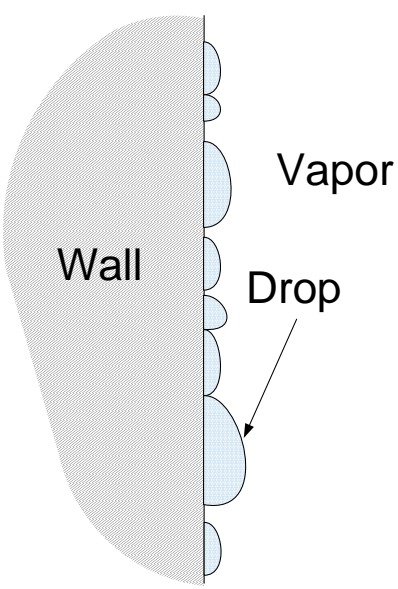

(b)

Figure 1.1: Modes of condensation schematics. 


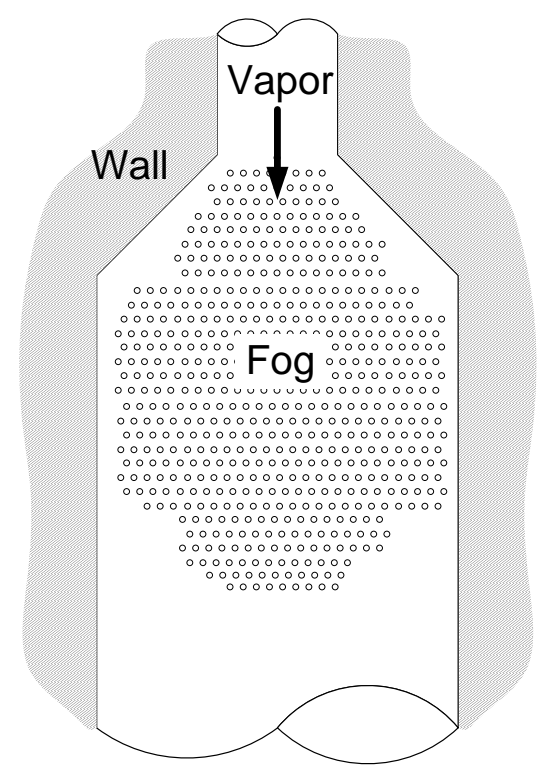

Figure 1.2: Homogeneous condensation schematics.

When the condensing surface is coated with a substance that inhibits wetting, a drop wise condensation will be developed (Figure 1.1b). The drops are initiated in pits, cracks, and cavities on the surface then growing and coalescing through continued condensation.

The condensate creates a heat transfer resistance between the vapor and the surface. This increases with the film thickness. In terms of sustaining high heat transfer rates, droplet formation is superior to film formation however, due to oxidation, fouling or outright removal, coatings gradually lose their effectiveness and for that reason it is not seen such type of surface so often. 


\subsection{Laminar Film Condensation on a Vertical Plate (Nusselt Analysis)}

The film begins at the top of the plate (Figure 1.3) and flows downwards driven by gravity. The condensate mass flow rate $\dot{\mathrm{m}}$, and the thickness $\delta$ increase with $x$. The temperature at the liquid-vapor interface is $\mathrm{T}_{\text {sat }}$. The surface temperature is always lower than the saturation temperature at the vapor pressure. In the most real condition, vapor at the inlet is superheated, and may be part of a mixture including one or more noncondensable gases. Also, there is a finite shear stress at the liquid-vapor interface which contributes to a velocity gradient in the film ${ }^{2,3}$. However, in Nusselt analysis discussed here, it is set to zero (i.e. shear stress at the interface has negligible effect).

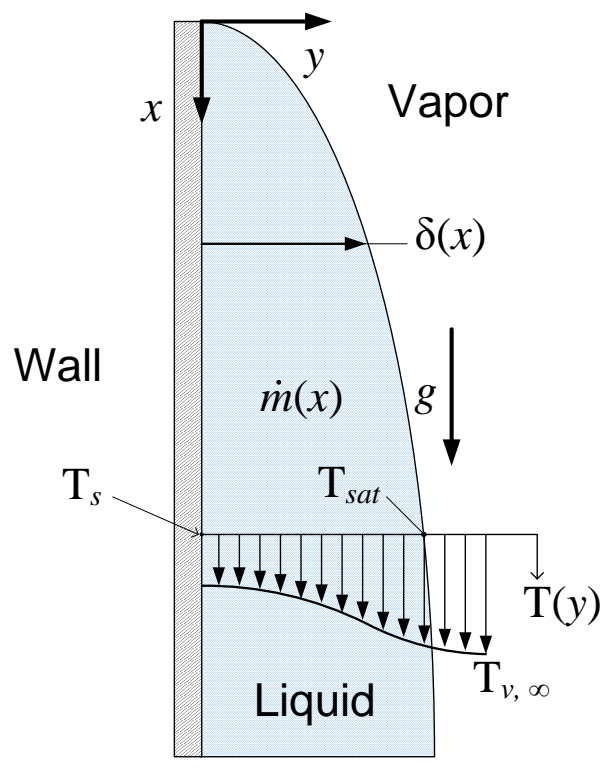

Figure 1.3: Laminar film condensation on a vertical plate.

Solutions may be obtained by making further assumptions that originated with an analysis by Nusselt ${ }^{2}$. The first one is that the flow is laminar and properties are constant. The next assumption is that the gas is pure vapor and at a uniform temperature $\mathrm{T}_{\text {sat. }}$. There is no temperature gradient in the vapor flow. The heat transfer in the liquid-vapor interface is solely due to condensation and not by conduction from the vapor. It is also 
assumed that the condensate film is thin and there is negligible momentum and energy transfer by advection in the condensate flow. Figure 1.4 shows the film conditions resulting from the assumptions for the Nusselt analysis.

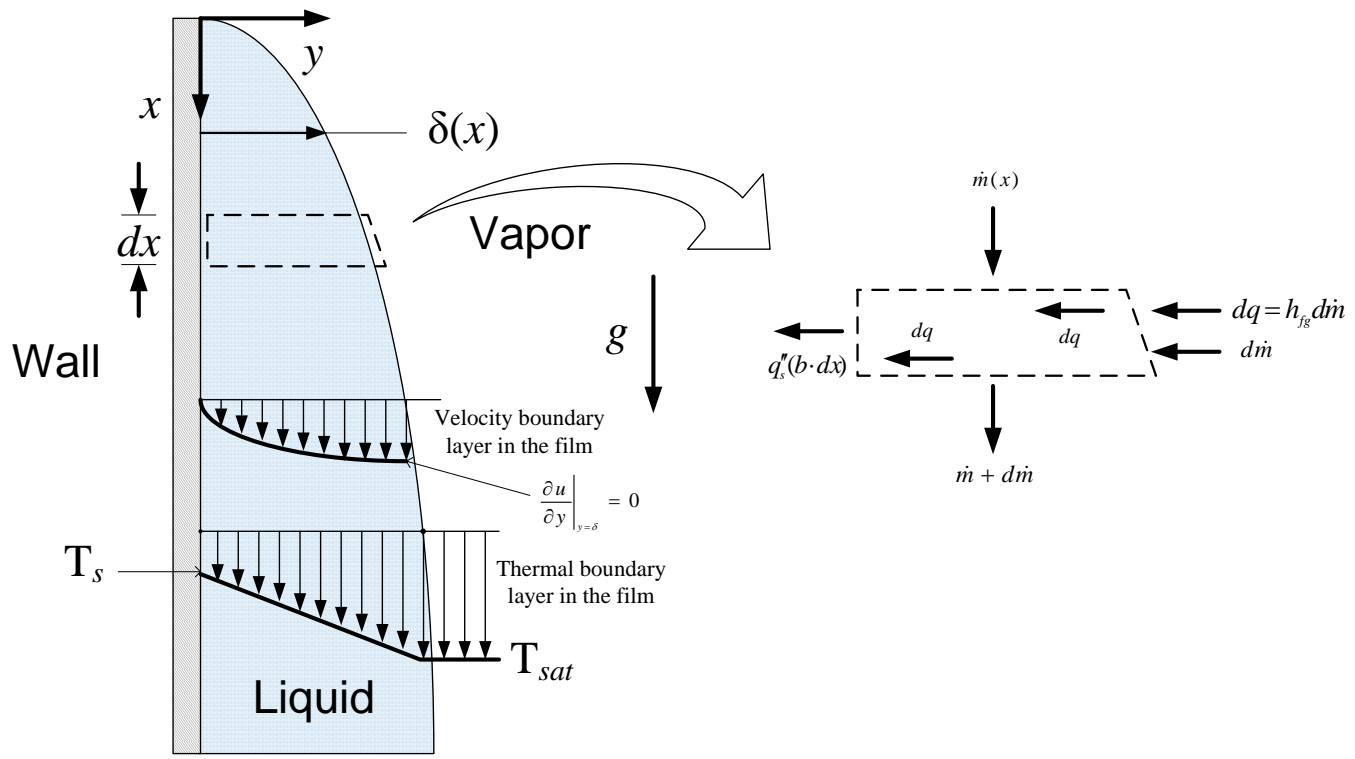

Figure 1.4: Film conditions from assumptions.

When momentum advection terms are neglected, the $x$ direction momentum equation is simplified as

$$
\frac{\partial^{2} u}{\partial y^{2}}=\frac{1}{\mu_{1}} \frac{d p}{d x}-\frac{X}{\mu_{1}}
$$

Where $\mathrm{X}$ is the body force equal to $\rho_{1} g$. The pressure gradient may be approximated as zero or one which leads to zero motion in the vapor, in which case, $(d p / d x) \approx \rho_{v} g$. Therefore:

$$
\frac{\partial^{2} u}{\partial y^{2}}=-\frac{g}{\mu_{l}}\left(\rho_{l}-\rho_{v}\right)
$$

Now, by integrating and applying the boundary conditions $\left(u(0)=0\right.$ and $\partial \mathrm{u} /\left.\partial \mathrm{y}\right|_{\mathrm{y}=\delta}$ $=0)$ we get 


$$
u(y)=\frac{g\left(\rho_{1}-\rho_{2}\right) \delta^{2}}{\mu_{1}}\left[\frac{y}{\delta}-\frac{1}{2}\left(\frac{y}{\delta}\right)^{2}\right]
$$

From here, a mass flow rate per unit width can be obtained as a function of an integral involving velocity profile

$$
\frac{\dot{m}(x)}{b}=\int_{0}^{\delta(x)} \rho_{1} u(y) d y \equiv \Gamma(x)
$$

Substituting for $u(y)$ from equation (1.2) from equation (1.3) we have

$$
\Gamma(x)=\frac{g \rho_{l}\left(\rho_{l}-\rho_{v}\right) \delta^{3}}{3 \mu_{l}}
$$

Next we analyze the differential element in Figure 1.4 for energy conservation. Note, at a portion of the liquid-vapor interface (unit width and length $d x$ ), the rate of heat transfer into the condensate, $d q$, must be equal to the rate of heat released due to condensation at the interface. Therefore:

$$
d q=h_{f g} d \dot{m}
$$

Because advection in the thin moving condensate can be neglected, the heat transfer through the interface must be equal to the rate of heat transfer to the wall. That is:

$$
d q=q_{s}^{\prime \prime}(b \cdot d x)
$$

Because of a linear distribution of the liquid temperature, Fourier's law may applied to express the surface heat flux yields:

$$
q_{s}^{\prime \prime}=k_{l} \frac{\left(T_{s a t}-T_{s}\right)}{\delta}
$$

Equations (1.3), (1.5), (1.6) and (1.7) together yield

$$
\frac{d \Gamma}{d x}=\frac{k_{1}}{\delta h_{f g}}\left(T_{s a t}-T_{s}\right)
$$

Also, by differentiating Equation (1.4) we get 


$$
\frac{d \Gamma}{d x}=\frac{g \rho_{l}\left(\rho_{l}-\rho_{v}\right) \delta^{2}}{\mu_{l}} \frac{d \delta}{d x}
$$

Combining (1.8) and (1.9), we have

$$
\delta^{3} d \delta=\frac{k_{l} \mu_{l}\left(T_{s a t}-T_{s}\right)}{g h_{f g} \rho_{l}\left(\rho_{l}-\rho_{v}\right)} d x
$$

Integrating this equation from $x=0$ to $\mathrm{x}$ with $\delta(0)=0$, we get:

$$
\delta(x)=\left[\frac{4 k_{l} \mu_{l}\left(T_{s a t}-T_{s}\right) x}{g \rho_{l}\left(\rho_{l}-\rho_{v}\right) h_{f g}}\right]^{\frac{1}{4}}
$$

Later Rohsenow ${ }^{4}$ included the thermal advection effects by proposing that a certain term added to the latent heat of vaporization can be adequate. Instead of using $\mathrm{h}_{\mathrm{fg}}$, Rohsenow ${ }^{4}$ recommended using a modified latent heat, $\mathrm{h}_{\mathrm{fg}}{ }^{\prime}=\mathrm{h}_{\mathrm{fg}}+0.68 \mathrm{C}_{\mathrm{p}, 1}\left(\mathrm{~T}_{\mathrm{sat}}-\mathrm{T}_{\mathrm{s}}\right)$.

Recently, Sadasivan and Lienhard ${ }^{5}$ have stated that the modified $\mathrm{h}_{\mathrm{fg}}$ ' also depends weakly on the liquid Prandtl number.

From Equation (1.7), the local convection coefficient is obtained as

$$
h_{x}=\frac{k_{l}}{\delta(x)}
$$

Rearranging Equation (1.10) with the corrected $h_{\mathrm{fg}}$, and inserting in the equation above for $h_{x}$, one gets

$$
h_{x}=\left[\frac{g \rho_{l}\left(\rho_{l}-\rho_{v}\right) k_{l}^{3} h_{f g}^{\prime}}{4 \mu_{l}\left(T_{s a t}-T_{s}\right) x}\right]^{\frac{1}{4}}
$$

Since

$$
\overline{h_{L}}=\frac{1}{L} \int_{0}^{L} h_{x} d x=\frac{4}{3} h_{L}
$$

One arrives at the result: 


$$
\overline{h_{L}}=0.943\left[\frac{g \rho_{l}\left(\rho_{l}-\rho_{v}\right) k_{l}^{3} h_{f g}^{\prime}}{\mu_{l}\left(T_{s a t}-T_{s}\right) L}\right]^{\frac{1}{4}}
$$

The average Nusselt number is

$$
\overline{N u_{L}}=0.943\left[\frac{g \rho_{l}\left(\rho_{l}-\rho_{v}\right) h_{f g}^{\prime} L^{3}}{\mu_{l} k_{l}\left(T_{s a t}-T_{s}\right)}\right]^{\frac{1}{4}}
$$

It is important to remark that all liquid properties (with sub index 1) must be evaluated at the film temperature i.e. $T_{f}=\left(T_{\text {sat }}+T_{s}\right) / 2$, and $h_{f g}$ should be evaluated at $T_{\text {sat }}$. Also note that the non-dimensional parameters on the right side of (1.13) are consistent with the dimensional analysis result in Equation (1.2).

Sparrow and $\mathrm{Gregg}^{3}$ performed a more detailed boundary layer analysis of equations governing film condensation on a vertical plate. Their results have shown that errors between their results and Equation (1.12) are less than $3 \%$ for $\mathrm{Ja} \leq 0.1$ and $1 \leq \operatorname{Pr} \leq$ 100.

The expression can be also used for vertical tubes only if the radius is much larger than the thickness of the film.

This thesis and Mitra ${ }^{6}$ et al. show later that, for the gravity dominate forced convection experiments reported here, Nusselt result in Equation (1.12) continues to hold because vapor motion and interfacial share effects are negligible.

\subsection{Turbulent Film Condensation}

Turbulent flow may exist in film condensation if the condensate is allowed to thicken and speed over a sufficient long length of the plate. Let's consider the vertical surface of Figure 1.5a. The transition criterion may be expressed in terms of a Reynolds number defined as: 


$$
\operatorname{Re}_{\delta} \equiv \frac{4 \Gamma}{\mu_{l}}
$$

Here $\mu_{1}$ is the viscosity of the liquid and $\Gamma$ is the mass flow rate per unit width

$$
\Gamma=\frac{\dot{m}}{b}
$$

However, the condensate mass flow rate can be expressed as

$$
\dot{m}=\rho_{l} u_{m} b \delta
$$

Thus

$$
R e_{\delta}=\frac{4 \rho_{l} u_{m} \delta}{\mu_{l}}
$$

Here $\rho_{1}$ is the density of the liquid, $\mathrm{u}_{\mathrm{m}}$ is the average liquid velocity, $\mathrm{b}$ is the surface width and $\delta$ is the film thickness which in this particular case is the characteristic length.

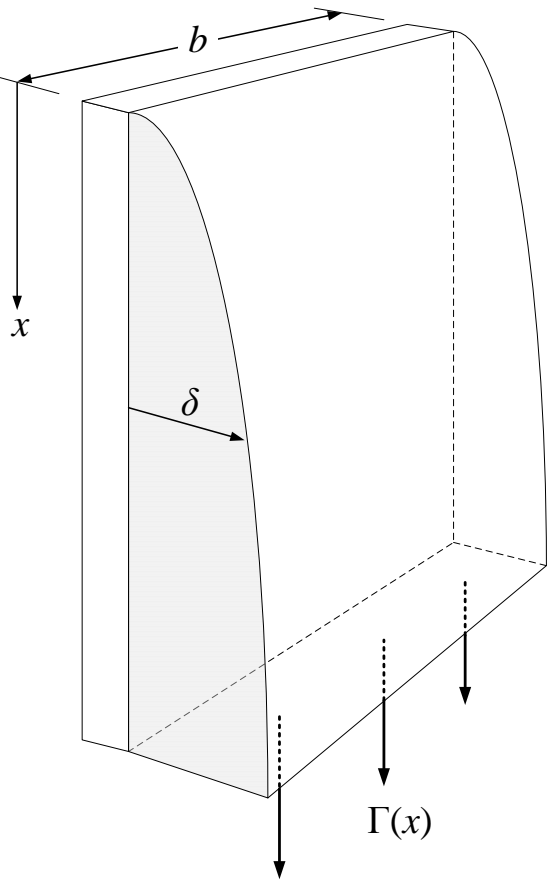

(a)

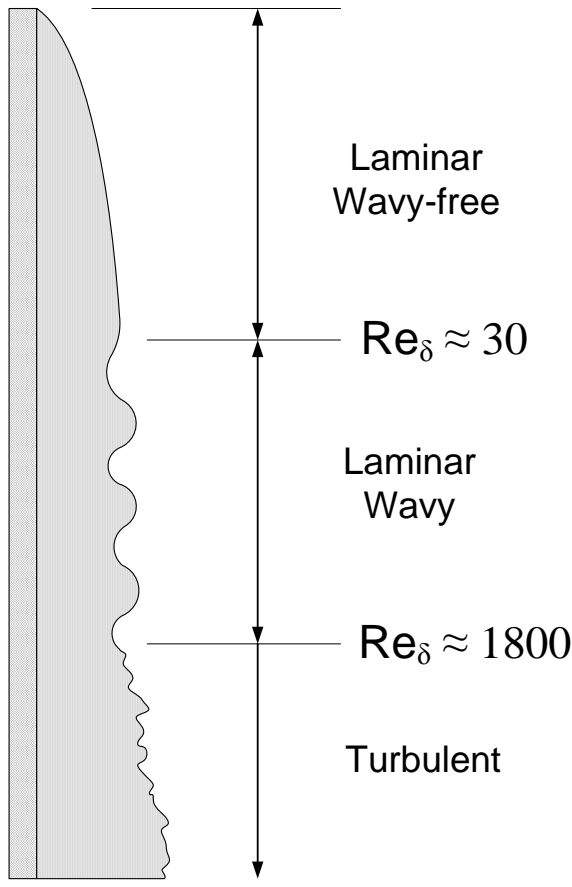

(b)

Figure 1.5: Schematic of a turbulent film. 
As we can see in Figure 1.5b, it is usually at Reynolds number estimated that if lower than 30, the film is laminar and wave free. As the thickness increases, it develops ripples and waves but the condition remains laminar, and when Reynolds number is approximately greater than 1800 , the flow can be assumed to be fully turbulent.

In the region, where we have a wave free laminar flow

$$
R e_{\delta}=\frac{4 g \rho_{l}\left(\rho_{l}-\rho_{v}\right) \delta^{3}}{3 \mu_{l}^{2}}
$$

Assuming that the liquid density is heavier than the vapor $\left(\rho_{1}>>\rho_{v}\right)$ and substituting from Equation (1.10) and then from (1.12), Equation (1.14) can be expressed as

$$
\operatorname{Co}=\frac{\overline{h_{L}}}{k_{l}}\left(\frac{v_{l}^{2}}{g}\right)^{\frac{1}{3}}=1.47 R e_{\delta}^{-1 / 3} \quad \text { for } R e_{\delta} \leq 30
$$

For the laminar wavy region, Kutateladze ${ }^{7}$ recommends

$$
\operatorname{Co}=\frac{\overline{h_{L}}}{k_{l}}\left(\frac{v_{l}^{2}}{g}\right)^{\frac{1}{3}}=\frac{R e_{\delta}}{1.08 \operatorname{Re}_{\delta}^{1.22}-5.2}
$$

For the turbulent region, Labuntsov ${ }^{8}$ recommends

$$
\operatorname{Co}=\frac{\overline{h_{L}}}{k_{l}}\left(\frac{v_{l}^{2}}{g}\right)^{\frac{1}{3}}=\frac{R e_{\delta}}{8750+58 \operatorname{Pr}^{-0.5}\left(\operatorname{Re}_{\delta}^{0.75}-253\right)} \quad \text { for } \operatorname{Re}_{\delta} \geq 1800
$$

Here Co is the condensate number. 


\subsection{Other Models for Laminar Wavy Region with Interfacial Waves}

When Reynolds number $(\operatorname{Re}=\Gamma / \mu)$ exceeds a critical value, it has been observed that the interface becomes wavy, however the condensate film is laminar. Kutateladze ${ }^{7}$ evaluated this value for different fluids and found out that ripples become visible if Reynolds number is greater than 7.5. When such ripples emerge, the heat transfer coefficient is enhanced. In his experimental results, Kutateladze concluded that the heat transfer coefficient can be approximated as

$$
{\overline{h_{L}}}^{*}=0.8 R e^{0.11} \overline{h_{L}}
$$

Where

$\overline{h_{L}}$ is the average heat transfer coefficient from Equation (1.12)

$\bar{h}_{L}^{*}$ is the average heat transfer coefficient with ripples

White ${ }^{9}$ proposes the following correlation attributed to Kutateladze for

$7.5<\operatorname{Re}<450$

$$
C o=\frac{R e}{1.47 R e^{1.22}-1.3}
$$




\section{Literature review}

\subsection{Introduction}

Heat transfer for condensing flows of pure vapor inside a vertical tube depends on flow regimes, inlet, exit and wall conditions. Figure 2.1 shows two schematics of a vertical in-tube condensation.

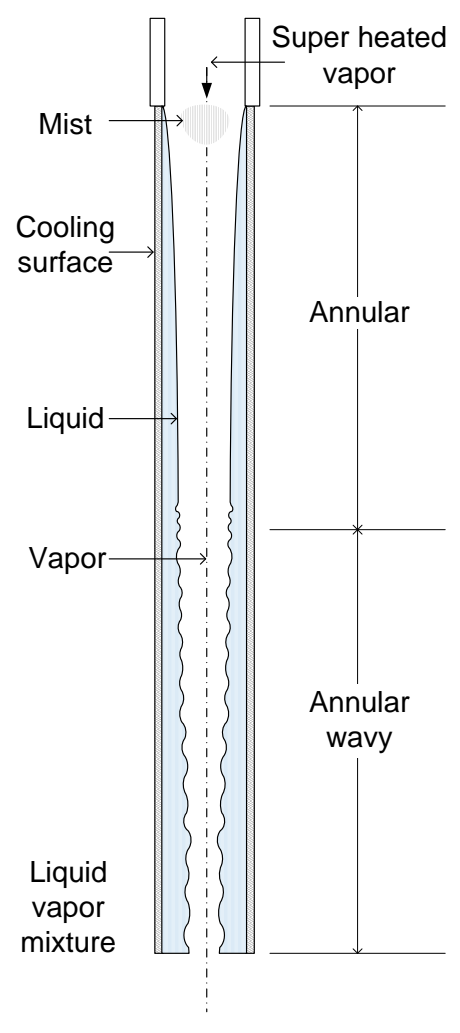

(a)

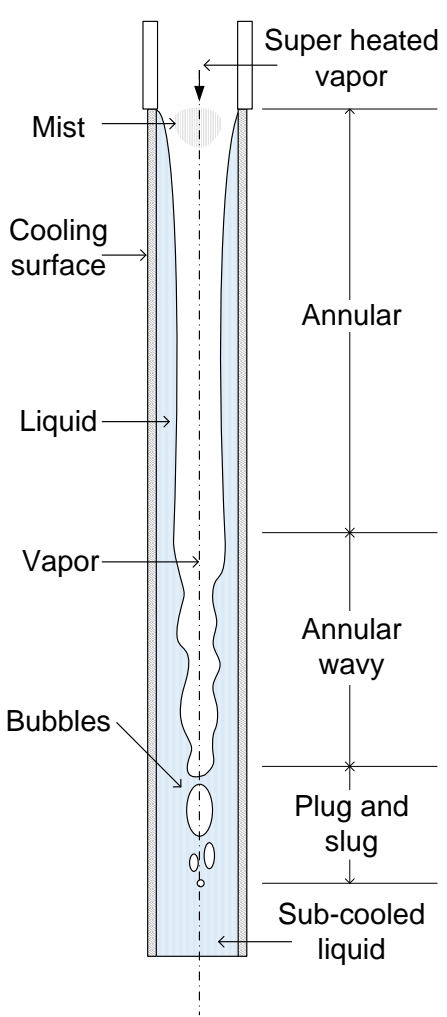

(b)

Figure 2.1: (a) Partial condensation. (b) Full condensation.

As condensation occurs along the vertical tube, the amount of condensed fluid increases with distance and eventually it can either leave the tube as a mixture of vapor 
and liquid (partial condensation in Figure 2.1a) or as pure liquid (complete condensation in Figure 2.1b). This flow, starts from the top of the condenser as an annular laminar flow and it may be followed by wavy, turbulent, slug, and plug flows.

For vertical tubes, the annular flow regime is known to be the dominant flow regime, being present over most of the length of condensation. ${ }^{2,10,11,12,13,14}$ In the annular flow regime, condensate develops on the inner periphery surface of the tube. When the inlet vapor speed and cooling conditions are within certain boundary (Mitra et al. ${ }^{6}$ ), the condensate flow is driven primarily by gravity and interfacial shear effects can be neglected.

In the reported experimental work, annular wavy laminar flow regime, (Figure 2.1) was seen for a large number of runs.

\subsection{Analytical Studies}

Nusselt ${ }^{2}$ was the first to analyze the film condensation on a vertical plate. In his solution, he assumed laminar flow regime. He also assumed that the thermo physical properties of the vapor and fluid were constant. The condensate sub cooling, momentum and interfacial shear stress were considered negligible. He also presumed temperature profile in the film as linear.

Jakob $^{15}$ was one of the first to remark a high deviation of the Nusselt analysis for experimental results corresponding to a turbulent flow regime.

Likewise, Akers and Rosson ${ }^{16}$ showed that the Nusselt analysis may not be valid when the effects of the liquid sub cooling or vapor shear are significant as well as when turbulent condensate flow is present.

$\mathrm{Koh}^{17}$ presented numerical solution to a system of differential equations (under boundary layer approximation) of mass, momentum and energy balance for condensation over a flat plate. The equation included inertia and convective terms. His results showed 
that, for a thin film and Prandtl number smaller than 10, the condensate velocity and temperature profiles are essentially linear. He also showed that neglecting the convective terms in the energy equation significantly underestimated the heat transfer rates for higher Prandtl numbers.

Shekrilasze and Gomelauri ${ }^{18}$ expressed some doubt about Koh's results regarding the effect of the inertia forces and the convective terms on the condensation heat transfer rates. On the assumptions that the temperature profile is linear and the inertia forces are negligible, a model of condensation on a flat plate was developed. They assumed the interfacial shear stress equal to the momentum associated with the condensing vapor for high vapor velocities.

\subsection{Recent Studies}

There are quite a few existing experimental papers with condensation in vertical tubes and passages ${ }^{19,20,21,22,23,24}$ which involve a number of pure fluids. Also there are several heat transfer correlations ${ }^{19-24}$ which have been developed to cover various different realms of internal condensing flow physics (including those involving horizontal

and vertical tubes). The experiments as well as the correlations in the literature ${ }^{19-24}$ cover a rather large set of internal condensing flow regimes and associated flow physics. For example, condensing flows in the literature involve: shear driven to gravity driven condensate motion (inside horizontal to vertical tubes and channels), laminar to turbulent nature of the flows in the vapor phase, and laminar (with or without waves) to turbulent (wavy) nature of condensate flows, and annular to various non-annular (plug/slug, bubbly, etc.) liquid/vapor interface-configuration patterns (also termed liquid/vapor morphologies). One of the goals of these types of investigations has been to synthesize analyses and experiments to provide reliable order of magnitude estimates for average heat transfer coefficients over the large set of flow physics conditions associated with condensing flows. In addition to the above, there are also modern condensing flow experiments for flows in $\mu \mathrm{m}$-mm scale ducts. ${ }^{25,26,27}$ These newer experiments typically 
involve shear driven and laminar condensate motion and exhibit even a greater variety of liquid-vapor morphologies (injection annular, plug/slug, etc.) for different steady/quasisteady and oscillatory realizations of these flows.

In the above context, the goal of the reported experiments is to use a reliable synthesis of experiments with computational/theoretical results obtained for a specific flow physics category and to develop a reliable heat transfer correlation (s) for the chosen category. In this thesis, gravity driven flows with laminar wavy and annular condensate flows are investigated. The theoretical/computational results ${ }^{6}$ and its synthesis with experimental results reported here is, to begin with, for the flow physics category of laminar condensate and laminar vapor (in the near interface region) flows which are annular with small to moderate waviness. The theoretical/computational results in Mitra et al. ${ }^{6}$ do not employ any ad hoc models (as in Cavallini, ${ }^{20}$ Dobson $^{21}$ and Coleman ${ }^{27}$ ) for interfacial shear stress, pressure gradient, condensate turbulence, etc. Results from this approach, in conjunction with experimental result are used to define flow physics boundaries. This is done by considering experimental data that agree with the theory in Mitra $^{6}$ as well as data that systematically deviates from the flow physics assumptions underlying the theory. Therefore this approach identifies nearby flow physics categories for which the agreement is not good and one needs to properly model the interactions between the vapor flow in the "near-interface" region and the condensate waviness associated with laminar or turbulent condensate flows. Over the identified regime of disagreement with theory, the "near interface" vapor flow and condensate waviness interactions are strong enough to significantly enhance the heat transfer rates compared to the laminar/laminar (with or without waves) approach. ${ }^{6}$ The eventual goal of this type of experiment/theory synthesis is that if one wants more accurate flow prediction tool and/or correlations, one should be able to develop (through appropriate synthesis of experiments and analysis) the theory and requisite correlations for other specific categories of condensing flow physics. The ability to develop this synthesis for laminar/laminar annular flows is presented here and, with the help of more and appropriate experimental data, the way to accomplish the same for more complex nearby flow-physics categories (such as cases involving significant interfacial waviness) is also outlined. 
Another objective of the reported investigations is to develop an experimental flow control strategy that helps us understand the role of boundary-condition sensitivities associated with different impositions of quasi-steady or time varying pressure-differences across the condenser. The presented experimental investigations have sufficient number of flow controls that allow one to independently vary the inlet mass flow rate $\dot{\mathrm{M}}_{\mathrm{in}}$, inlet or exit pressures, and vapor to condensing-surface temperature difference $\Delta \mathrm{T}$. The exit condition for the condenser is specified by exit pressure through appropriate flow control strategies. Due to an error in some of our earlier results ${ }^{28,29,30,31}$ for gravity driven partial condensation flows inside a vertical tube, we wrongly stated that condensing flows are generally "elliptic" because, for a given set of inlet and wall conditions, one can always impose different steady exit conditions and achieve different steady annular flows. The corrections on these earlier reported theory and computations have been recently made in Kulkarni et al, ${ }^{32}$ and we find that there exists sensitivity to boundary conditions (termed "parabolic sensitivity" in Kulkarni ${ }^{32}$ ). But the sensitivity is limited mostly to certain cases involving shear/pressure driven flows and presence of time-varying fluctuations at the inlet pressure which lead to different non-natural steady pressure-difference ${ }^{6,32}$ for a given quasi-steady mass flow rate and cooling conditions. It is reiterated that this sensitivity is limited only to shear driven or mixed driven (partially shear and partially gravity driven) internal condensing flow situation.

The experimental and theoretical results confirming "subcritical" and "supercritical" parabolic sensitivity for shear driven flows (whether they occur in $\mu \mathrm{m}$ scale ducts or perfectly horizontal channels or zero-gravity duct flows) are reported separately in Kulkarni. ${ }^{32}$ These results are of enormous significance in properly ensuring repeatable realizations of annular/stratified shear driven flows - which happen to be less repeatable and robust than the gravity driven flows reported in this thesis. The shear driven flows' parabolic sensitivity results are also important in understanding the greater variety and complexity of shear driven condensing flows' liquid/vapor morphologies such as those observed in large diameter horizontal tubes (see Carey ${ }^{33}$ ) and in $\mu \mathrm{m}$-scale ducts. ${ }^{25,26,27}$ Improper or inadvertent imposition of inlet or exit pressure conditions in the presence of fluctuations may also be the cause for various flow transients ${ }^{34,35,36}$ observed 
for "mixed" or purely shear driven internal condensing flows in horizontal tubes. Furthermore, as theoretically and experimentally shown in Kulkarni, ${ }^{32}$ availability of suitable time-periodic fluctuations in flow variables (mass flow rate, inlet/outlet pressures, etc.) is key to enabling multiple pressure-difference impositions that, independent of any impact on mean flow rates, affects condensate thickness and leads to different quasi-steady shear driven annular flows with large changes (> $200 \%$ ) in heat transfer rates.

It is shown here that gravity driven and gravity dominated internal condensing annular flows (see Mitra et al. ${ }^{6}$ for the definition of this flow) do not allow externally imposed changes in self-selected pressure difference conditions if inlet pressure, inlet mass flow rate, and condensing-surface thermal conditions are specified (i.e. the problem is "parabolic" with insignificant sensitivity to presence of compressor-induced fluctuations on the mean inlet pressure). Most of the vertical tube cases reported here fall in this gravity driven and gravity dominated annular internal condensing flow category.

Since this thesis deals only with gravity dominated flows and Kulkarni ${ }^{32}$ deals only with purely shear/pressure driven flows, we expect that our planned future experiments dealing with mixed driven flows will exhibit parabolic-sensitivity behavior that is intermediate between these two limiting cases. 


\section{Experimental facility}

\subsection{Primary Cooling Water Loop}

\subsubsection{Loop}

In order to keep the test section wall at a constant and nearly uniform temperature, a primary cooling water loop is installed (Figure 3.1). Its components consist of a centrifugal pump, a filter, a flow meter, a tank/reservoir and a heat exchanger. This last part is responsible for transferring heat from this loop to the secondary cooling water loop. 


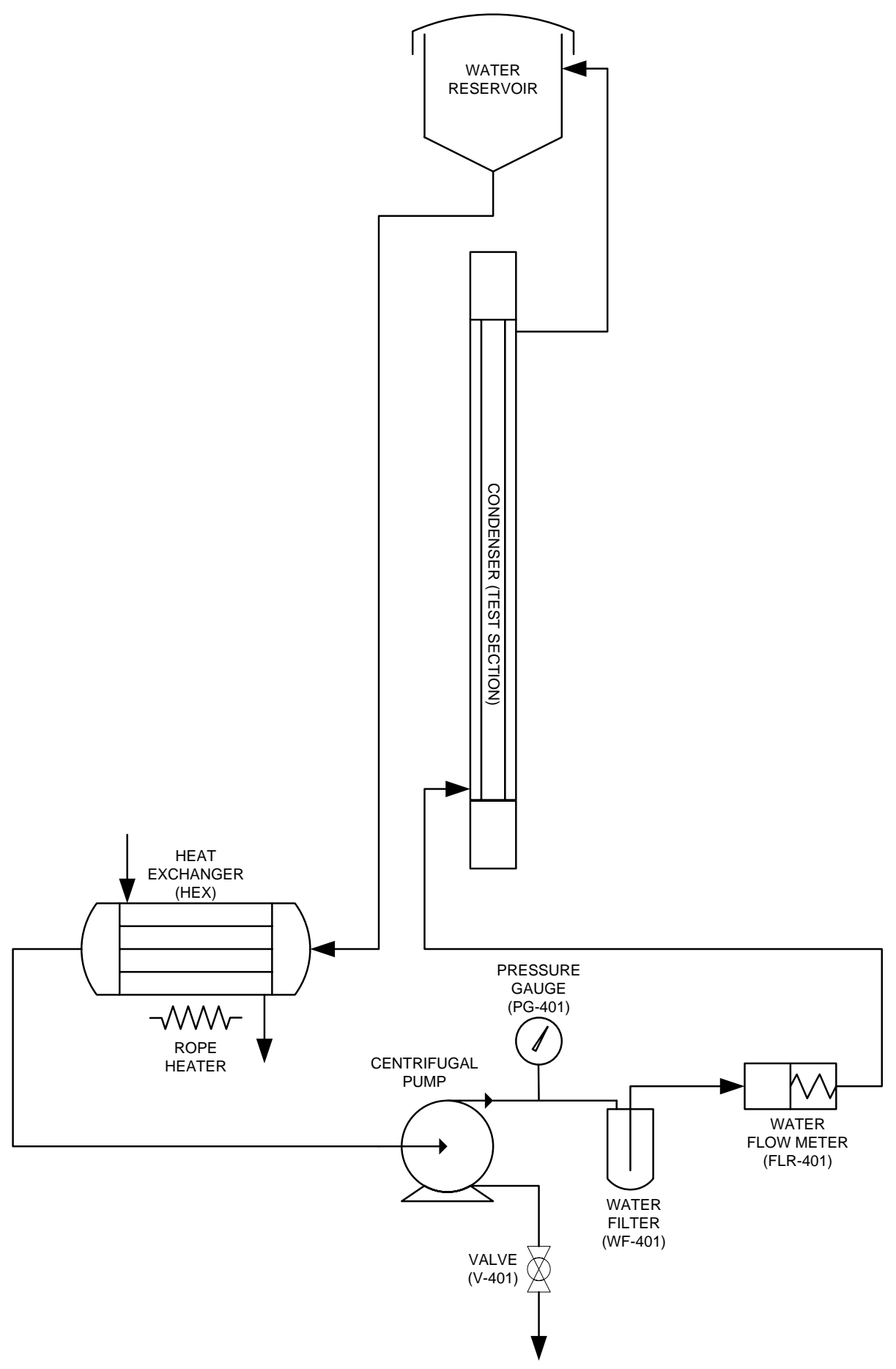

Figure 3.1: Schematic of the primary cooling loop. 


\subsubsection{Loop Components}

The pump (see Figure 3.2) is designed for a continuous operation. According to the technical specifications from the manufacturer, it is a 3/4 HP class 1 pump. It is rated for $65 \mathrm{GPM}$ flow rate at $30 \mathrm{ft}$ head (13 psi). It has a 2 inches suction diameter and $1 \frac{1}{2}$ inches discharge diameter.

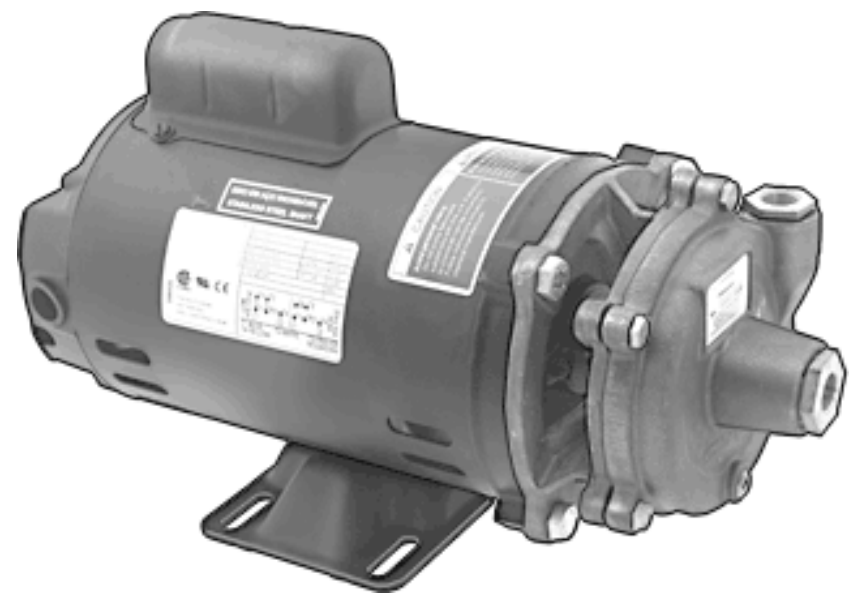

Figure 3.2: Pump utilized for the primary cooling loop.

The total dynamic head, $T D H$, the energy that the pump imparts to the liquid in this closed loop operation, takes into account differences in pressure, liquid elevation, friction losses, pressure drop through instrumentation and flow velocity between the inlet and the outlet of the pump.

In this particular case, this pump only needs to overcome frictional losses I the closed loop. This is important to note because we are looking for a high flow rate with minimal frictional losses in order to achieve a constant wall temperature inside the test section. In other words, heat coming into the coolant flow (from condenser) plus heat generated by frictional loss together must be removed by the heat exchanging to the secondary loop. 
The pump's electric motor is single phase asynchronous type. Its bearings need to be lubricated. This pump is mounted at the lowest point of the line and therefore we don't expect major problems such as cavitations.

It is important to mention that a previous pump installed in this loop was oversized and heat generated due to fluid friction was very significant. The new pump's power is such that we get high volume flow rate at a low head just enough to overcome the friction losses in this loop.

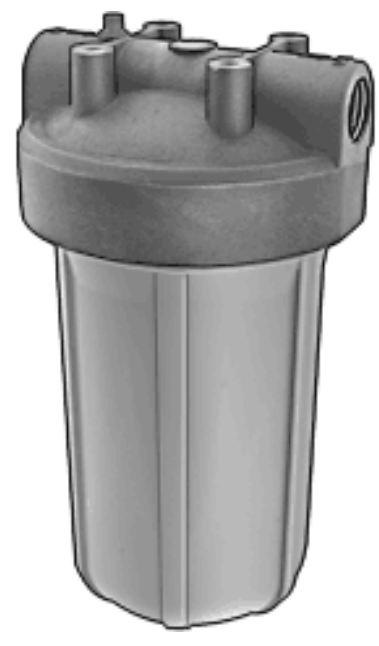

Figure 3.3: Water filter used in the primary cooling loop.

The water filter WF-401 (Figure 3.3) has a larger housing and cartridge that provides high dirt holding capacity. Both the housing and the cartridge are made of FDAgrade materials. The filter includes a pressure-release button for safe cartridge replacement. This filter can work with any double open-end (DOE) filter cartridge with the same OD and length. Its connections are 1 inch pipe size NPT females. This filter can stand a maximum flow of $10 \mathrm{GPM}$, maximum pressure of $100 \mathrm{psi}$ and maximum temperature of $100^{\circ} \mathrm{F}$. The housing for the filter cartridge has a 7-1/4 inches of diameter and 13-1/8 inches of height. The filter cartridge material is polyester, micron rating of 50 and has 4-1/2 inches of outside diameter and 9-3/4 inches of height. 


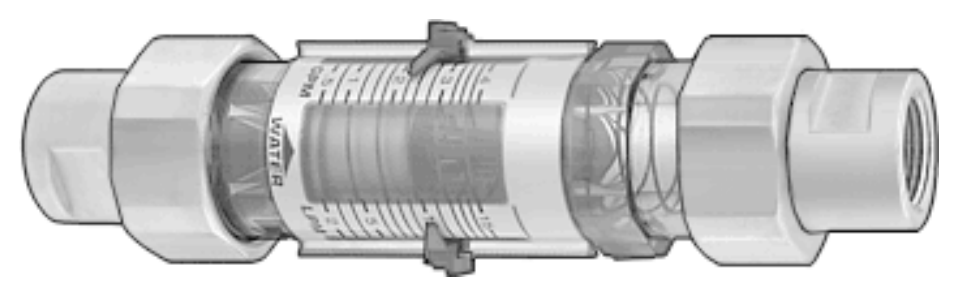

Figure 3.4: Water flow meter installed in the primary cooling loop.

The FLR-401 water flow meter (Figure 3.4) flow range is 1 - 7 GPM and has a transparent body so flow can be monitored in addition to reading the scale. It has a shockresistant spring-loaded piston so it can be mounted horizontally, vertically, or at any angle. The dual scale shows flow rate in both gallons per minute and liters per minute. Body is polysulfide, O-rings are Buna-N and accuracy is $\pm 5 \%$. Maximum pressure is 325 psi at $70^{\circ} \mathrm{F}$. This flow meter has 1 inch pipe NPT female fittings. The maximum temperature at which this can operate is $250^{\circ} \mathrm{F}$.

The tank/reservoir (Figure 3.5) is located on the top of the system. This is part of the loop and is used to remove any trapped air bubble in the primary cooling water loop.

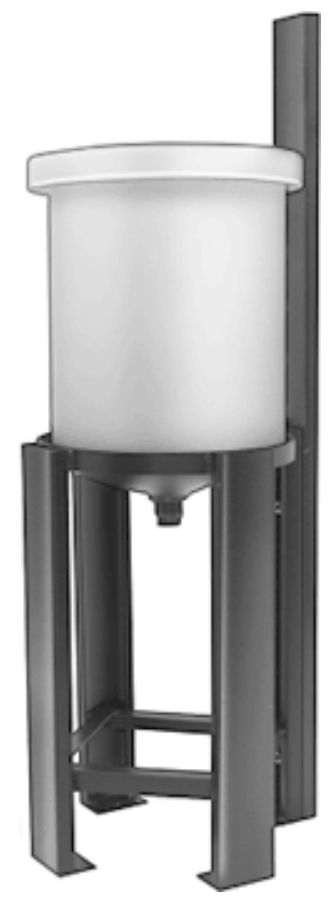

Figure 3.5: Water tank mounted at the highest point of the primary cooling loop. 
In the past, bubbles were trapped and, as a consequence, noise and cavitations developed in the pump. The cone-shaped bottom of this tank is sloped to ensure easy and complete drainage. It is made of polyethylene (with cover) and has a $19^{\circ}$ bottom slope with seamless, heavy-wall construction, and rounded corners. It has a loose-fitting cover and PVC NPT female drain fitting with EPDM gasket. The maximum temperature that this can stand is $140^{\circ} \mathrm{F}$. Its translucent material allows an indirect view of the liquid level. The rated capacity of this tank is 5 gallons and has a body diameter of $12-1 / 2$ inches with a height of 15-1/8 inches. The tank wall thickness is 3/16 inches. The drain fitting is a $1 \frac{1}{2}$ inch NPT(M).

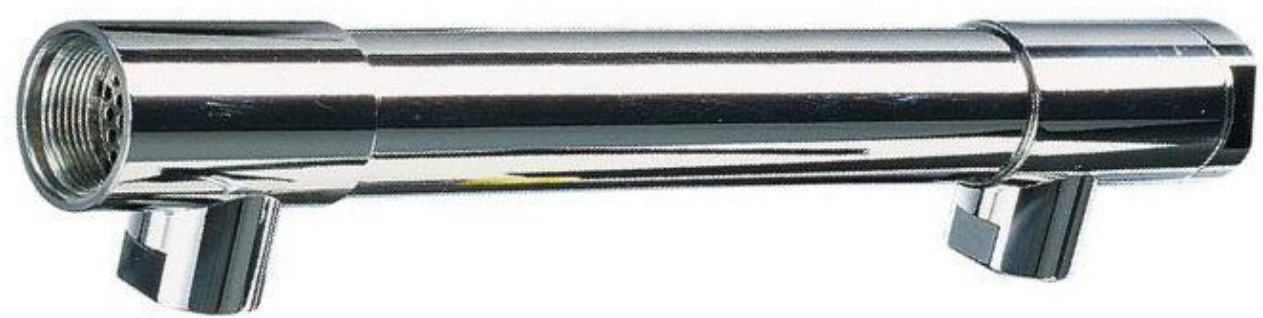

Figure 3.6: Heat exchanger used at the cooling loops.

The heat exchanger (HEX) has a compact design that allows maximum thermal efficiency. This is a sanitary heat exchanger (Figure 3.6) that meets all cGMP and ANSI standards. It is constructed of $316 \mathrm{~L}$ stainless steel with nickel-chromium vacuum-brazed joints. The total heat transfer area is $0.803 \mathrm{~m}^{2}$. The temperature range for the shell side is -60 to $232{ }^{\circ} \mathrm{C}$, the tube side -25 to $205^{\circ} \mathrm{C}$, and the maximum operating temperature is $425{ }^{\circ} \mathrm{C}$. The shell volume is $0.0788 \mathrm{~m}^{3}$ and the tube volume is $0.042 \mathrm{~m}^{3}$. The shell inner diameter is 1 inch NPT (F). This heat exchanger is designed to ensure efficient thermal control for process requirements. 


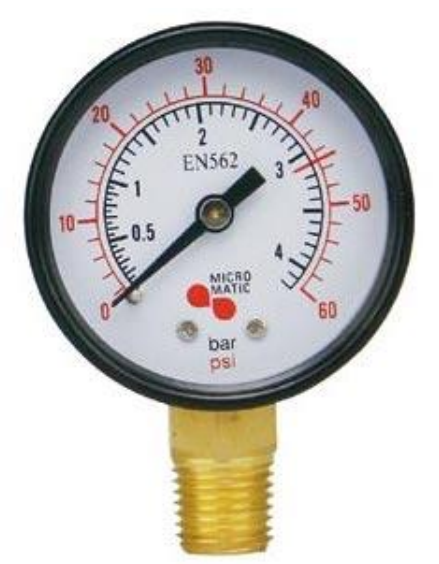

Figure 3.7: Pressure gauge installed at the exit of the pump.

A pressure gauge (PG-401) is installed after the centrifugal pump. This measurement of the pump exit pressure allows us to monitor the pump performance. The scale of this instrument is 0 - 60 psi (Figure 3.7).

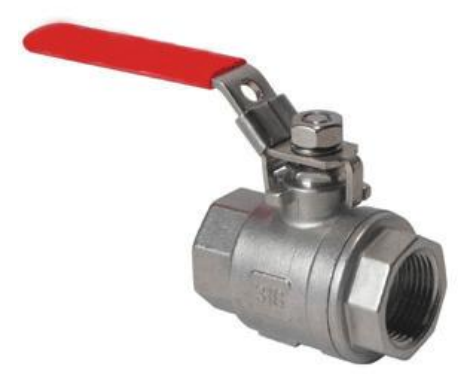

Figure 3.8: A typical ball type valve utilized in this loop.

The V-401 valve is incorporated and used for pump water purge. This valve (Figure 3.8) is used for emptying the primary cooling water loop. To serve this purpose, this valve is located at the lowest point of the primary loop.

Flexible tubing was used for the primary coolant loop. In all cases, large diameter tubing ( $1 \frac{1}{2}$ inches) with high temperature and pressure resistant materials were selected. To accomplish the highest performance for the primary cooling water loop design, this 
tubing choice allowed low pressure drop due to fluid friction. For this reason, there is no valve in this loop and all connecting lengths were sized to be as short as possible. Due to its location, V-401 does not interfere with the flow.

\subsubsection{Operation}

Once primed with water, the loop (Figure 3.1) is operated by just turning on the centrifugal pump. A fixed water flow rate is attained and no water temperature control is feasible without the heat exchanger and a secondary coolant loop. It is important to use distilled water for this loop. In the past, tap water was used and this resulted in significant amount of corrosion inside the jacket of the test section.

\subsubsection{Recommendations on the Primary Loop}

Another pressure gauge is recommended to be installed on the upstream side of the centrifugal pump. This is to allow measurement and verification of performance of the pump. Current flow meter FLR-401 should be replaced by a higher scale flow meter due to a higher volume flow rate this loop is currently developing.

\subsection{Secondary Cooling Water Loop}

The secondary loop involves two independent cooling water loops. A loop for heat removal from the primary loop is called Koolant secondary cooling water loop. This loop is run through a water chiller of brand name Koolant. Another, but a separate loop for heat removal from different portions of the loop other than the test-section (such as the accumulator, the auxiliary condenser, the temperature bath surrounding new evaporator, etc.) is called Teca secondary cooling water loop. Again, this second loop is also run through a water chiller, in this case brand Teca. 


\subsubsection{Koolant Water Chiller Loop Components}

Mainly designed to control the cooling water temperature in the primary loop, this loop (Figure 3.9 and Figure 3.10) has a 5000 BTU/hr capacity chiller, a three-way valve, a filter, a heat exchanger, a rotameter, a rope heater, a variable transformer, a pressure gauge, 2 temperature sensors and 5 ball valves.

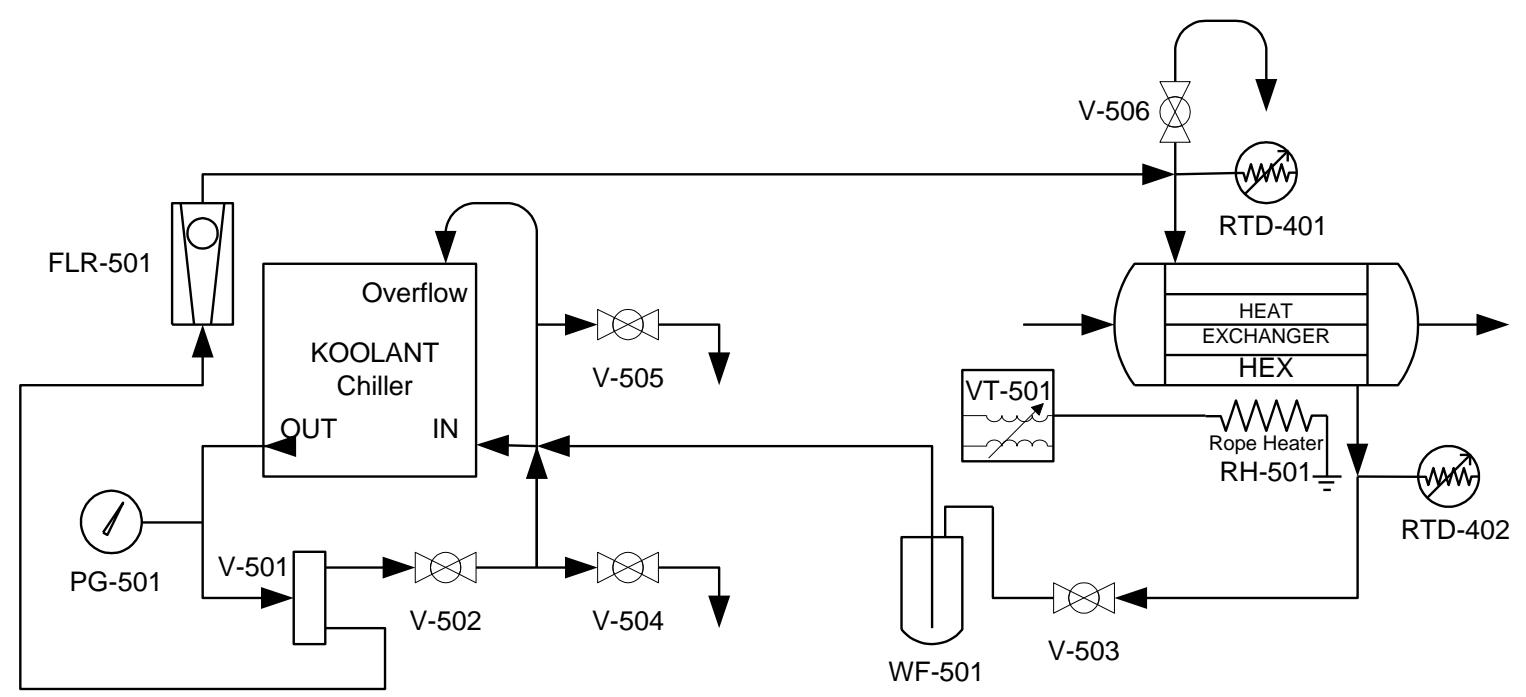

Figure 3.9: Schematic of the Koolant secondary cooling water loop.

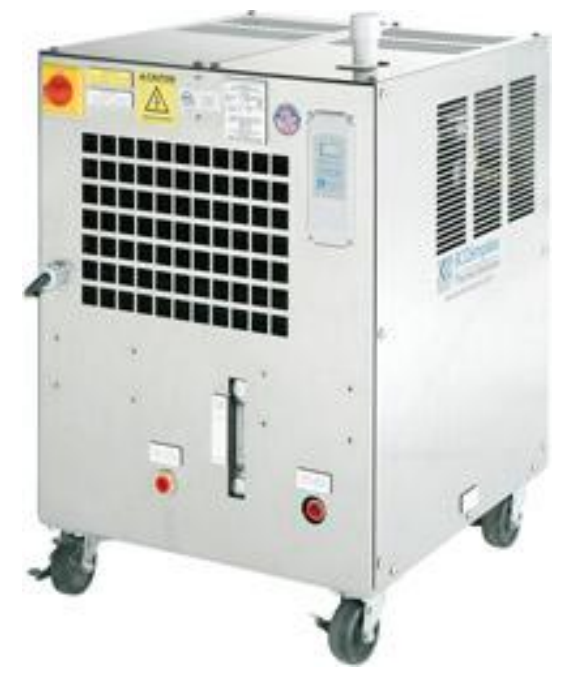

Figure 3.10: A picture of the Koolant water chiller installed in the secondary cooling water loop. 
The chiller (Figure 3.10) has a hermetically sealed compressor for its refrigerant, a high pressure vane-type positive displacement re-circulating pump, a built-in digital temperature controller of process fluid temperature and submerged copper coil evaporator which is less susceptible to damage caused by accidental freezing. The rated power for this model is $1.5 \mathrm{~kW}$ at $18^{\circ} \mathrm{C}$. The pump flow at $50 \mathrm{psi}$ is $2 \mathrm{GPM}$. The maximum rated amp is $13 \mathrm{~A}$. Its reservoir holds 7 gallons of coolant.

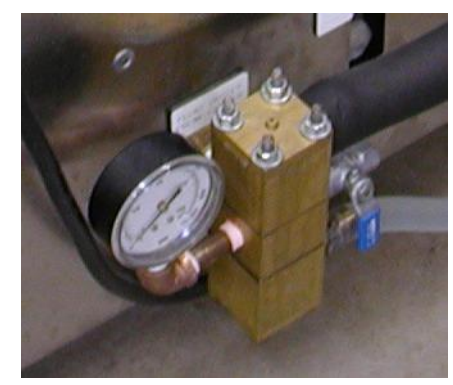

Figure 3.11: A picture of the customized three way valve.

The three-way valve (V-501 in Figure 3.9) is a custom designed valve. In order to have an efficient flow control in this loop, a valve that has a low pressure drop was necessary to be utilized. Originally designed to be actively controlled with a servo motor, (Figure 3.11) it is made of brass with $1 / 2$ inches inlet and 3/8 inch outlet NPT (F) ports. Currently, this valve is manually operated. This valve was designed, built and mounted by Michael Kivisalu. 


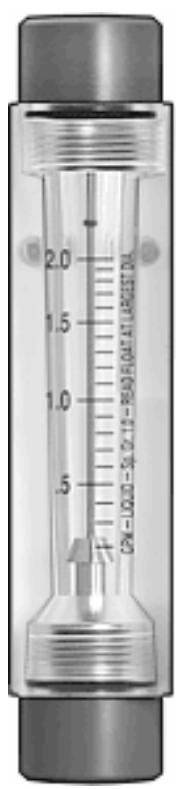

Figure 3.12: Water flow meter used in the secondary cooling loop.

The FLR-501 (Figure 3.12) rotameter for water flow measurement has a 5 GPM full scale with an accuracy of $2 \%$. It has an acrylic tube, a type $316 \mathrm{~L}$ stainless steel float and rod, and ethylene propylene (EPR) O-rings. The maximum pressure is $116 \mathrm{psi}$ at $70^{\circ}$ $\mathrm{F}$. The minimum temperature is $33^{\circ} \mathrm{F}$ and the maximum temperature for water is $130^{\circ} \mathrm{F}$. It has $1 / 2$ inches NPT $(F)$ pipe size connections.

The rope heater (RH-501 in Figure 3.9) wrapped on the outer surface of the heat exchanger (Figure 3.6) has a maximum heat output of $125 \mathrm{~W}$. This was ideal for spot warming metal pipes and situations involving odd shapes. This heating element was necessary to allow rapid attainment of steady state in situations where higher coolant temperature was required. 


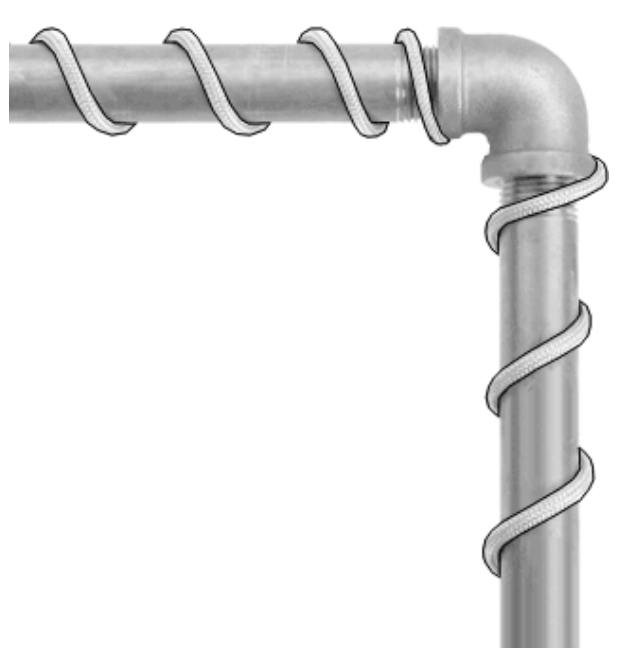

Figure 3.13: Typical rope heater used at the exit of the evaporator.

This heater (Figure 3.13) is single phase and made of resistance wire covered with a fiberglass braid. Leads on each end permit easy connection to a power source or a voltage controller. To prevent burnout, rope was not overlapped and to ensure full contact with the surface being heated a high temperature epoxy was applied. This rope is $0.165 "$ thick and operates on $120 \mathrm{VAC}$. Exposure temperature range for the heater is from room temperature to $900^{\circ} \mathrm{F}$. This is a UL recognized and CSA certified device.

In order to power the above heater, a variable transformer (VT-501) is utilized. This power supply (Figure 3.14) is rated for 7.5 A and is a single phase type transformer. Input voltage is $120 \mathrm{~V}$ and output voltage can vary between 0 to $140 \mathrm{~V}$. The rated power is $1 \mathrm{~kW}$. It has a case, Cord, Plug, Switch, Light, Fuse and Receptacle. 


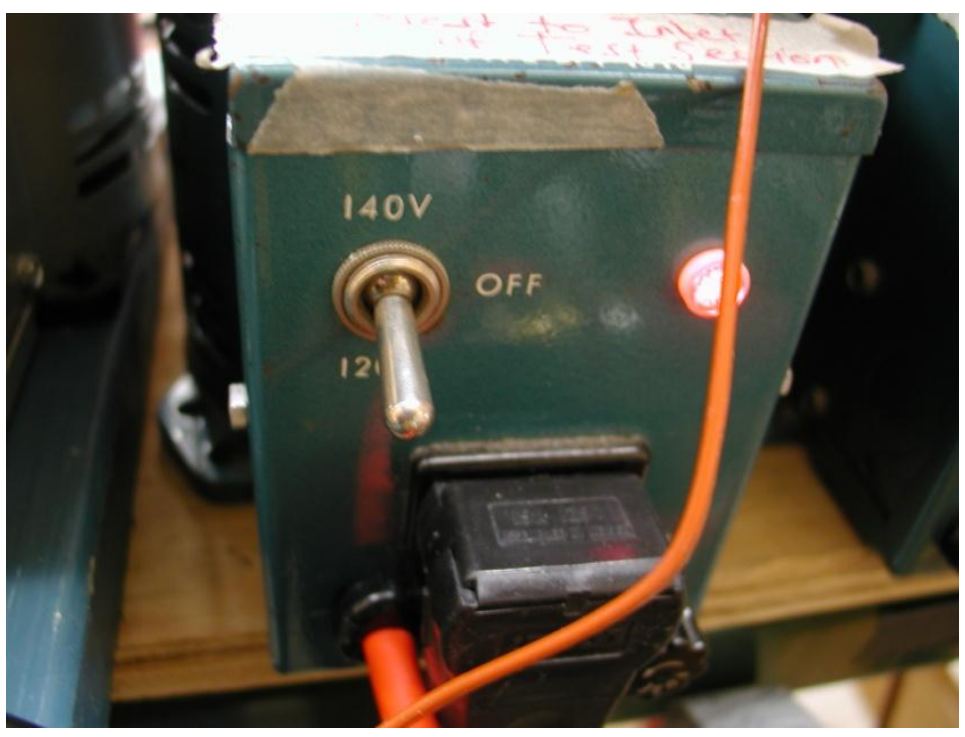

Figure 3.14: Picture of a variable transformer used to control heating power.

The technical specification for the (HEX) heat exchanger is already described in the Primary Cooling Water Loop section. The water filter (WF-501) installed in this loop is the same of the one installed at the primary loop (WF-401). All 5 valves are WOG ball type with 3/8 inches NPT (F) connections. Flexible but high pressure resistant clear tubes of 5/8 inches inner diameter were utilized in this loop. Brass barbed fittings suitable for this dimension were used as required. To ensure good performance, insulating foams were applied on tubes where cooling water was flowing.

A pressure gage of 160 psi full scale (PG-501 in Figure 3.9) is installed after the Koolant chiller in order to verify flow pressure at the exit of the positive displacement pump (located inside the chiller). Temperature sensors (RTD) are installed to monitor cooling water heat transfer rate in the heat exchanger. RTD-411 and RTD-412 are located at the inlet and exit of the heat exchanger respectively. 


\subsubsection{Operation}

By turning on the Koolant chiller the built-in positive displacement pump drives the cooling water flow through this water filled loop. At the same time, Koolant inner refrigeration unit starts functioning to cool down this cooling water flow until it reaches the set point temperature. At this point, the operator may input a desired set point value.

Volume flow rate to the heat exchanger may be adjusted though the 3-way valve (V-501 in Figure 3.9). The by-pass valve (V-502 in Figure 3.9) should be opened all time during operations as well as drain valves (V-504, V-505 and V-506 in Figure 3.9). For maintenance work, all drain valves must be opened and water filter (WF-501 in Figure 3.9) cartridge must be replaced as needed. Always use distilled water for this loop.

Some operating conditions may require the use of the rope heater RP-501 (for high wall temperature cases). In such situations, variable transformer VT-501 is available for this purpose.

\subsubsection{Recommendations}

A valve after WF-501 may be installed to let filter be removed for maintenance without draining water from the loop. A servo motor is desired to be mounted on V-501 for its control and this will implement of finalizing the original idea of active control. A band heater, instead of a rope heater, will be more suitable for heat supply at HEX (in Figure 3.9).

\subsubsection{Teca Secondary Cooling Water Loop}

This was mainly designed to control the cooling water temperature at the auxiliary condenser, the accumulator, and the water bath for a new evaporator. This loop (Figure 
3.15) has a $1400 \mathrm{BTU} / \mathrm{hr}$ capacity chiller, a needle valve, a rotameter, a pressure gage, a reservoir, a filter, a positive displacement pump and 11 valves.

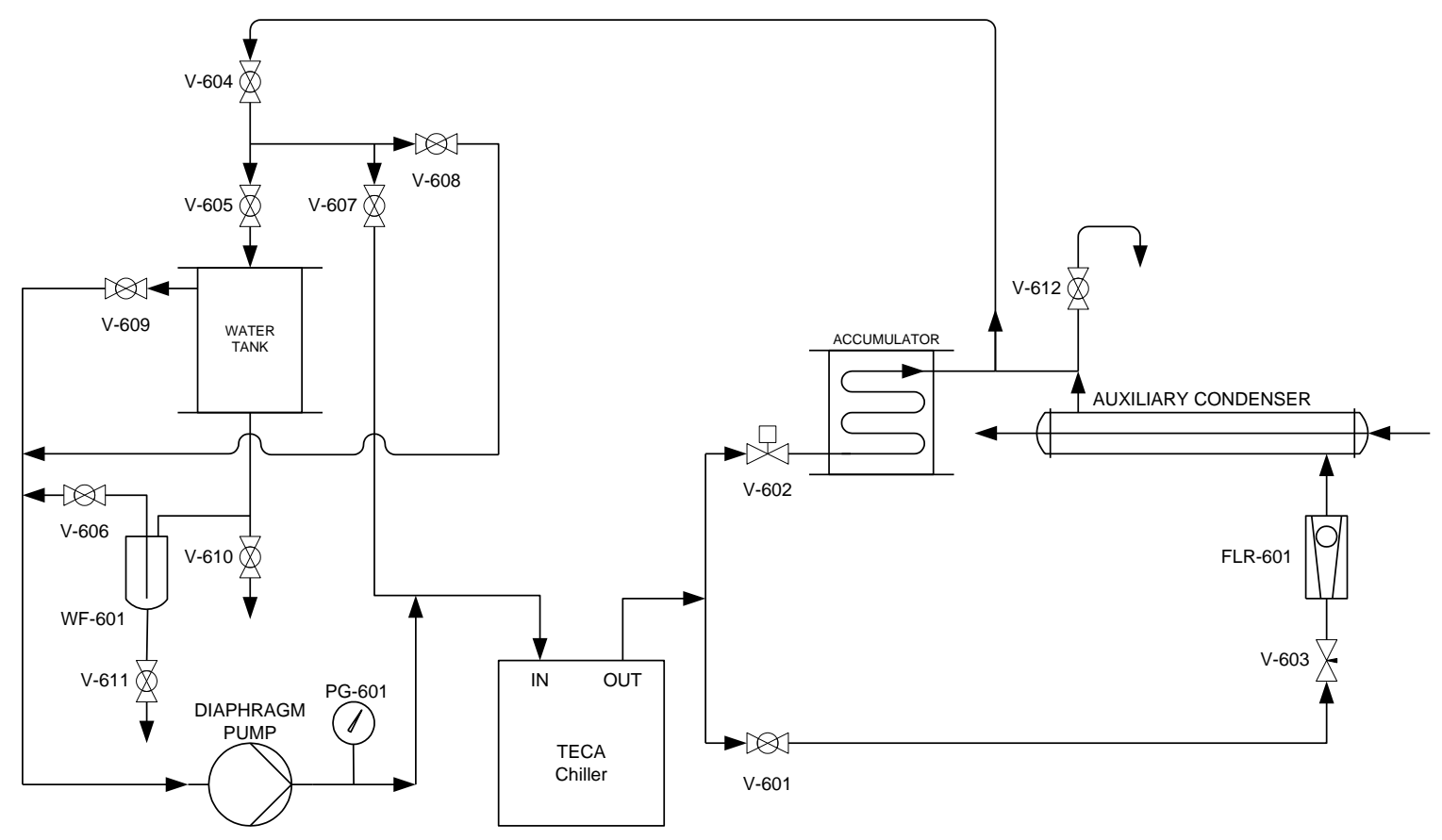

Figure 3.15: Schematic of the Teca secondary cooling water loop.

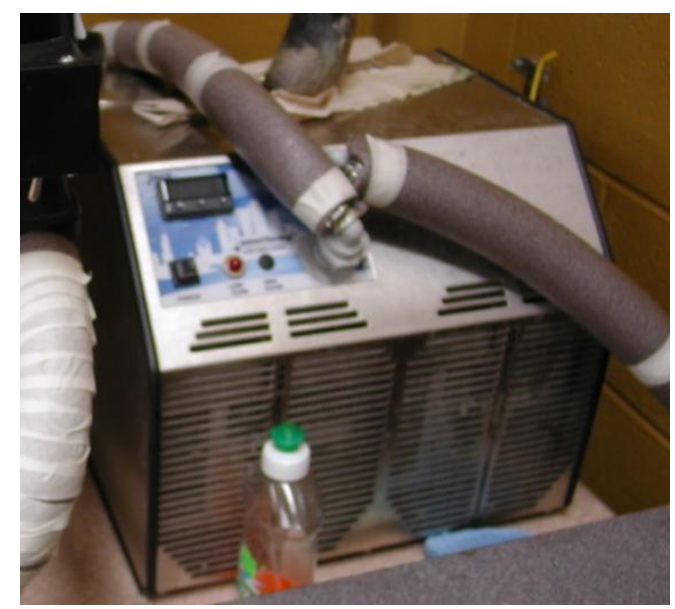

Figure 3.16: Picture of the Teca chiller installed in the secondary water loop. 
The rated power for this Teca chiller (Figure 3.16) is $410 \mathrm{~W}$ at $0{ }^{\circ} \mathrm{C}$ Delta T. It is designed to work under ambient temperature not higher than $50{ }^{\circ} \mathrm{C}$. There is no built-in compressor since it is a thermoelectric type of refrigeration system. It has an integral PID "tunable" temperature control. This unit comes with low pressure drop fluid quick connects. In addition, a self priming pump/reservoir is installed inside this Teca chiller. Per our specific request, the built-in pump was removed. This decision was made in order to be able to pump cooling water at a high pressure drop due to high pipe friction losses. According to the manufacturer's specs, the rated electric current is $7 \mathrm{~A}$ and the fluid temperature range is from -5 to $65^{\circ} \mathrm{C}$. This means that it can operate not only as a heat sink but also as a heat source.

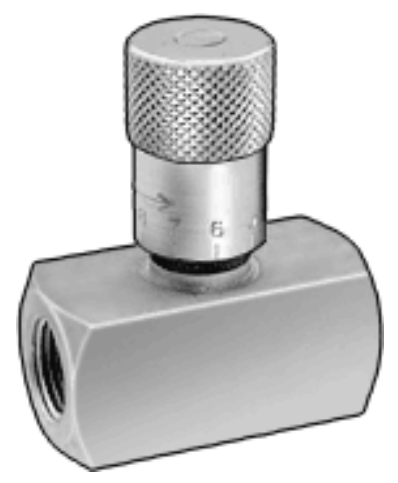

Figure 3.17: Needle valve used for accurate and repeatable flow control.

The needle valve (V-603 in Figure 3.15) is mounted just before the flow meter (FLR-601) to enable precision flow control. A finely threaded needle, or tapered plug, on the end of the valve stem functions as the control. The tapered part of the needle is smaller than the orifice and seats after passing through the orifice, allowing for a very gradual increase or decrease in the size of the opening. $\mathrm{Cv}$ factor (coefficient of volume) is the amount of water (in GPM) that will pass through a fully open valve at 1 psi with 1 specific gravity $\left(60^{\circ} \mathrm{F}\right)$. For pressure drops other than 1 psi, we can state that $\mathrm{Cv}$ factor for this valve is 0.78 . It has a $3 / 8$ inches pipe size NPT(F) connections. The orifice diameter is 0.219 inches. Temperature range is from -15 to $400^{\circ} \mathrm{F}$. For this valve (Figure 3.17 ), made of a brass material, the maximum pressure is $2000 \mathrm{psi}$ at $400{ }^{\circ} \mathrm{F}$. 


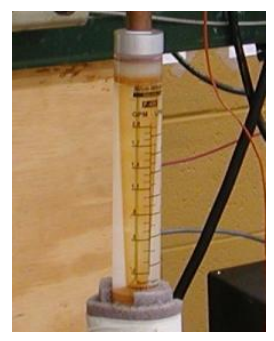

Figure 3.18: Water flow meter located at the exit of the Teca chiller.

The FLR-601 rotameter (Figure 3.18) for water flow measurement has a 2 GPM full scale with an accuracy of $\pm 5 \%$ FS. It has a cast acrylic tube, a type 316 stainless steel float, and Viton O-rings. The maximum pressure is $150 \mathrm{psi}$ at $70^{\circ} \mathrm{F}$. The maximum working temperature for water is $120^{\circ} \mathrm{F}$. It has $3 / 8$ inches NPT $(\mathrm{F})$ pipe size connections.

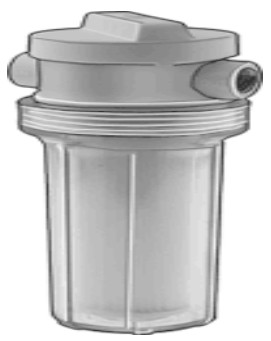

Figure 3.19: Water filter at the secondary cooling water loop.

The water filter (Figure 3.19) WF-601 has smaller housing and cartridge that provides lower dirt holding capacity. Both housing and cartridge are made of FDA-grade materials. It includes a pressure-release button for safe cartridge replacement. This filter can work with any double open-end (DOE) filter cartridge with the same OD and length. Its connections are 3/4 inch pipe size NPT males. This filter can stand a maximum flow of 25 GPM, maximum pressure of 150 psi and maximum temperature of $200 \mathrm{~F}$. The filter material is glass filled polypropylene with 316 stainless steel screen, micron rating of 533. 


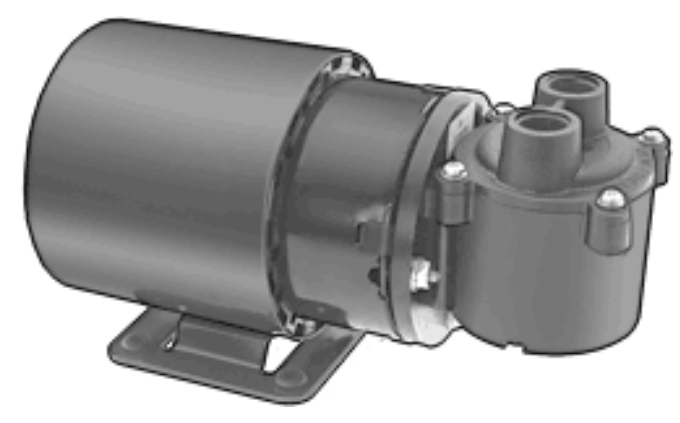

Figure 3.20: Diaphragm pump for the Teca chiller loop.

The diaphragm pump (Figure 3.20) shown in Figure 3.15 has a capacity of 4.0 GPM open flow. It has Viton ${ }^{\circledR}$ valves, Santoprene $®$ diaphragm, 25 psi demand switch, 40 psi off switch and 1/2" NPT (M) ports. This pump can self prime up to 10 vertical lift feet. It has a built-in check valve. Its motor is ready for continuous duty. Electric motor power supply is $120 \mathrm{~V}$, single phase and $1.8 \mathrm{~A}$.

The reservoir (Figure 3.21) is made of carbon steel and shown in Figure 3.15. The total volume is $3100 \mathrm{in}^{3}$. The inner diameter and the height are 10 inches. This tank is painted with synthetic resin to provide corrosion resistant. 


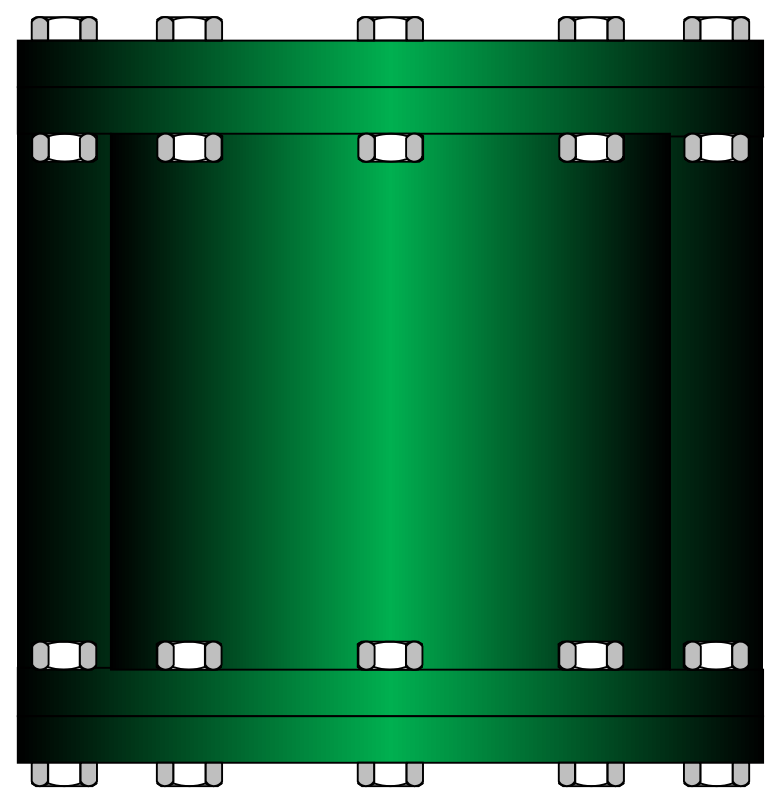

Figure 3.21: Water tank installed at the highest point of the secondary cooling loop.

Valves V-603, V-605, V-606, V-607, V-608, V-609, V-610, V-611 and V-612 from Figure 3.15 are WOG ball type with 5/8 inches NPT (F) connections. 2 valves (V604 and V-601) are WOG gate type with 1/2 inches NPT (F) connections. Valve V-602 is pneumatic actuated type. Flexible but high pressure resistant clear tubes of 3/8 inches inner diameter were utilized in this loop. Brass barbed fittings suitable for this dimension were used as needed. To ensure good performance, insulating foams were applied on tubes where cooling water was flowing.

A pressure gage of 30 psi full scale (PG-601) is installed after the diaphragm pump in order to verify flow pressure at the inlet of the Teca chiller.

\subsubsection{Operation}

To run this loop, Teca chiller and diaphragm pump need to be turn on after ensuring the loop is water filled. Since there is no flow control in this loop, a fixed volume flow rate is attained. Temperature of the cooling water can be PID controlled 
through the built-in digital temperature controller. For standard operation, valves V-601, V-602, V-604, V-605 and V-606 should be kept open in order to allow cooling water flow through tank and filter. For maintenance work, all drain valves must be opened (V610, V-611 and V-612) and water filter (WF-601) cartridge must be replaced when necessary. A case for which a flow by-pass is needed, in Figure 3.15 V-605 should be closed and V-608 should be opened. This will skip the cooling water flow through the reservoir and the filter. The purpose of V-609 valve is to protect the reservoir from overflowing and therefore it should always be kept open. V-612 should be opened only when this loop is re-filling with water. This will ensure no trapped bubbles are in the line. Again, only distilled water use is allowed for this loop.

\subsubsection{Recommendations}

Another pressure gage installed before the diaphragm pump will help in monitoring the pump performance. A valve after the tank will help filter removal for maintenance. Valve V-607 may be removed and V-609 should be discharging to a sink.

\subsection{Complete Condensation Refrigerant Loop}

This experimental set-up for condensing flow is an improvement of a previous work by Siemionko ${ }^{37}$ and is schematically shown later on in Figure 3.22. In this configuration, experiments with full condensation mode was conducted i.e., no liquidvapor mixture left the vertical tube condenser. Refrigerant used for all experimental runs were pure FC-72 (3M Corp.). Refrigerant vapor is generated from an evaporator and admitted to the cylindrical tube condenser (test section) mounted vertically where all the vapor condenses and leaves the test section as pure liquid. The exit of the test section is connected to a tank (L/V separator) filled with liquid FC-72. A peristaltic pump (pump 100 ) is responsible to drive the liquid flow from this tank back to the evaporator. 


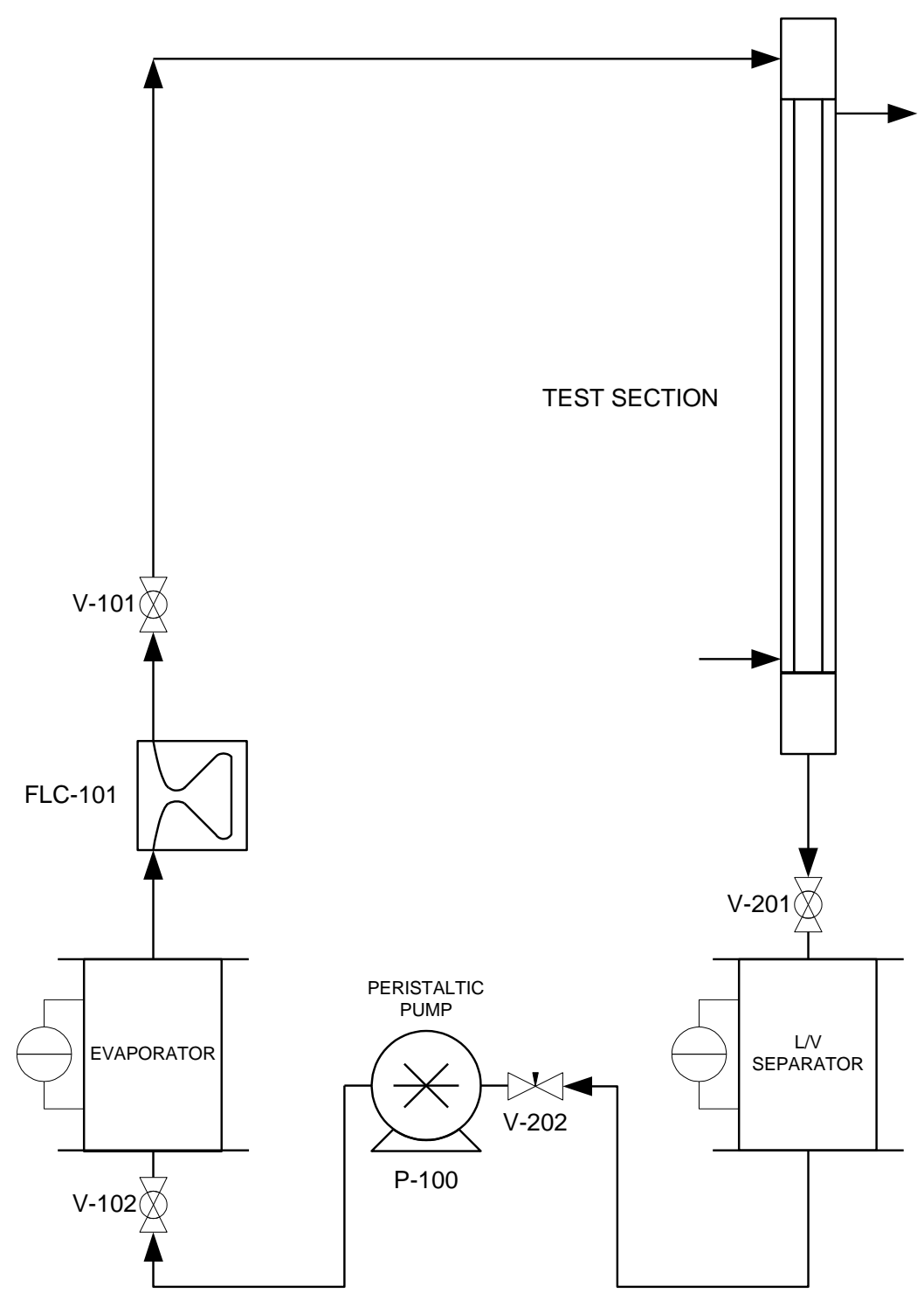

Figure 3.22: Schematic of the complete condensation refrigerant loop.

\subsubsection{Evaporator}

Details of the evaporator design are shown in Figure (3.23). The $0.02 \mathrm{~m}^{3}$ capacity evaporator was fabricated from stainless steel and the maximum designed working pressure is 50 psia. At start-up, the evaporator's refrigerant content is about $500 \mathrm{ml}$. Evaporator tank flanges are sealed with the use of a paper gasket combined with silicone. 


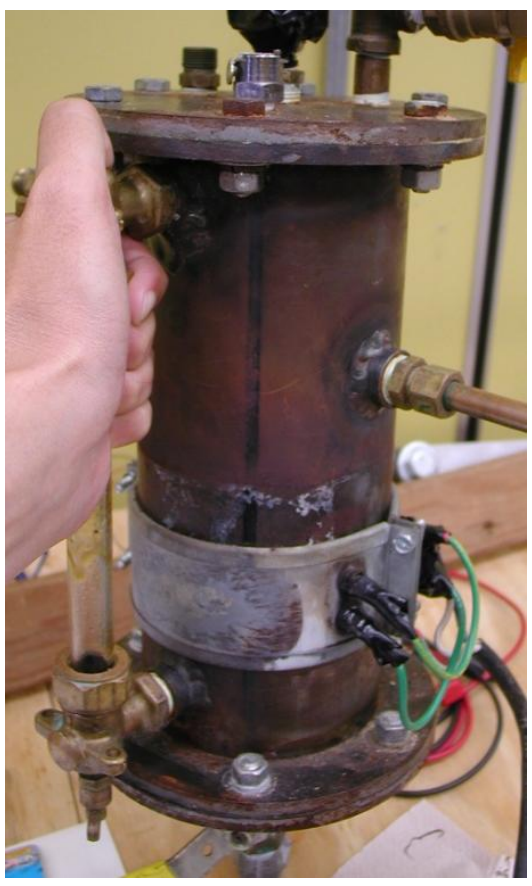

Figure 3.23: The evaporator without heat insulators.

The evaporator is heated by a $500 \mathrm{~W}$ band heater mounted on the lower outer surface of the evaporator. Therefore, the refrigerant is not in direct contact with the heat source. This heater has a 10 inches inner diameter and has power supply specifications of single phase $120 \mathrm{~V}$ at a maximum current of $7.7 \mathrm{~A}$. This, in turn, is electrically connected in series with a solid state relay (SSR-101) which allows us to actively control the electric current to the heating element. The relay (Figure 3.24) is rated for 3 A output (maximum load current) with an input of 3 to $32 \mathrm{DCV}$ (control voltage). The most important characteristic of this relay is its capability of a linear response to its input. 


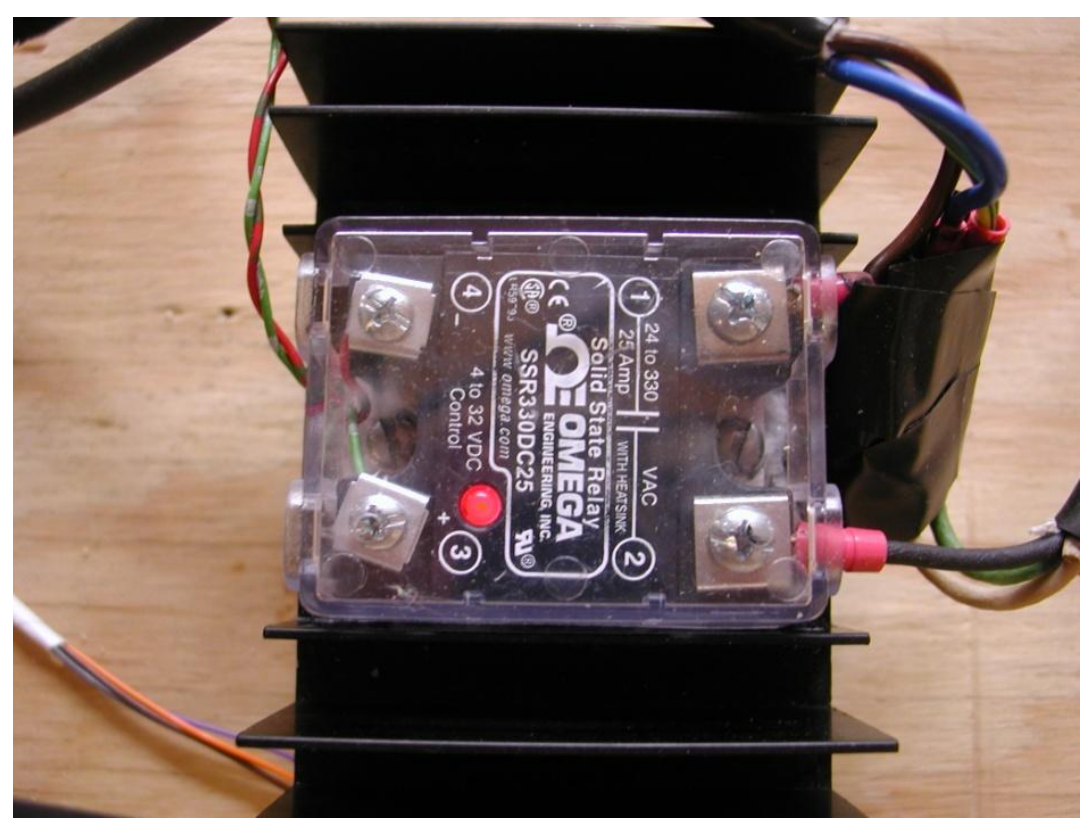

Figure 3.24: Solid state relay used for current control.

Evaporator pressure measurement is accomplished through an absolute pressure transducer APT-101. For details see Table 3.1.

The total accuracy for this transducer (Figure 3.25) includes linearity, hysteresis and repeatability. The vibration sensitivity at $20 \mathrm{~g}$ peak sinusoidal vibration is from 10 $\mathrm{Hz}$ to $2000 \mathrm{~Hz}$ (1.2" D.A.). The output shall not exceed $0.04 \% \mathrm{FS} / \mathrm{g}$ for 15 psi range to $0.005 \% \mathrm{FS} / \mathrm{g}$ for $100 \mathrm{psi}$ and above. Natural Frequency: >35 kHz for 100 psi range. 
Table 3.1: Technical specifications for the APTs.

\begin{tabular}{|l|l|}
\hline Voltage Output & 0 to $5 \mathrm{Vdc}$ \\
\hline Excitation & $24 \mathrm{Vdc}$ at $15 \mathrm{~mA}$ \\
\hline Zero Balance & $0 \mathrm{Vdc} \pm 2 \% \mathrm{FSO}$ \\
\hline Accuracy & $0.25 \% \mathrm{FS}$ \\
\hline Operating Temperature & -54 to $121^{\circ} \mathrm{C}$ \\
\hline $\begin{array}{l}\text { Compensated } \\
\text { Temperature }\end{array}$ & -20 to $80^{\circ} \mathrm{C}$ \\
\hline Thermal Effects & $0.04 \% \mathrm{FS} /{ }^{\circ} \mathrm{C}$ \\
\hline Proof Pressure & $150 \%$ \\
\hline Burst Pressure & $300 \%$ range max \\
\hline Response Time & 2 ms typical \\
\hline Gage Type & $\begin{array}{l}\text { Diffused silicon } \\
\text { strain gages }\end{array}$ \\
\hline Pressure Port & $1 / 4-18 \mathrm{NPT}$ \\
\hline
\end{tabular}

PX219-100G5V conn

Figure 3.25: Absolute pressure transducer. 


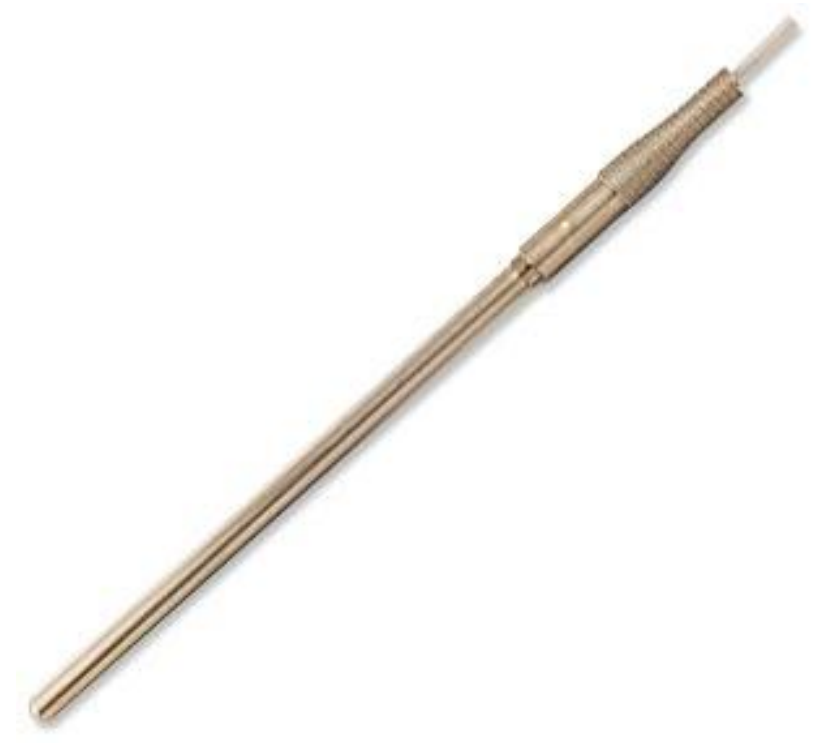

Figure 3.26: The three cable Resistive Thermal Device (RTD) picture.

Temperature measurement RTD-101 in the evaporator is done through the vapor side i.e., sensing probe tip is placed in the upper part of the evaporator. Figure 3.26 is a picture of this sensor and Table 3.2 are the technical specifications.

Table 3.2: Technical specification for RTDs.

\begin{tabular}{|l|l|}
\hline Sensor Type & Resistance Temperature Detection \\
\hline Configuration & 3 wires \\
\hline Class & A (IEC-751) \\
\hline Wire Wound & Platinum \\
\hline R0 & 100 Ohms at 0 C \\
\hline Alpha & 0.00385 \\
\hline
\end{tabular}




\subsubsection{Test Section}

The schematic of the test section (condenser) is shown in Figure 3.27. The test section consisted on a cylindrical tube vertically mounted. It is provided with a jacket for the cooling water. This condenser is made of two tubes concentrically assembled having the annular space for the cooling water flow.

The vertical tube condenser test-section, which is shown in Figure 3.27, is a part of a closed flow loop shown in Figure 3.28. The flow loop is designed for investigation of partial and fully condensing flows although fully condensing flows alone are of interest to this paper. It has three independent feedback control strategies that can fix and steady the values of: inlet mass flow rate $\dot{\mathrm{M}}_{\mathrm{in}}$ through active feedback control of the heat input to the evaporator/boiler, condensing surface temperature $\mathrm{T}_{\mathrm{w}}(\mathrm{x})$ (uniform or non-uniform) through feedback control of coolant water flow rate and its temperature, and inlet pressure $p_{\text {in }}$ through active feedback control of one of the controllable displacement pumps in the set up. The flow in Figure 3.27 is also especially designed to allow development of procedures under which condensing flows can be allowed to reach steady state while seeking their own self-selected exit conditions (exit quality or pressure). These flows with self-selected exit conditions are termed 'natural' flows. This closed flow loop also allows development of procedures (section 5) which are able to tell us, in somewhat different ways than some other open loop experiments (e.g. $\mathrm{Wu}^{25}$ and Quan ${ }^{26}$ ), as to whether or not gravity driven (and gravity dominated) condensing flows will accommodate different externally imposed quasi-steady pressure-difference values that are different from the self-selected natural value. 


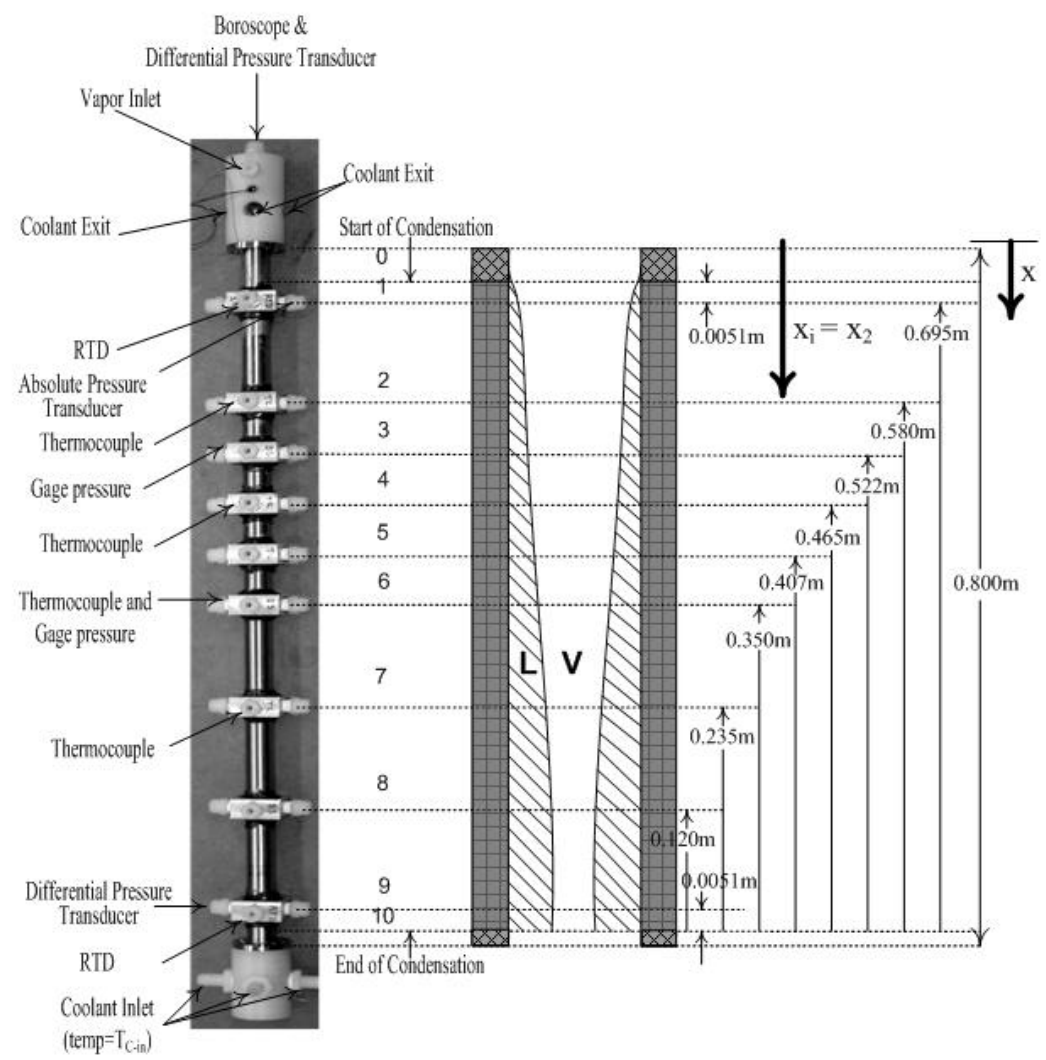

(a)

(b)

$\varpi$ : Nylon entrance and exit sections $\square$ : Refrigerant tube wall 1.7 : Developed liquid film V: Flowing vapor

Figure 3.27: (a) The photograph of condenser test-section. (b) The test-section schematic (diameters in (a) and (b) are not to the same scale). The condensing surface covers the zone $x_{0} \leq x \leq x_{10}$. 


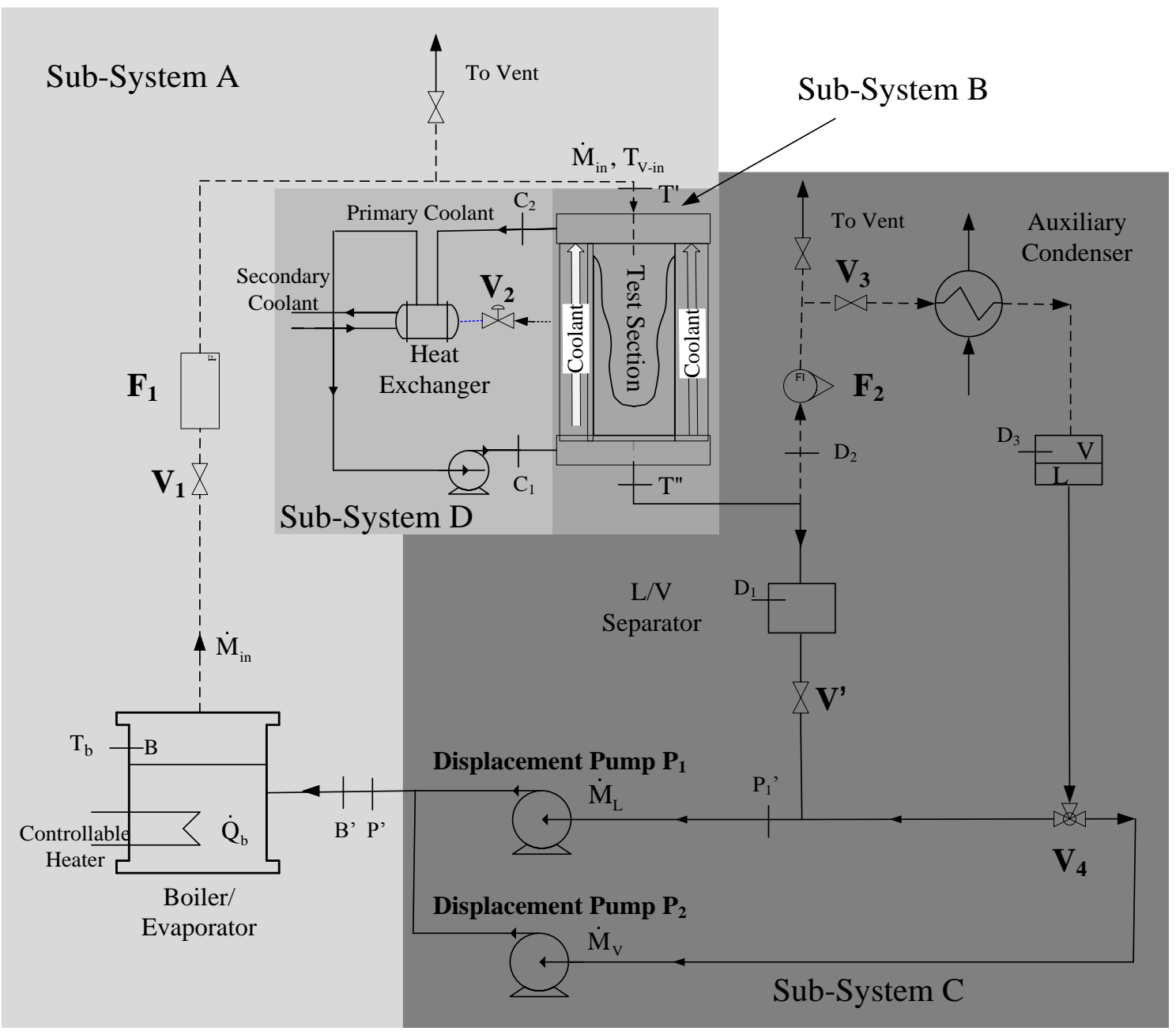

Figure 3.28: The schematic of the flow loop for achieving unspecified exit condition flows for partial or full condensation cases. For full condensation cases, valve $V_{3}$ is closed and the auxiliary condenser is not in use.

A 0-540 W electric heater wrapped around the evaporator/boiler in Figure 3.23 causes the working fluid (FC-72) to evaporate and/or experience nucleate boiling near the heater surface. The vapor mass flow rate out of the evaporator $\dot{\mathrm{M}}_{\mathrm{in}}$ is fed into the test section. This mass flow rate is measured by a Coriolis flow meter $F_{1}$ and, this value is controlled, as needed, by a feedback controlled heating of the evaporator (for this, electric heating is controlled by a solid state relay that undergoes a PID control through LabVIEW that is also sensing the mass flow rate from $\mathrm{F}_{1}$ ). Under steady conditions 
though, the value of $\dot{\mathrm{M}}_{\text {in }}$ gets approximately fixed by a constant steady electrical heating rate in to the evaporator. This is due to the restriction imposed by the evaporator energy balance, viz., $\dot{\mathrm{M}}_{\mathrm{in}} \approx \dot{\mathrm{Q}}_{\mathrm{b}} / \mathrm{h}_{\mathrm{fg}}\left(\mathrm{p}_{\mathrm{B}}\right)$. Here $\dot{\mathrm{Q}}_{\mathrm{b}}$ is the net heat rate into the evaporator, $\mathrm{p}_{\mathrm{b}}$ is the steady evaporator pressure, $\mathrm{T}_{\mathrm{b}}$ is the steady evaporator temperature (which, depending on the nature of the phase-change process in the boiler, may or may not nearly equal the saturation temperature $T_{\text {sat }}\left(\mathrm{p}_{\mathrm{b}}\right)$ of the fluid at the evaporator pressure $\left.\mathrm{p}_{\mathrm{b}}\right)$, and $\mathrm{h}_{\mathrm{fg}}$ is the heat of vaporization at the mean pressure $\mathrm{p}_{\mathrm{b}}$ in the evaporator.

The test-section in Figure 3.27 is a $0.8 \mathrm{~m}$ long (however the condensing-surface itself is $0.7 \mathrm{~m}$ long), vertical, stainless steel (316 SS) tube of $6.6 \mathrm{~mm}$ inner diameter, $\mathrm{D}$, and $7.94 \mathrm{~mm}$ outer diameter. At the entrance of the test-section, the inlet vapor temperature is denoted as $\mathrm{T}_{\mathrm{V} \text {-in }}$, the inlet pressure is denoted as $\mathrm{p}_{\mathrm{in}}$, and the inlet vapor is kept slightly superheated (i.e. $\mathrm{T}_{\mathrm{V} \text {-in }}$ is $2-10{ }^{\circ} \mathrm{C}$ above $\mathrm{T}_{\text {sat }}\left(\mathrm{p}_{\text {in }}\right)$ ). A suitable thermocouple and an absolute pressure transducer respectively measure the temperature, $\mathrm{T}_{\mathrm{V} \text {-in }}$, and pressure, $p_{i n}$, of the vapor at the inlet. The dynamic view from an axial boroscope, mounted at the top of the test-section shown in Figure 3.29, is used to visualize and ascertain the nature of the flow in the test-section. The boroscope videos verified that the quasi-steady flows reported here were indeed wavy annular. The use of this boroscope (Figure 3.29) also allowed us to ascertain and ensure the dryness of the incoming vapor at the entrance to the test-section. 


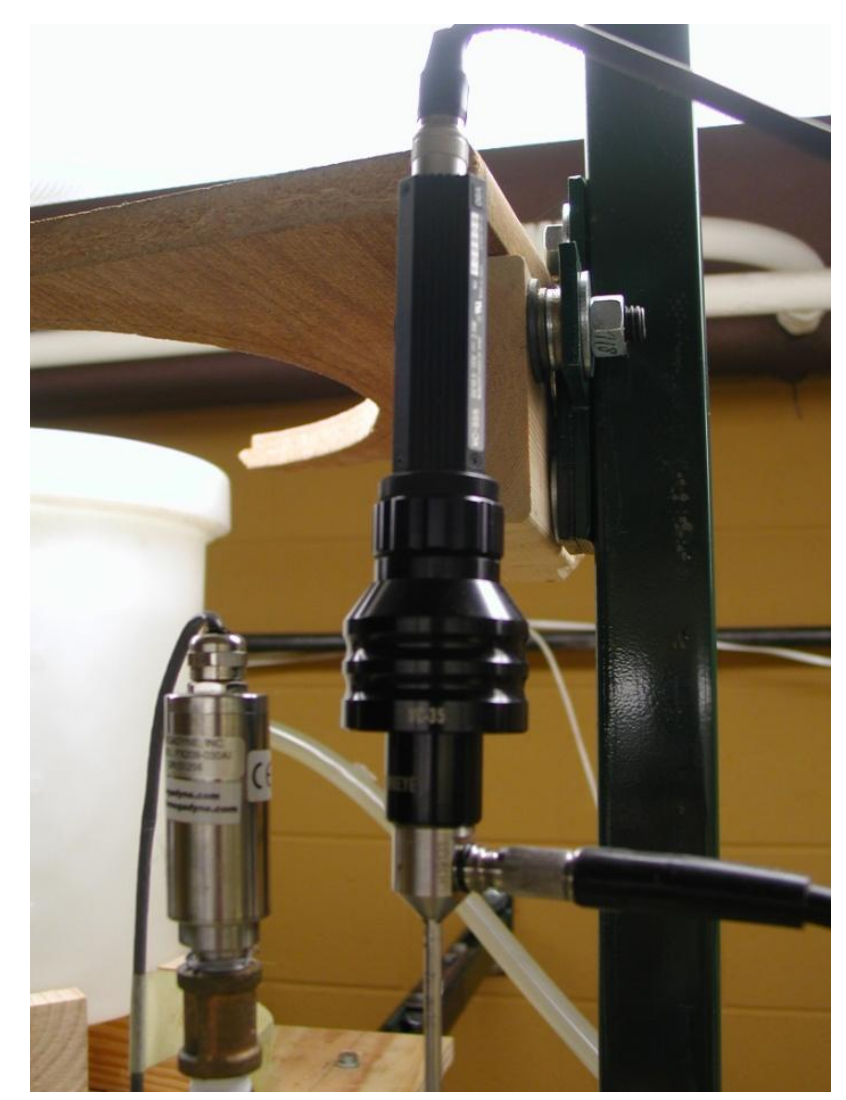

Figure 3.29: Borescope with video camera mounted on top of the test section.

This test-section (see Figure 3.27) is suitably instrumented with various sensors (thermocouples, pressure transducers, etc.). The technique used for mounting all the sensors in the test-section is described in detail in Siemonko. ${ }^{37}$ An improved method that allows sensors to be replaced or removed more easily is used in this new test section.

The test-section in Figure 3.27b (not shown to size relative to the outer tube in Figure 3.27a) is centrally aligned in the hollow space of a larger diameter stainless steel (314 SS) tube. This outer tube has an inner diameter of $35 \mathrm{~mm}$ and an outer diameter of $42 \mathrm{~mm}$. The test-section tube is cooled by the counter flow of cold water in the annulus formed by the outer surface of the test-section tube and the inner surface of the outer tube. As shown in Figure 3.28, this primary flow of coolant water is made possible by a closed loop that contains a heat-exchanger and a pump. A 3/4 hp centrifugal pump drives water through the loop at a high flow rate (> 26.5 liters $/ \mathrm{min}$ ) to minimize temperature 
variations along the wall of the test-section. A separate closed loop described before has water, as secondary coolant, flowing through the tube-side of the shell-in-tube heat exchanger in the primary loop. This separate loop assures secondary coolant (water) flow at a steady constant temperature which is adjusted with the help of a chiller and a semiautomatically adjusted value of the water flow rate $(0-17$ liters/min $)$ through the tubeside of the heat exchanger in Figure 3.28. This arrangement provides for a good control of the steady value of condensing-surface temperatures $T_{w}(x)$ and temperature $T_{C 1}$ at the coolant inlet location in Figure 3.28.

Resistance temperature device (RTDs) and type-T thermocouples measure temperatures at different locations of the test-section (see Figure 3.27) and at other flow loop locations marked by points $\mathrm{B}^{\prime}, \mathrm{B}, \mathrm{T}^{\prime}, \mathrm{T}^{\prime \prime}, \mathrm{C}_{1}, \mathrm{C}_{2}, \mathrm{D}_{1}, \mathrm{D}_{2}, \mathrm{D}_{3}, \mathrm{P}_{1}^{\prime}$, and $\mathrm{P}^{\prime}$ in Figure 3.28. Absolute pressure transducers measure pressures at: test-section locations 1, 3, 6, and 9 in Figure 3.27 and at locations $\mathrm{B}, \mathrm{P}_{1}{ }^{\prime}$ and $\mathrm{D}_{2}$ in Figure 3.28. A sensitive, variable reluctance differential pressure transducer measures pressure differences in the testsection (in Figure 3.27, this is between locations 1 and 6). Two electronically controllable displacement pumps $\mathrm{P}_{1}$ and $\mathrm{P}_{2}$ (see Figure 3.28) can pump liquid FC-72 at a steady or unsteady specification of volume or mass flow rates. Flow meters at locations marked $\mathrm{F}_{1}$ (Coriolis meter that directly measures mass flow rate), $\mathrm{F}_{2}$ (a volume flow rate measuring rotameter), $\mathrm{P}_{1}$ (volume flow rate meter imbedded in pump $\mathrm{P}_{1}$ ), and $\mathrm{P}_{2}$ (volume flow rate meter imbedded in pump $\mathrm{P}_{2}$ ) are corrected as necessary to yield mass flow rates through those locations. Most of the details of the employed data acquisition system are available in Siemionko ${ }^{37}$ and the following sections. The purging process, detailed in Siemionko ${ }^{37}$ and Kurita et $\mathrm{al}^{38}$. and mentioned in section 5, ensures that the vapor flowing in the test section is pure over the duration of the experimental run and that non-condensable air in the flow loop has an insignificant presence.

For convenience in discussing the behavior of this flow loop, the system in Figure 3.28 is broken into the following sub-systems. (i) Sub-system A is the portion of the flow loop between points $\mathrm{P}^{\prime}$ and $\mathrm{T}^{\prime}$ (this portion contains the flow into the evaporator, the evaporator, the flow meter $F_{1}$, valve $V_{1}$, and the tubing leading the flow into the test- 
section). (ii) Sub-system B in the test-section portion of the flow loop between points $\mathrm{T}^{\prime}$ and $\mathrm{T}^{\prime \prime}$ in Figure 3.28. (iii) Sub-system $\mathrm{C}$ is the portion of the flow loop between points $\mathrm{T}^{\prime \prime}$ and $\mathrm{P}^{\prime}$ (this portion consists of the L/V separator used for partially condensing flows, the two branches of the flow in the liquid line and the auxiliary-condenser line, and pumps). (iv) Sub-system D consists of the primary coolant loop shown in Figure 3.28 and a portion of the secondary coolant loop (not shown here but described in previous sections). These sub-section names are used, as needed, for later discussions of the experimental results.

The facility reported above can be and has been used for partially condensing flows. However, since a good comparison for gravity driven partially condensing flows experimental data of Lu and Suryanarayana ${ }^{39}$ with the theory ${ }^{6}$ has already been achieved, they are not considered in this paper. Though, in future, the use of the above experimental facility for investigations of boundary condition sensitivities of partially condensing flows is planned. 


\section{Data acquisition software}

\subsection{Introduction}

For this research a high-speed multifunction data acquisition (DAQ) board optimized for superior accuracy at fast sampling rates was utilized, this is, an 18-bit analog-to-digital converter providing a $4 \mathrm{X}$ resolution increase. This hardware is designed to support readings from type $\mathrm{T}$ thermocouples, three-wire configuration Resistive Thermal Devices (RTD), Absolute Pressure Transducers, diaphragm type Differential Pressure Transducer, Coriolis Mass Flow Meter, Rotameter for gas flow measurement and current output from both Peristaltic Pumps and Thermoelectric devices. The same hardware is designed to enable active control through analog current/voltage output to Solid State Relays, Thermoelectric devices, speed controlled Pumps, and inverters for rpm controlled compressors. For power control of the heating element in the evaporator a USB connected 16-Bit, $250 \mathrm{kS} / \mathrm{s}$ Multifunction DAQ was installed. This work included the wiring and organizing of signal and power wires, system configuration and sensor calibration according to strict standards in order to ensure accuracy and safety. The software utilized as the user interface was LabVIEW v8. This experimental thermal system was operated through an NI-DAQmx driver software and NI LabVIEW Signal Express LE interactive data-logging software. This enabled to operate the flow loop in different modes such as manual, active and semi-automated. In this, successful implementation of PID control, tracking mode control and manual control was accomplished. This led to a more efficient operation of this highly complex thermal system. A visualization and recording of the condensing phenomena inside the $6.6 \mathrm{~mm}$ inner diameter tube during the whole system operation was feasible by a state-of-the-art borescope mounted with a camera dedicated for this purpose. 


\subsection{Acquiring a Signal in NI-DAQmx}

For sensor measurements a DAQ Assistant Express (Figure 4.1) Virtual Instrument was used to create a task in NI-DAQmx. This is a programming interface was used to communicate with data acquisition devices in the LabVIEW 8.x environment.

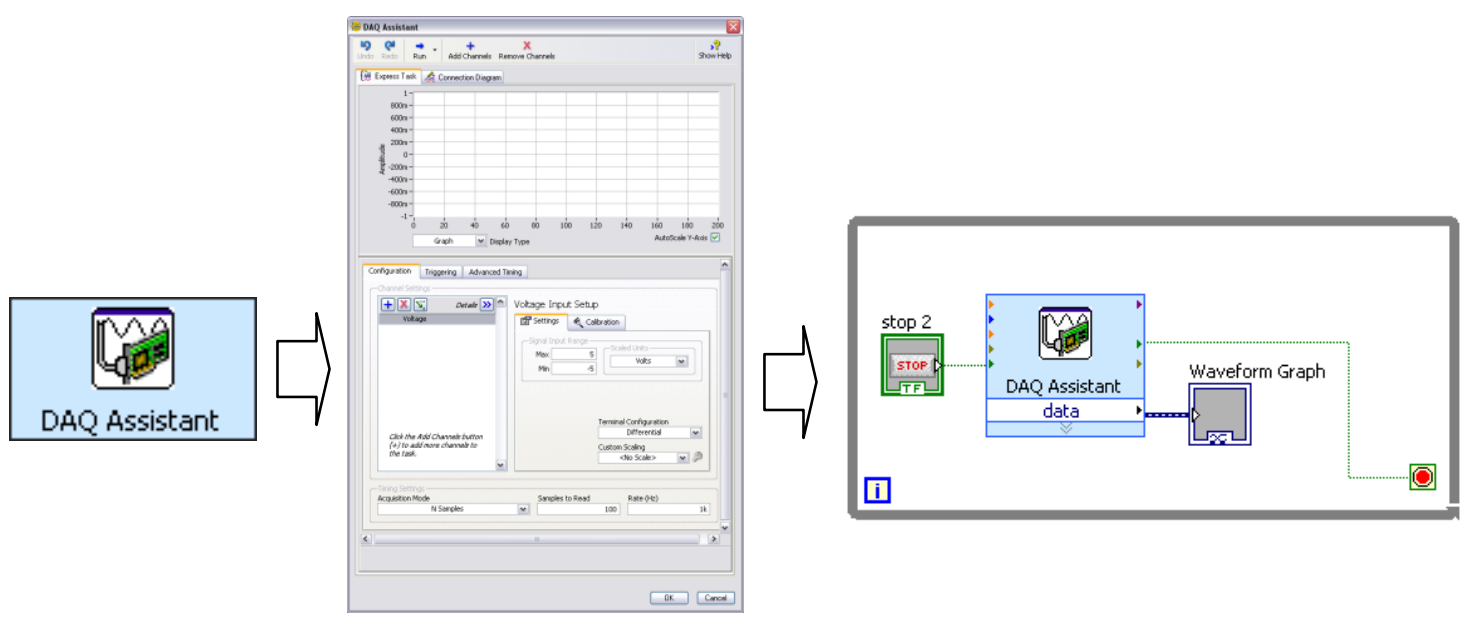

Figure 4.1: DAQ assistant windows showing parameters to set.

A task is a compilation of one or more channels, which contains timing, triggering, and other properties. Therefore, a task represents a dedicated measurement intended to perform. To arrange this design, steps to create and configure a task that reads a voltage or current level from a DAQ device was completed.

For this work, (Figure 4.2) the following block diagram was used. 

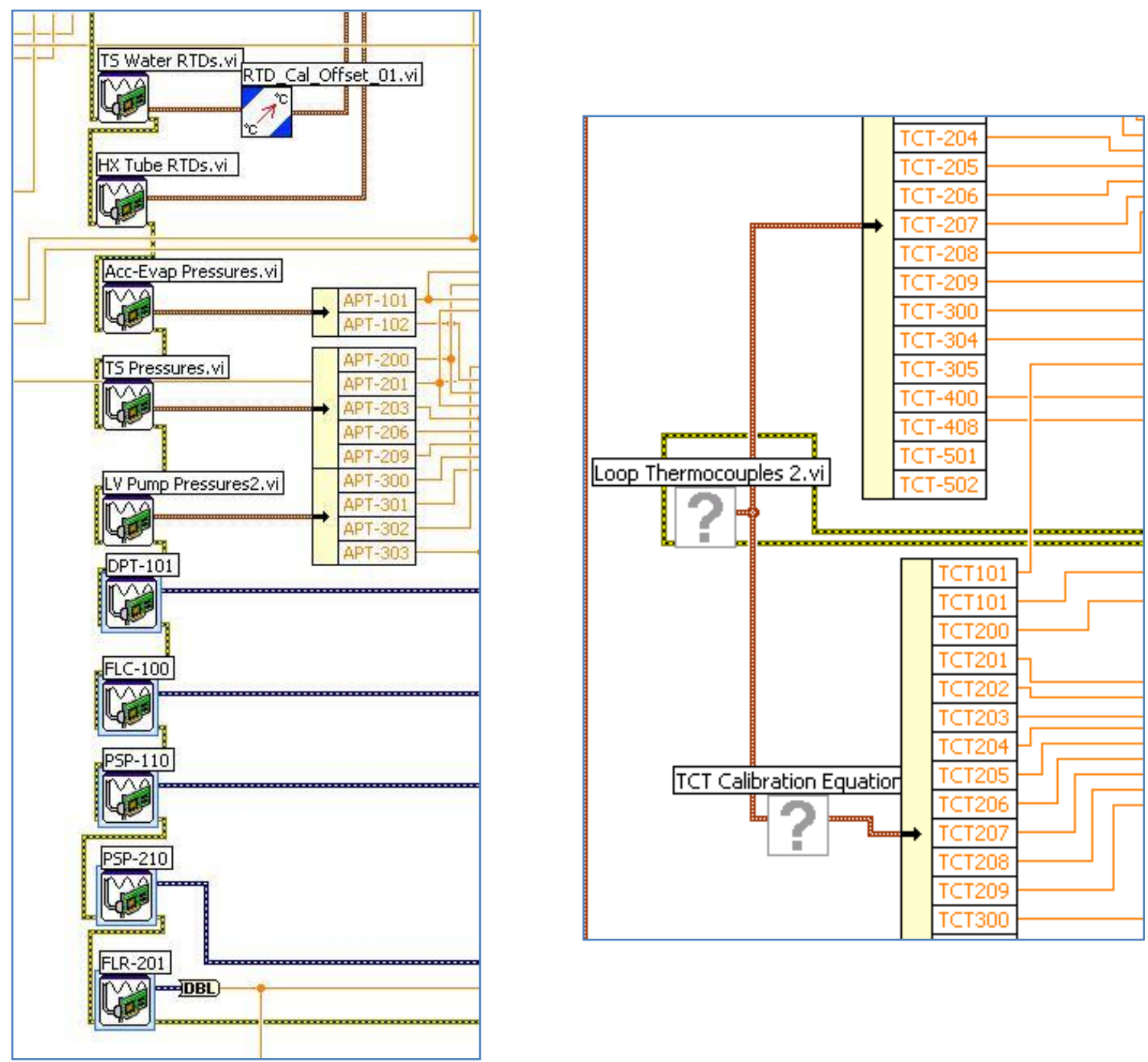

Figure 4.2: LabVIEW block diagram showing DAQ wiring for Thermocouples, RTD's, APT's, DPT, Peristaltic pump outputs and flowmeters.

A sub VI was required to implement the calibration equations in order to ensure accurate values of temperature readings from $\mathrm{T}$ type thermocouples. This is shown as "TCT Calibration Equation" in the figure above. 


\subsection{Supported Physical Channel}

The Supported Physical Channels are shown below. They are the physical channels to which each sensor and actuator connects the input or output signal to the computer. The following are the Tables 4.1-4.2 showing all instruments.

Table 4.1: Physical channel labeling where TCT stands for $\mathbf{T}$ type thermocouples, RTD stands for Resistive Thermal Devices, TS for Test Section, BH for Bulk Head, LV for Liquid/Vapor Separator, AC for Accumulator, $P$ for Peristaltic Pump and HEX for Heat Exchanger.

\begin{tabular}{|c|c|c|c|c|c|c|c|}
\hline \multicolumn{4}{|c|}{1102} & \multicolumn{4}{|c|}{1122} \\
\hline Channel & Name & Description & Status & Channel & Name & Description & Status \\
\hline ai00 & & & $w$ & ai00 & & & \\
\hline ai01 & & & & ai01 & RTD-401 & Forward 1 & w \\
\hline ai02 & TCT-102 & Acumulator & w & ai02 & RTD-402 & Backward 1 & w \\
\hline ai03 & & & & ai03 & RTD-403 & Forward 2 & w \\
\hline ai04 & & & & ai04 & RTD-404 & Backward 2 & w \\
\hline ai05 & TCT-400 & TS W inlet & w & ai05 & RTD-405 & Forward 3 & w \\
\hline ai06 & TCT-407 & TS W outlet & w & ai06 & RTD-406 & Backward 3 & w \\
\hline ai07 & & & & ai07 & & & w \\
\hline ai08 & TCT-408 & TS W inlet-n & w & ai08 & RTD-411 & HEX inlet & w \\
\hline ai09 & & & & ai09 & RTD-412 & HEX outlet & w \\
\hline ai10 & TCT-200 & TS inlet & w & ai10 & & & \\
\hline ai11 & TCT-201 & TS BH \#1 & w & ai11 & RTD-101 & Evap & w \\
\hline ai12 & TCT-202 & TS BH \#2 & w & ai12 & & & \\
\hline ai13 & TCT-203 & TS BH \#3 & w & ai13 & & & \\
\hline ai14 & TCT-204 & TS BH \#4 & w & ai14 & & & \\
\hline ai15 & TCT-205 & TS BH \#5 & w & ai15 & & & \\
\hline ai16 & TCT-206 & TS BH \#6 & w & & & & \\
\hline ai17 & TCT-207 & TS BH \#7 & w & & & & \\
\hline ai18 & TCT-208 & TS BH \#8 & w & & & & \\
\hline ai 19 & TCT-209 & TS BH \#9 & w & & & & \\
\hline ai20 & TCT-300 & LV & w & & & & \\
\hline ai21 & TCT-301 & $A C$ inlet & & & & & \\
\hline ai22 & TCT-302 & AC outlet & & & & & \\
\hline ai23 & TCT-303 & P200 inlet & w & & & & \\
\hline ai24 & TCT-304 & P100 inlet & w & & & & \\
\hline ai25 & TCT-305 & Pumps exit & w & & & & \\
\hline ai26 & TCT-306 & Channel Pump Inlet & & & & & \\
\hline ai27 & & & & & & & \\
\hline ai28 & & & & & & & \\
\hline ai29 & & & & & & & \\
\hline ai30 & & & & & & & \\
\hline ai31 & & & & & & & \\
\hline
\end{tabular}


Where aixx are the physical channel inputs, RTD-xxx are three wire type RTD and TCT-xxx are the T type thermocouples. It is important to clarify that not all channels were fully functioning. Only tested and verified channels were utilized and labeled as w.

Table 4.2: Physical channel labeling where FLC stands for Coriolis Flow Meter, FLR for Rotameter, PSP for Peristaltic Pump, DPT for Differential Pressure Transducer, PCV for Pneumatic Controlable Valve, TEC for Thermoelectric Controller and CMP for Compressor.

\begin{tabular}{|c|c|c|c|c|c|c|c|c|}
\hline \multicolumn{5}{|c|}{$1102 \mathrm{~B}$} & \multicolumn{4}{|c|}{1124} \\
\hline Channel & Name & Description & Status & Resistance & Channel & Name & Description & Status \\
\hline ai00 & & & w & 217.2 & ao00 & PCV-400 & Water Valve & w \\
\hline ai01 & APT-101 & & w & 217.5 & ao01 & PSP-111 & P100 Control & w \\
\hline ai02 & APT-102 & & w & 219.4 & ao02 & PSP-211 & P200 Control & \\
\hline ai03 & FLC-100 & Coriolis & w & 216.8 & ao03 & TEC-101 & TEC Direction & $w$ \\
\hline ai04 & FLR-200 & Rotameter & & 237.1 & ao04 & CMP-100 & Compressor & \\
\hline ai05 & APT-300 & LV & w & 237.0 & ao05 & PCV-101 & Evaporator & Not Used \\
\hline ai06 & & & $n / w$ & 249.8 & & & & \\
\hline ai07 & APT-302 & AC outlet & & 251.3 & & & & \\
\hline ai08 & APT-303 & Pump inlet & & 249.5 & & & & \\
\hline ai09 & APT-301 & $A C$ inlet & w & 250.2 & & & & \\
\hline ai10 & APT-200 & TS inlet & w & 250.5 & & & & \\
\hline ai11 & APT-201 & TS BH \#1 & w & 250.5 & & & & \\
\hline ai12 & & & & 250.5 & & & & \\
\hline ai13 & AРТ-203 & TS BH \#3 & w & 272.8 & & & & \\
\hline ai14 & PSP-110 & P100 Flow & & 270.3 & & & & \\
\hline ai15 & PSP-210 & P200 Flow & & 271.3 & & & & \\
\hline ai16 & APT-206 & TS BH \#6 & w & 271.2 & & & & \\
\hline ai17 & & & & 271.5 & & & & \\
\hline ai18 & & & & 292.7 & & & & \\
\hline ai19 & APT-209 & TS BH \#9 & w & 268.6 & & & & \\
\hline ai20 & DPT-101 & TS DP & w & & & & & \\
\hline ai21 & DPT-102 & Channel DP & & & & & & \\
\hline ai22 & & & & & & & & \\
\hline ai23 & & & & & & & & \\
\hline ai24 & & & & & & & & \\
\hline ai25 & & & & & & & & \\
\hline ai26 & & & & & & & & \\
\hline ai27 & & & & & & & & \\
\hline ai28 & & & & & & & & \\
\hline ai29 & & & & & & & & \\
\hline ai30 & & & & & & & & \\
\hline ai31 & & & & & & & & \\
\hline
\end{tabular}

Where aoxx are the physical channel outputs, APT-xxx absolute pressure transducers, DPT-xxx differential pressure transducers, FLC Coriolis mass flow meter, FLR rotameter and PSP-xxx peristaltic pump I/O. 


\subsection{Control Schemes}

The control strategy for internal condensing flow was dealing with three basic issues. The primary of these was the regulation of the inlet vapor conditions. This was possible through an active controlled heater in the evaporator and a diagram type compressor at the inlet of the condenser. Another very essential control parameter was the temperature regulation of the cooling water. The water temperature was one of the main elements that determine the wall condition. This was playing a very important role to specify whether full or partial condensation occurred within the system. This control scheme also used a PID controller embedded in both the thermoelectric water chiller from TECA and the main water chiller from KOOLANT.

The last control issue addressed within the system was the control of the exit condition, for both, partial condensation and full condensation. Two peristaltic transfer pumps were used to transport the liquid refrigerant. The pump $100\left(\mathrm{P}_{1}\right)$ was dedicated to drive condensed FC-72 from the test section back to the evaporator. And the pump 200 $\left(\mathrm{P}_{2}\right)$ was employed to drive the condensate from the auxiliary condenser back to the evaporator.

For full condensation, where there is no exiting vapor downstream the condenser, the pump $100\left(\mathrm{P}_{1}\right)$ was operated in three different modes. The first mode was the tracking mode with the inlet mass meter via a feed forward control scheme controlled the pump $100\left(\mathrm{P}_{1}\right)$. The pump rate was adjusted so that the exiting liquid had the same mass rate as the inlet vapor rate. This approach thus provides results for natural exit condition for full condensation cases. The second mode was the manual mode. This scheme was designed to be able to operate in either, fixed angular velocity or fixed mass flow rate. The last control mode was the proportional integral derivative (PID) mode. This enabled us to fix the inlet pressure by means of controlling the liquid volume upstream this pump.

For natural partial condensation cases, pump $100\left(\mathrm{P}_{1}\right)$ adjusted its rate according to the difference between the inlet mass rate and the pump $200\left(\mathrm{P}_{2}\right)$ rate. This last one 
was operated at a manual mode. All three control strategies were implemented within the condensing flow loop and are explained in detail in the subsequent sections.

\subsection{PID control}

Currently, the Proportional-Integral-Derivative (PID) algorithm is the most common control algorithm used in industry. PID control processes that include heating and cooling systems, fluid level monitoring, flow control, and pressure control are often used by engineers. In this control mode, a process variable and a setpoint must be specified. The process variable is the system parameter to be controlled, such as temperature, pressure, or flow rate, and the setpoint is the desired value for the parameter.

A PID controller determines a controller output value, such as the heater power or angular velocity. The controller applies the controller output value to the system, which in turn drives the process variable toward the setpoint value.

\subsection{Pump 100 control}

The following Figure 4.3 is the labVIEW block diagram implemented to control the pump $100\left(\mathrm{P}_{1}\right)$. 


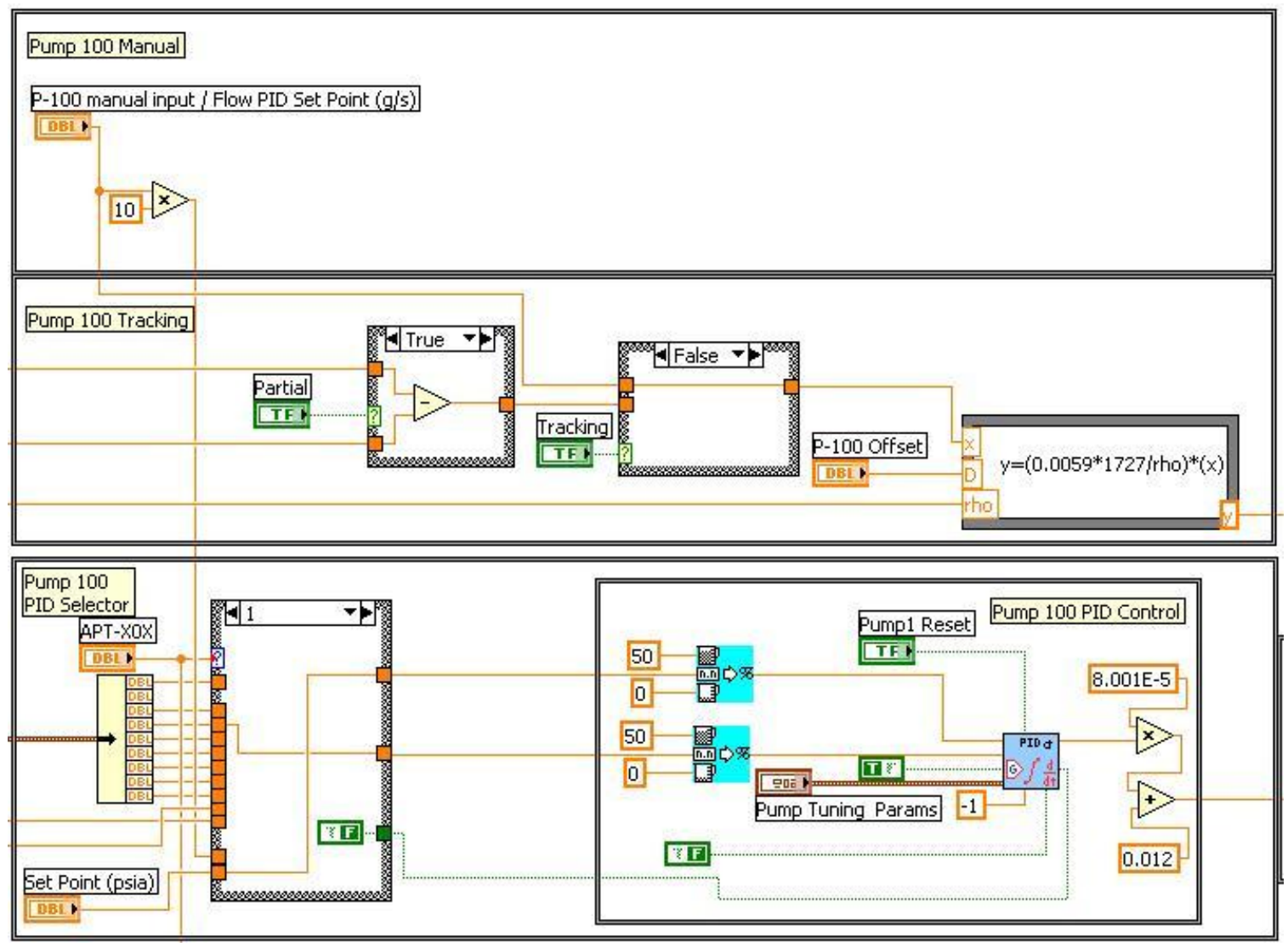

Figure 4.3: LabVIEW block diagram showing the pump control strategy.

\subsection{Control Output Rate Limiting}

For many control applications, sudden changes in control output are often undesirable or even dangerous. For example, an abrupt large change in setpoint can cause a very large change in controller output. Although in theory this large change in controller output results in quick reaction of the system, it may also cause pointless wear on electromechanical devices or rapid power demands. In addition, the PID controller can amplify noise in the system and result in a constantly changing controller output. For this reason, a simple strategy of limiting the output was applied as seen in Figure 4.4. 


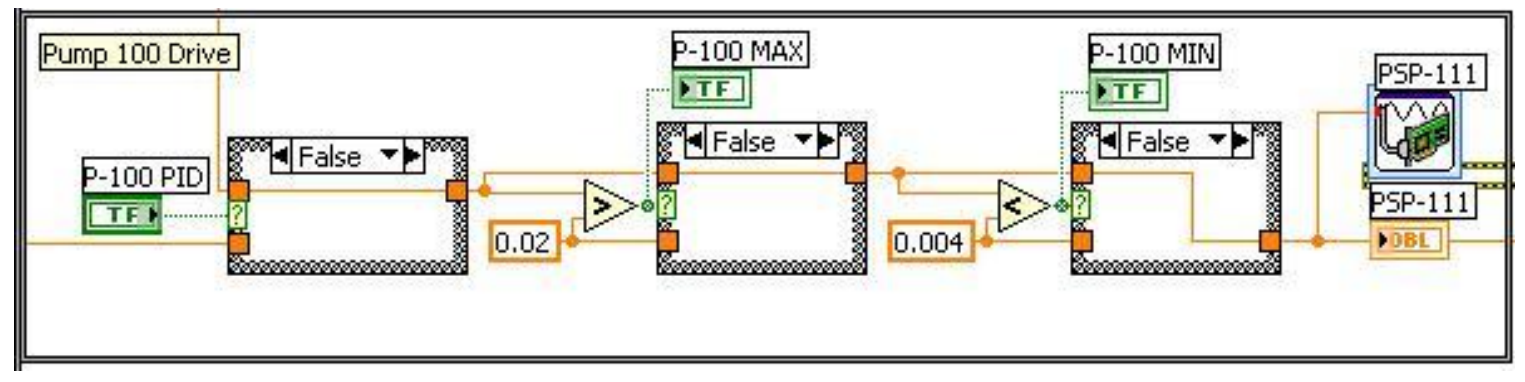

Figure 4.4: LabVIEW block diagram showing the control output rate limiting.

\subsection{Evaporator power control}

Likewise the pump $100\left(\mathrm{P}_{1}\right)$, the heating element of the evaporator was actively controlled through a PID scheme. This enabled an effective control of the mass flow rate of the refrigerant that goes into the test section. This application was largely feasible due to the recent development of the solid state relay technology.

The following Figure 4.5 shows this labVIEW block diagram that enabled us to implement this strategy.

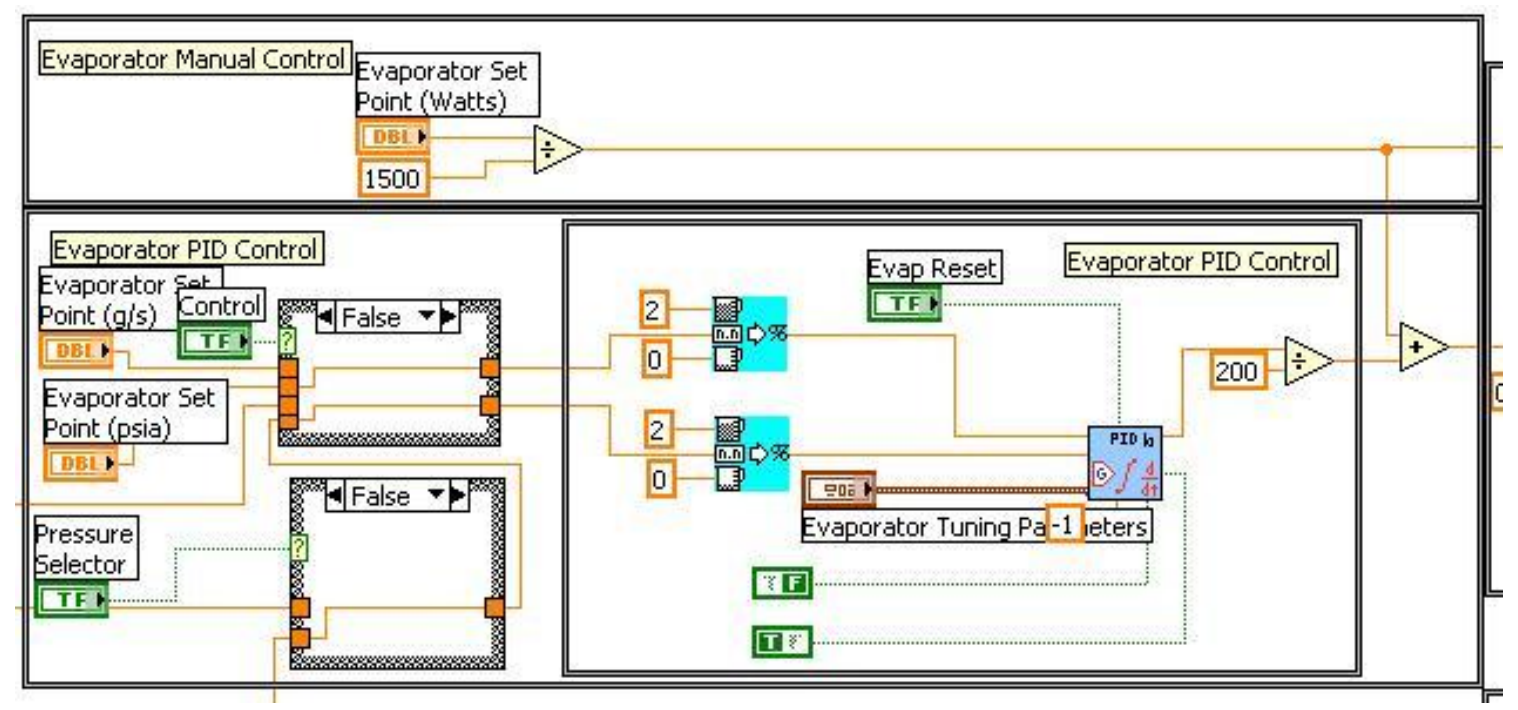

Figure 4.5: LabVIEW block diagram showing the evaporator power control using PID. 
The Figure 4.6 shows details on output configuration from this control strategy that operates the solid state relay. Technical specifications of this relay are already described in section 3 .

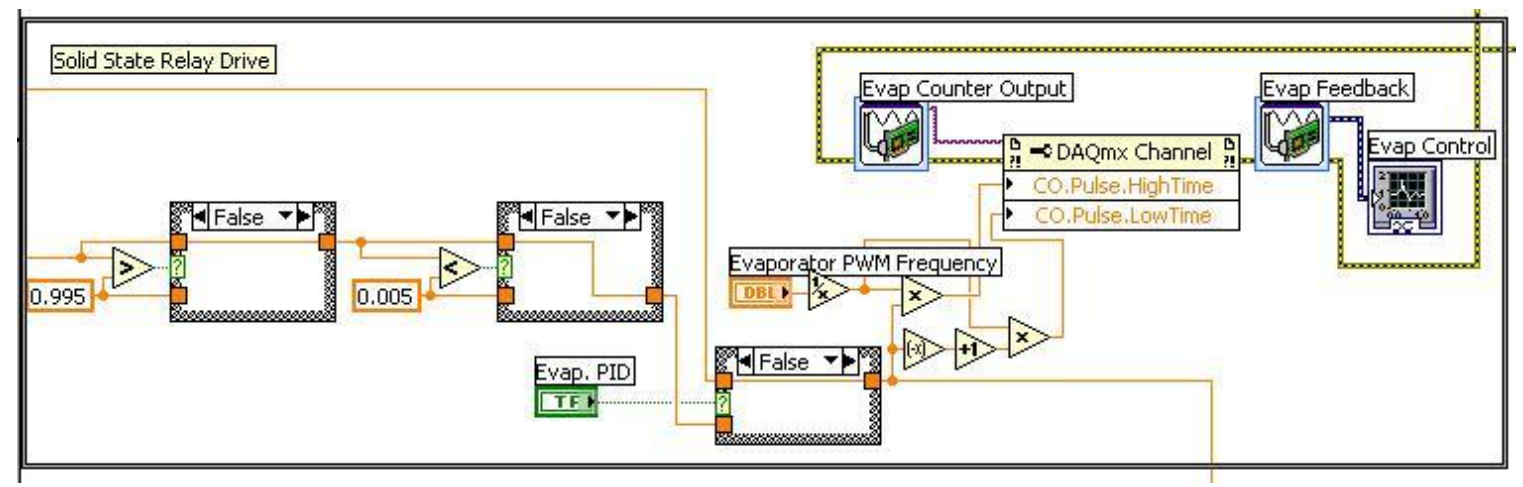

Figure 4.6: LabVIEW block diagram showing the evaporator power control.

\subsection{Pump 200 control}

The following Figure 4.7 is the labVIEW block diagram implemented to control the pump $200\left(\mathrm{P}_{2}\right)$.

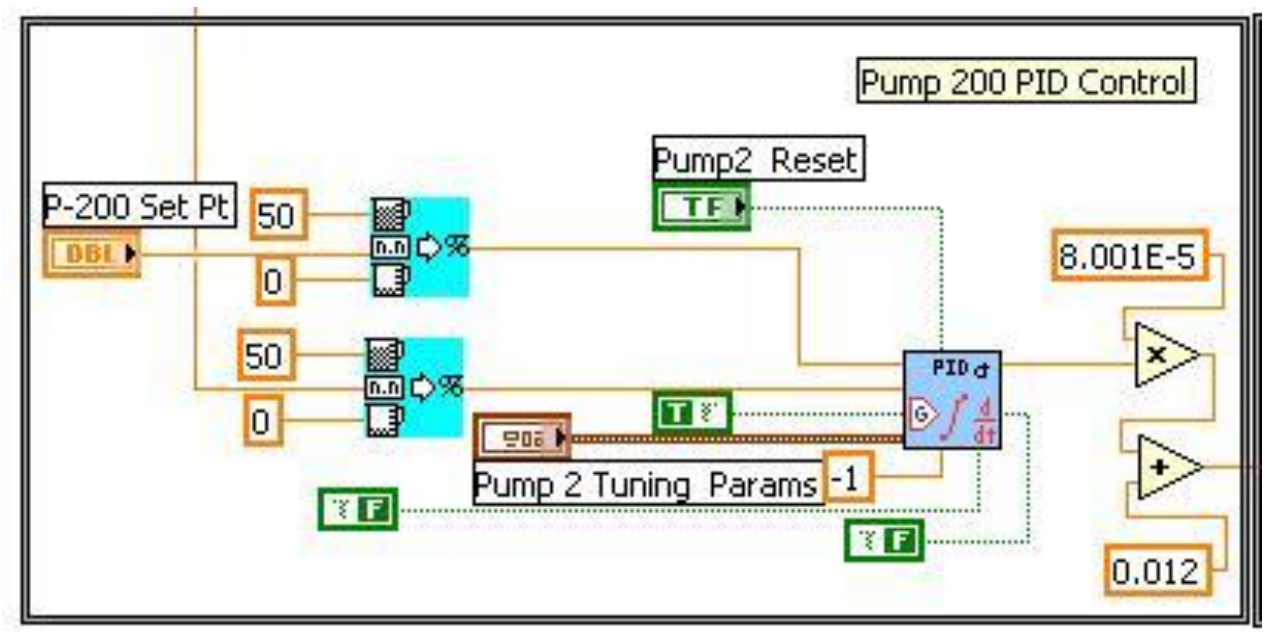

Figure 4.7: LabVIEW block diagram showing the pump 200 (P2) control strategy. 
As it can be seen in Figure 4.8, a series of calculation was performed in order to compute an accurate vapor mass flow rate through the auxiliary condenser. This took into consideration the pressure reading of the vapor at the inlet of the auxiliary condenser and the volumetric flow rate from the rotameter.

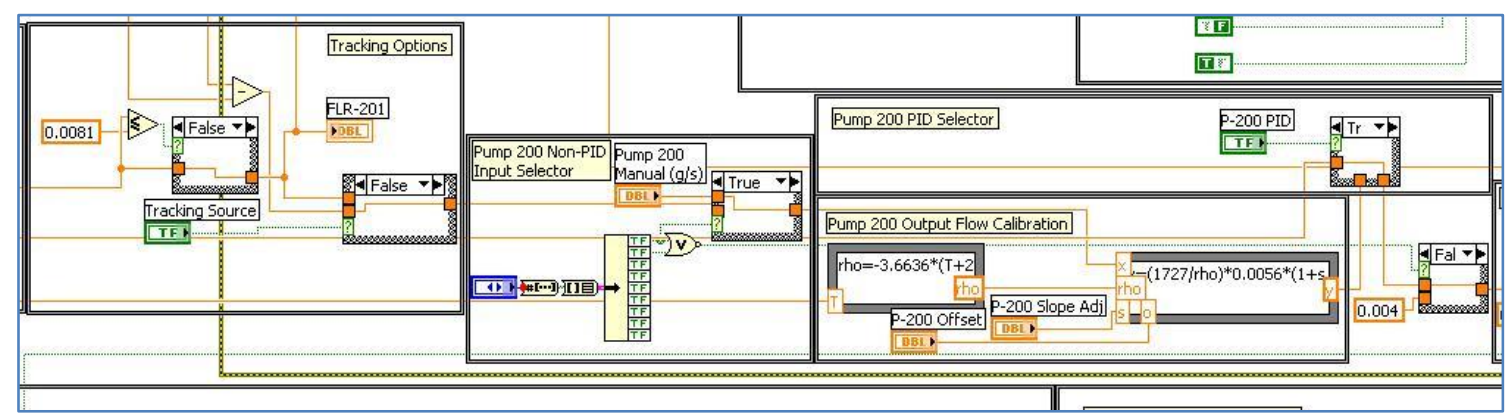

Figure 4.8: LabVIEW block diagram showing the pump 200 (P2) tracking mode strategy.

A tracking mode (Figure 4.8) for the pump $200\left(\mathrm{P}_{2}\right)$ was available through this configuration. A calibrated reading from the rotameter gave this control scheme a superb versatility that could offer the pump $200\left(\mathrm{P}_{2}\right)$ the flexibility to track the rotameter's mass flow rate output or the difference between the total mass flow rate and the liquid mass flow rate.

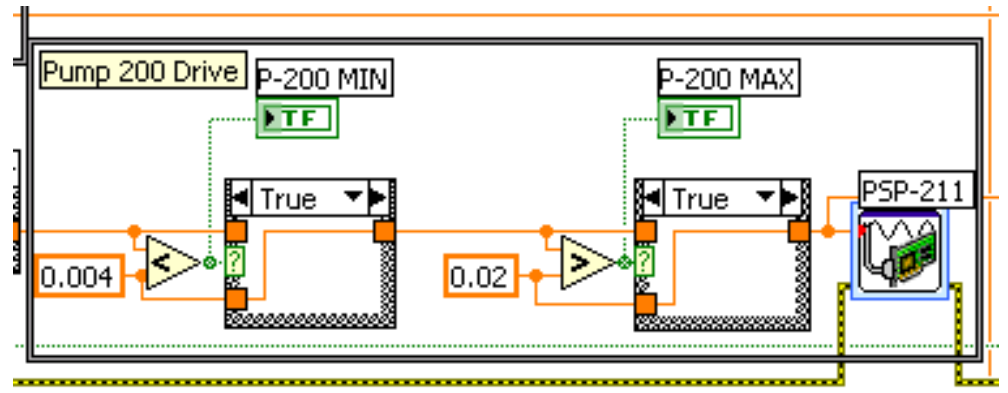

Figure 4.9: LabVIEW block diagram showing the limiting output strategy for pump 100 (P1).

Similar to pump $100\left(\mathrm{P}_{1}\right)$, in order to limit any abrupt pump operation a simple strategy of limiting the output was applied (Figure 4.9). 


\section{Operating procedure}

\subsection{Procedure for "Natural/Unspecified" Exit Condition Cases for Fully Condensing Gravity Driven Flows}

To realize fully condensing flows in the flow loop schematic of Figure 3.28, the auxiliary condenser flow-section is removed (valves $\mathrm{V}_{3}$ and $\mathrm{V}_{4}$ are closed). The liquid completely fills the line from some "point of full condensation" in the test-section all the way to the boiler/evaporator (this means that the liquid fills all the locations marked as $T^{\prime \prime}, \mathrm{L} / \mathrm{V}$ separator, and the electronically controllable displacement pump $\mathrm{P}_{1}$ ). "Natural/self-selected" fully condensing flow cases is achieved in this set-up by two different procedures.

In procedure-1, the inlet mass flow rate $\dot{\mathrm{M}}_{\mathrm{in}}$ is held fixed by the evaporator heater control, the condensing surface temperature $\mathrm{T}_{\mathrm{w}}(\mathrm{x})$ by coolant temperature and flow rate control of the coolant in the secondary loop, and, inlet vapor temperature $\mathrm{T}_{\mathrm{V} \text {-in }}$ is steadied (at a desired value through an electric heating tape on the vapor line feeding into the testsection). The inlet pressure is allowed to seek a natural value of $\mathrm{p}_{\mathrm{in}}=\mathrm{p}_{\mathrm{in}} \mid \mathrm{Na}$ as well as the exit pressure is allowed to seek a certain natural value of $\mathrm{p}_{\text {exit }}=\mathrm{p}_{\text {exit }} \mid \mathrm{Na}$ by making the exit liquid mass flow rate $\dot{\mathrm{M}}_{\mathrm{L-e}}$ (through the displacement pump $\mathrm{P}_{1}$ ) track the inlet mass flow rate $\dot{\mathrm{M}}_{\text {in }}$ (measured through Coriolis meter $\mathrm{F}_{1}$ ) through the tracking equation $\dot{\mathrm{M}}_{\mathrm{L}-\mathrm{e} \mathrm{P}_{1}}=\dot{\mathrm{M}}_{\mathrm{in}}$. The steady values of the inlet and exit pressures that are eventually achieved lead to a well defined self-selected "natural" pressure difference $\Delta \mathrm{p}\left|\mathrm{Na}=\mathrm{p}_{\mathrm{in}}\right| \mathrm{Na}$ $-\mathrm{p}_{\text {exit }} \mid \mathrm{Na}$. The dryness of the vapor at the inlet is ensured through boroscope visualization and a check that the superheat condition $\mathrm{T}_{\mathrm{V} \text {-in }}>\mathrm{T}_{\text {sat }}\left(\mathrm{p}_{\text {in }}\right)$ is satisfied.

The same value of $\Delta \mathrm{p} \mid \mathrm{Na}$ is also achieved by a second (and preferred) procedure, viz. procedure-2. In this procedure-2, different long term steady values of inlet vapor mass flow rate $\dot{\mathrm{M}}_{\text {in }}$ are achieved by active evaporator heat control while the displacement 
pump $\mathrm{P}_{1}$ holds fixed the inlet pressure $\mathrm{p}_{\mathrm{in}}=\mathrm{p}_{\mathrm{in}}{ }^{*}$ at different set values. This is possible because the pump $\mathrm{P}_{1}$ is controlled through a Proportional-Integral-Derivative (PID) controller which, through ups and downs in the flow rate passing through $\mathrm{P}_{1}$ is able to attain a steady $\mathrm{p}_{\mathrm{in}}=\mathrm{p}_{\mathrm{in}}$ * and a steady in the mean flow rate through $\mathrm{P}_{1}$. These mass flow rate shifts through the pump $\mathrm{P}_{1}$ eventually become minuscule around the steady continuous mass flow rate value of $\dot{\mathrm{M}}_{\text {in }}$ through the Coriolis meter $\mathrm{F}_{1}$. During this operation, inlet temperature $\mathrm{T}_{\mathrm{V} \text {-in }}$ (manipulated through the control of the tape heater on the line between $F_{1}$ and the test-section inlet), and the mean wall temperature $\bar{T}_{W}$ (manipulated through the control of the secondary coolant's flow rate and its chiller controlled temperature) are steadied and held fixed at approximate desirable values. When the flow steadies to some "self selected/natural" steady exit pressure pexit", a steady value of $\Delta \mathrm{p}=\mathrm{p}_{\mathrm{in}} * \mathrm{p}_{\mathrm{exit}} *=\Delta \mathrm{p} \mid \mathrm{Na}$ is obtained.

It is found, for the same $\dot{\mathrm{M}}_{\mathrm{in}}$ and $\Delta \mathrm{T}, \Delta \mathrm{p}$ values obtained from procedure- 2 is the same as the one obtained through procedure-1. The advantage of procedure- 2 is that it allows one to change temperature difference $\Delta \mathrm{T} \equiv \mathrm{T}_{\text {Sat }}\left(\mathrm{p}_{\mathrm{in}}\right)-\overline{\mathrm{T}}_{\mathrm{W}}$ by changing pressure $p_{\text {in }}$ without any need for changing $T_{w}(x)$ to achieve different mean temperatures $\bar{T}_{w}$.

\subsection{Error Analysis, Repeatability, and Flow Morphology for the Experimental Data}

The accuracies of all the instruments (except the Coriolis meter $F_{1}$ ) used for reported values of directly measured variables were established after their in-house calibrations with the help of suitable and reliable reference instruments of known resolution and appropriate reference physical conditions (temperature, flow rate, pressure, etc.).

The accuracy of the Coriolis meter was established by the vendor support staff at the time of its installation. The error estimates for the calculated variables reported in Table 5.1 were obtained by well-known standard procedures (see Holman ${ }^{40}$ ) described in 
the Appendix. When experimental results are given in a tabular form (such as Table 5.1), the accuracies of both measured and calculated variables within a column is taken into account. For variables whose errors are either due to resolution in the measurement or are significantly lower order of magnitude than the variables involved, the maximum value of these errors are reported in the headers of appropriate columns in Table 5.1. For variables whose errors correlate with the mean values of the variables itself, percentage relative errors (both mean and maximum values) are reported in the relevant column headers.

Table 5.1: Representative experimentally measured data and some key calculated and computed variables for natural fully condensing steady flows.

\begin{tabular}{|c|c|c|c|c|c|c|c|c|c|c|c|c|c|c|c|c|c|}
\hline$\dot{0}$ & $\cdot \Sigma^{E}$ & 1 & 唔 & $\doteq$ & $\tilde{e}^{\tilde{c}}$ & $\begin{array}{l}0 \\
e^{1} \\
\rho_{x}^{x}\end{array}$ & 2. & 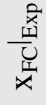 & $\frac{\tilde{J}}{\mathrm{U}}$ & $\frac{\bar{a}}{\tilde{a}}$ & $\frac{\bar{\Xi}}{\tilde{\Xi}}$ & $\ddot{\alpha}$ & $\circlearrowright$ &.$\stackrel{\bar{\Xi}}{0}$ & $\mid=\sigma$ & 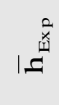 & $\mid$ \\
\hline $\overrightarrow{\underline{\alpha}}$ & $\frac{\widehat{x}}{000}$ & 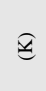 & 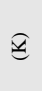 & $\frac{\sqrt{\pi}}{\frac{\pi}{y}}$ & 粷 & $\frac{\widetilde{\pi}}{\frac{\pi}{2}}$ & $\frac{\pi}{2}$ & ह्छ & ब्ह & $\frac{\hat{b}}{x}$ & $\frac{0}{x}$ & & 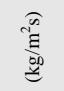 & $\stackrel{\overbrace{}}{હ}$ & 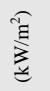 & 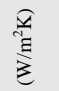 & 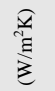 \\
\hline 荹 & $\begin{array}{l}\qquad \\
0 \\
\dot{+}\end{array}$ & $\stackrel{a}{+}$ & $\frac{r}{+1}$ & $\frac{n}{0}$ & $\frac{n}{0}$ & $\frac{n}{0}$ & $\frac{n}{0}$ & $\begin{array}{l}0 \\
8 \\
0 \\
+1\end{array}$ & $\frac{50}{7+1}$ & $\begin{array}{l}\circ \\
\frac{1}{8} \\
\stackrel{+1}{+1}\end{array}$ & 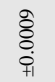 & $\frac{80}{71}$ & $\stackrel{\circ}{+}$ & $\frac{m^{\circ}}{+1}$ & 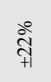 & 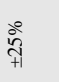 & $\frac{\circ 0}{71}$ \\
\hline 1 & 0.25 & 296 & 13 & 48 & 50 & 52 & 57 & 11 & 11 & 3.9 & 16.4 & 4426 & 7.31 & 22.71 & 10.3 & 804 & 775 \\
\hline 2 & 0.25 & 296 & 9 & 41 & 42 & 45 & 50 & 15 & 16 & 3.3 & 15.7 & 4479 & 7.31 & 22.97 & 7.4 & 820 & 769 \\
\hline 3 & 0.25 & 295 & 6 & 34 & 34 & 36 & 41 & 24 & 26 & 2.8 & 14.9 & 4540 & 7.31 & 23.26 & 4.7 & 836 & 768 \\
\hline 4 & 0.25 & 295 & 5 & 32 & 33 & 34 & 39 & 28 & 29 & 2.7 & 14.7 & 4557 & 7.31 & 23.34 & 4.1 & 819 & 771 \\
\hline 5 & 0.25 & 295 & 5 & 32 & 32 & 33 & 38 & 28 & 33 & 2.6 & 14.7 & 4559 & 7.30 & 23.34 & 3.9 & 867 & 760 \\
\hline 6 & 0.25 & 295 & 4 & 31 & 32 & 33 & 38 & 30 & 34 & 2.6 & 14.6 & 4563 & 7.30 & 23.36 & 3.7 & 862 & 770 \\
\hline 7 & 0.25 & 295 & 4 & 31 & 31 & 32 & 37 & 31 & 36 & 2.6 & 14.6 & 4571 & 7.31 & 23.40 & 3.7 & 903 & 783 \\
\hline 8 & 1.00 & 296 & 10 & 43 & 44 & 44 & 43 & 69 & 90 & 3.5 & 16.0 & 17836 & 29.22 & 91.50 & 6.4 & 617 & 478 \\
\hline 9 & 1.00 & 296 & 11 & 45 & 46 & 45 & 45 & 68 & 82 & 3.7 & 16.1 & 17793 & 29.23 & 91.30 & 6.5 & 576 & 482 \\
\hline 10 & 1.00 & 296 & 12 & 47 & 47 & 47 & 47 & 64 & 76 & 3.8 & 16.3 & 17740 & 29.23 & 91.03 & 6.8 & 569 & 480 \\
\hline 11 & 1.00 & 296 & 13 & 48 & 49 & 49 & 49 & 61 & 71 & 3.9 & 16.5 & 17684 & 29.22 & 90.75 & 7.1 & 560 & 482 \\
\hline 12 & 1.00 & 297 & 17 & 59 & 59 & 59 & 62 & 47 & 53 & 4.8 & 17.4 & 17441 & 29.25 & 89.50 & 9.2 & 543 & 483 \\
\hline 13 & 1.00 & 306 & 18 & 83 & 83 & 59 & 87 & 46 & 51 & 6.6 & 20.4 & 16971 & 29.26 & 86.90 & 9.1 & 521 & 480 \\
\hline 14 & 1.00 & 303 & 42 & 165 & 166 & 169 & 174 & 16 & 19 & 13.8 & 24.6 & 15967 & 29.25 & 80.53 & 24.4 & 575 & 492 \\
\hline
\end{tabular}

In addition to error estimates, repeatability of the fully condensing flows for independent runs were established for a few randomly selected flow cases. For brevity, the repeatability is only shown for a set of fully condensing flows in Figures 5.1 - 5.2. 
Identical results were obtained over three independent time segments shown in Figures 5.1 - 5.2. These repeatable condensing flow results also indicate the repeatable performance and control of the pumps, cooling systems, temperature controls, etc. that form the various subsystems shown in Figure 3.28. Furthermore, procedure - 1 for fully condensing flows (described in section 5.1) was used for achieving the steady flow in the first time segment of Figure 5.1 and procedure - 2 was used for achieving steady flows shown in the second and third time segments of Figure 5.1. Since $\Delta \mathrm{p}$ values in Figure 5.2 are the same for all the three steady states (which have approximately the same $\dot{\mathrm{M}}_{\text {in }}$ and $\Delta \mathrm{T}$ values), the result experimentally demonstrates the fact that these gravity driven flows are sufficiently stable ${ }^{31}$ and are able to self-seek their own exit conditions (like "parabolic" flows) in multiple experimental realizations.

The boroscope video mounted on the top of the test-section indicated that all the gravity driven flows reported and investigated here (see Figure 5.3) exhibited an ability to seek and retain robust wavy annular flows. 


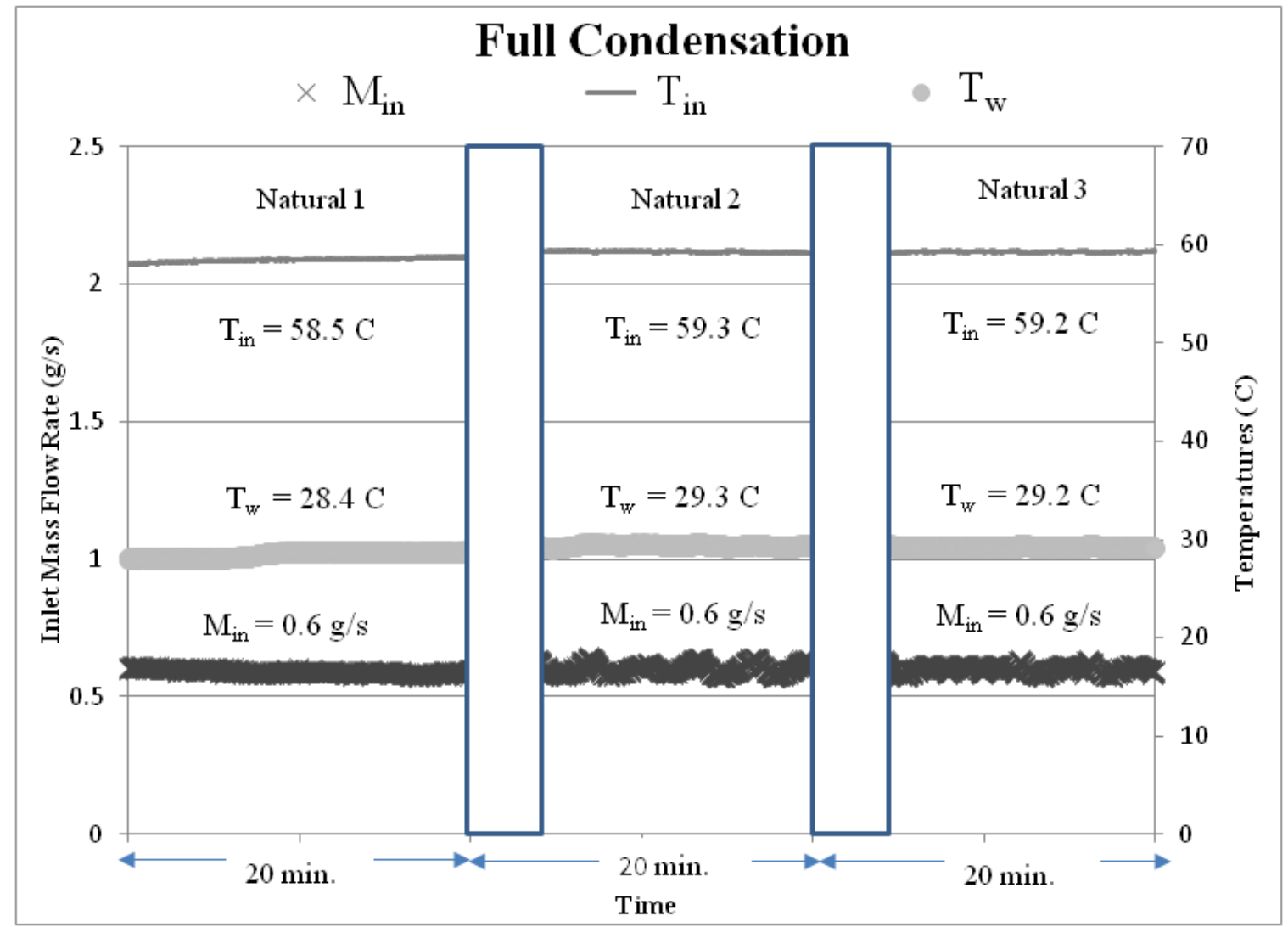

Figure 5.1: These time histories of inlet mass flow rate, inlet saturation temperature, and average wall temperature are nearly the same for three separate steady realizations over three separate time intervals. They are termed unspecified ("natural") exit condition cases - namely Natural-1, Natural-2, and Natural-3. 


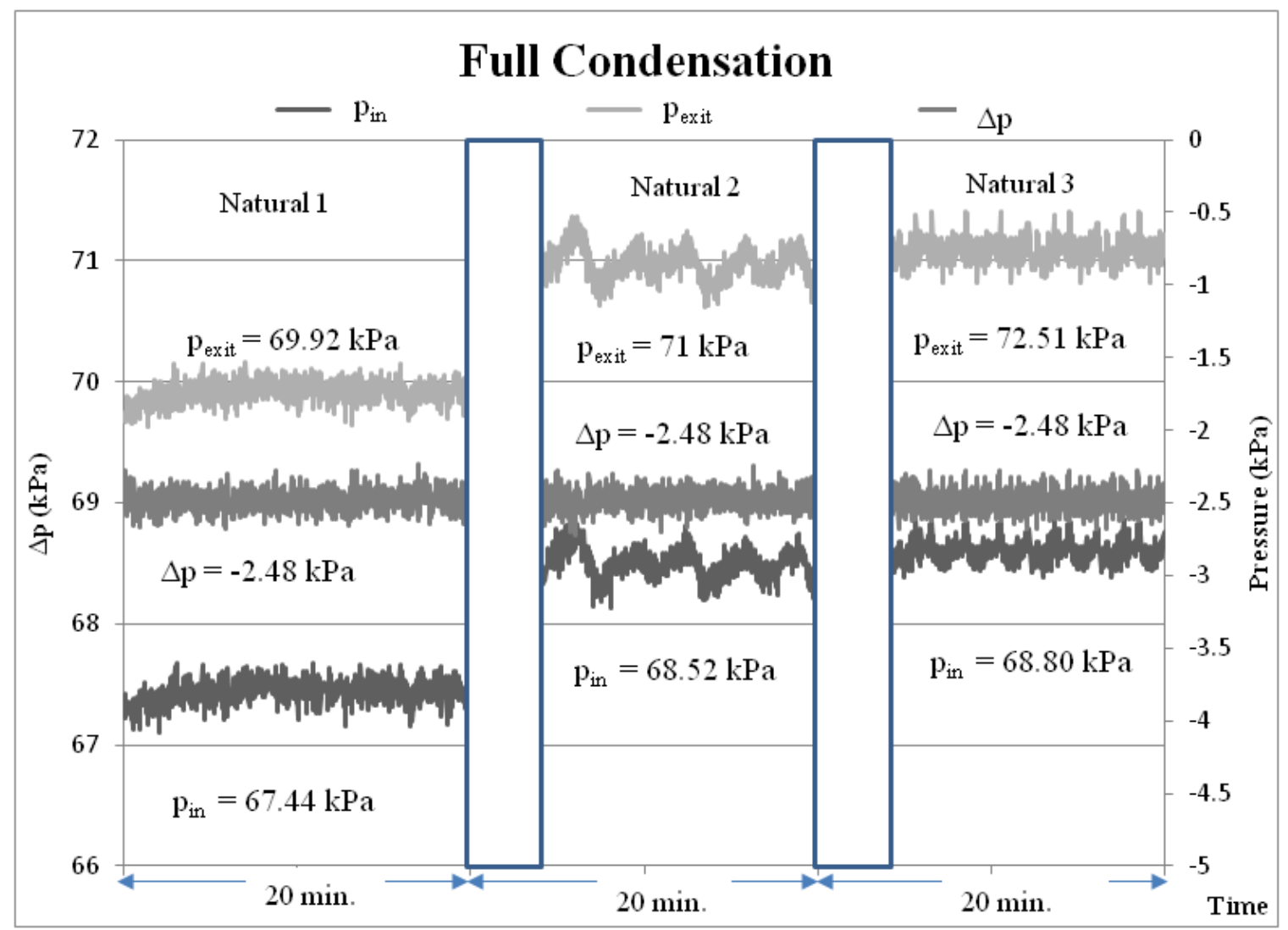

Figure 5.2: Time histories of $p_{\text {in }}$, $p_{\text {exit, }}$ and $\Delta p$ for the three unspecified pressuredifference runs shown in Figure 5.1. The first time-segment's steady flow realization was by procedure-1 and the steady realizations in the second and the third time segments were by procedure-2. Though $p_{\text {in }}$ in the first segment is different, the natural pressure-difference $\Delta p$ values are seen to be equal for all the three runs because $\dot{\mathbf{M}}_{\mathrm{in}}$ and $\Delta \mathrm{T} \equiv \mathrm{T}_{\text {Sat }}\left(\mathrm{p}_{\mathrm{in}}\right)-\overline{\mathrm{T}}_{\mathrm{W}}$ values are approximately the same for all the three cases. 


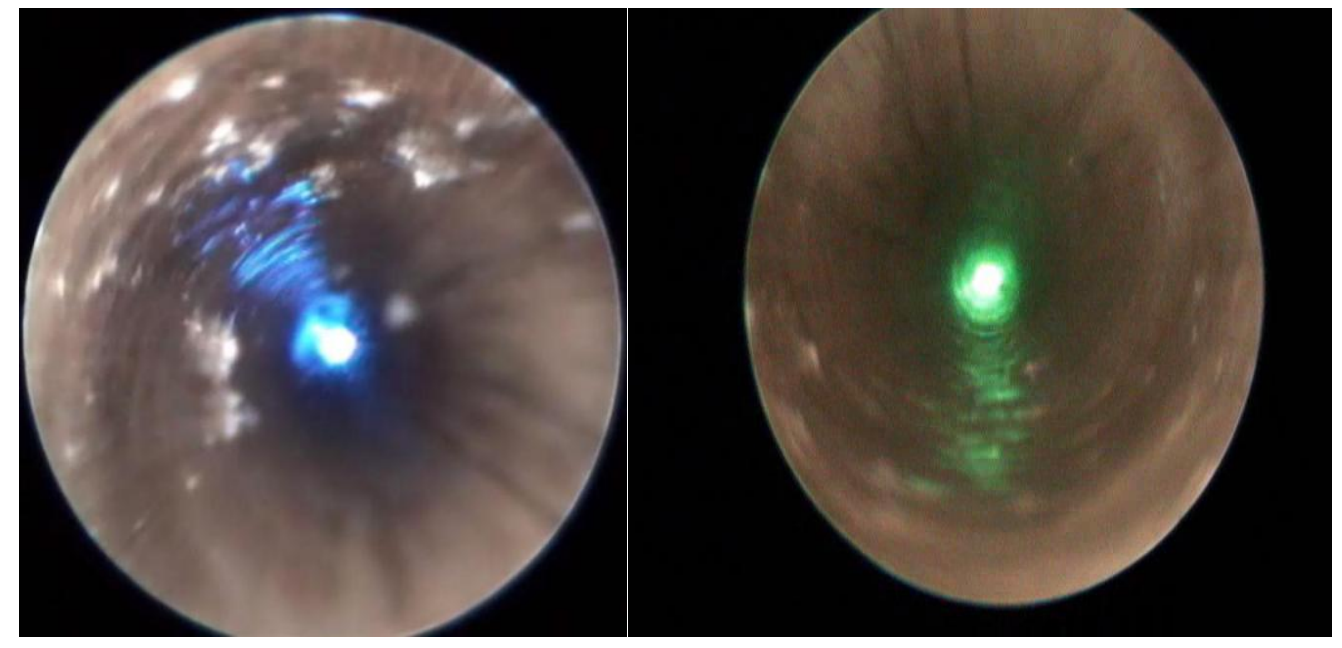

Figure 5.3: The light reflected from the interface depicts typical wavy annular flows realized in vertical tube experiments. The borescope views are taken from the top of the test-section and the blue/green lights are vertically down at a location below the test-section. The blue light picture on the left is for a representative partial condensation case and the green light picture on the right is for a representative full condensation case. 


\section{Experimental results for vertical tube and comparisons with theory}

\subsection{Notations Used for Reporting Experimental Results}

Let $\dot{\mathrm{M}}_{\mathrm{in}}$ be the inlet mass flow rate of the vapor, and $\Delta \mathrm{T}$ be a fixed representative value of a certain vapor to wall temperature difference profile. Let $\dot{\mathrm{M}}_{\mathrm{L}}(\mathrm{x})$ and $\dot{\mathrm{M}}_{\mathrm{V}}(\mathrm{x})$ be the condensate and the vapor mass flow rates at any given location $\mathrm{x}(0 \leq \mathrm{x} \leq \mathrm{L})$ along the test section length. Let the inlet Reynolds number be given as $\operatorname{Re}_{\text {in }} \equiv \rho_{2} U D / \mu_{2}$ where $\mathrm{U}$ is the average speed of vapor at the inlet (i.e. $\dot{\mathrm{M}}_{\mathrm{in}} \equiv \pi /{ }_{4} \mathrm{D}^{2} * \rho_{2} \mathrm{U}$ ). Here $\rho_{2}$ and $\mu_{2}$ are, respectively, representative constant values of vapor density and viscosity. Note that all vapor properties are assumed to be approximately uniform and their representative constant values are evaluated at the pressure of $\mathrm{p}_{\mathrm{in}}$ (the test-section inlet pressure) and a temperature of $1{ }^{\circ} \mathrm{C}$ superheat over the saturation temperature associated with $\mathrm{p}_{\text {in. }}$. Thus the Reynolds number represents a specific non-dimensional form of $\dot{\mathrm{M}}_{\mathrm{in}}$. The non dimensional temperature difference $\Delta \mathrm{T}$ is expressed as the ratio of condensate Jacob Number $\left(\mathrm{Ja} \equiv \mathrm{Cp} \mathrm{p}_{1} . \Delta \mathrm{T} / \mathrm{h}_{\mathrm{fg}}\right)$ to the condensate Prandtl Number $\left(\operatorname{Pr}_{1}=\mu_{1} \cdot \mathrm{Cp}_{1} / \mathrm{k}_{1}\right)$ i.e. $\mathrm{Ja} / \operatorname{Pr}_{1}=\Delta \mathrm{T} . \mu_{1} / \mathrm{h}_{\mathrm{fg}} \cdot \mathrm{k}_{1}$. Here $\rho_{1}, \mu_{1}, \mathrm{k}_{1}$, and $\mathrm{Cp}_{1}$ are, respectively, representative constant values of liquid density, viscosity, thermal conductivity, and specific heat. All liquid properties are evaluated at the pressure of $p_{\text {in }}$ and a temperature of " $\bar{T}_{W}+0.5$. $\Delta \mathrm{T}$." Also $\mathrm{h}_{\mathrm{fg}} \approx \mathrm{h}_{\mathrm{fg}}\left(\mathrm{p}_{\mathrm{in}}\right)$ is the heat of vaporization at a representative pressure that is close to the mean condenser pressure for the reported experimental runs. The gravity vector is expressed in terms of the components $g_{x}$ - along the test section and $g_{y}$ - in the transverse direction, where their non dimensional values are $\mathrm{Fr}_{\mathrm{x}-1}=\mathrm{g}_{\mathrm{x}} \cdot \mathrm{D} / \mathrm{U}_{2}$ and $\mathrm{Fr}_{\mathrm{y}-1}=\mathrm{g}_{\mathrm{y}} \cdot \mathrm{D} / \mathrm{U}_{2}$. Since $\mathrm{g}_{\mathrm{y}}=0$ for a vertical tube, $\mathrm{Fr}_{\mathrm{y}-1}=0$. For convenience, we have replaced $\mathrm{Fr}_{\mathrm{x}-1}$ by a new non dimensional gravity parameter $G_{P}=\mathrm{Fr}_{\mathrm{x}}^{-1} \cdot \mathrm{Re}_{\mathrm{in}}^{2}=\rho_{2}^{2} \cdot \mathrm{g}_{\mathrm{x}} \mathrm{D}^{3} / \mu_{2}^{2}$ which is independent of the inlet flow rate. Therefore the non-dimensional parameter set that impacts and characterizes the vertical in-tube condenser flow is: $\left\{\mathrm{x} / \mathrm{D}, \mathrm{Re}_{\mathrm{in}}, \mathrm{GP}, \mathrm{Ja} / \mathrm{Pr}_{1}\right.$, $\left.\rho_{2} / \rho_{1}, \mu_{2} / \mu_{1}\right\}$. 
Because, for most reported data, the counter flow of cooling water surrounding the test-section is at a fixed flow rate $(8$ gallons/min) and at nearly fixed temperatures (20-30 ${ }^{\circ} \mathrm{C}$ - sufficient to ensure that water properties do not change significantly), the condensing-surface temperature variations $\mathrm{T}_{\mathrm{w}}(\mathrm{x})$ is adequately modeled by the assumption of a uniform surface temperature $\overline{\mathrm{T}}_{\mathrm{W}}$. This is because for any two representative experimentally measured wall temperature variations $\mathrm{T}_{\mathrm{w} 1}(\mathrm{x})$ and $\mathrm{T}_{\mathrm{w} 2}(\mathrm{x})$ shown in Figure 6.1, it is found that the variation of non-dimensional condensing-surface temperature $\theta_{\mathrm{W}}(\tilde{\mathrm{x}})\left(\equiv\left(\mathrm{T}_{\mathrm{W}}(\tilde{\mathrm{x}})-\overline{\mathrm{T}}_{\mathrm{W}}\right) / \Delta \mathrm{T}\right)$ with non-dimensional distance $\tilde{\mathrm{x}} \equiv \mathrm{x} / \mathrm{D}$ is nearly the same function (within experimental errors) for all cases. This means that, in the non-dimensional formulation of the problem, ${ }^{6}$ the thermal condition for the condensingsurface remains the same. Furthermore we verified that the simulation results (based on the methods described in Mitra ${ }^{6}$ ) were nearly the same, with regard to the overall quantities of interest to this paper, for a non-uniform temperature $\mathrm{T}_{\mathrm{w}}(\mathrm{x})$ and for the associated uniform temperature $\overline{\mathrm{T}}_{\mathrm{W}}$. The non-monotonous trend of $\theta_{\mathrm{W}}(\tilde{\mathrm{x}})$ in Figure 6.1 is understandable and its $\tilde{x}$ variations associated with varying flow physics of increasing thickness of a nearly smooth condensate, onset of significant waviness, and eventual single phase nature of the flow. 


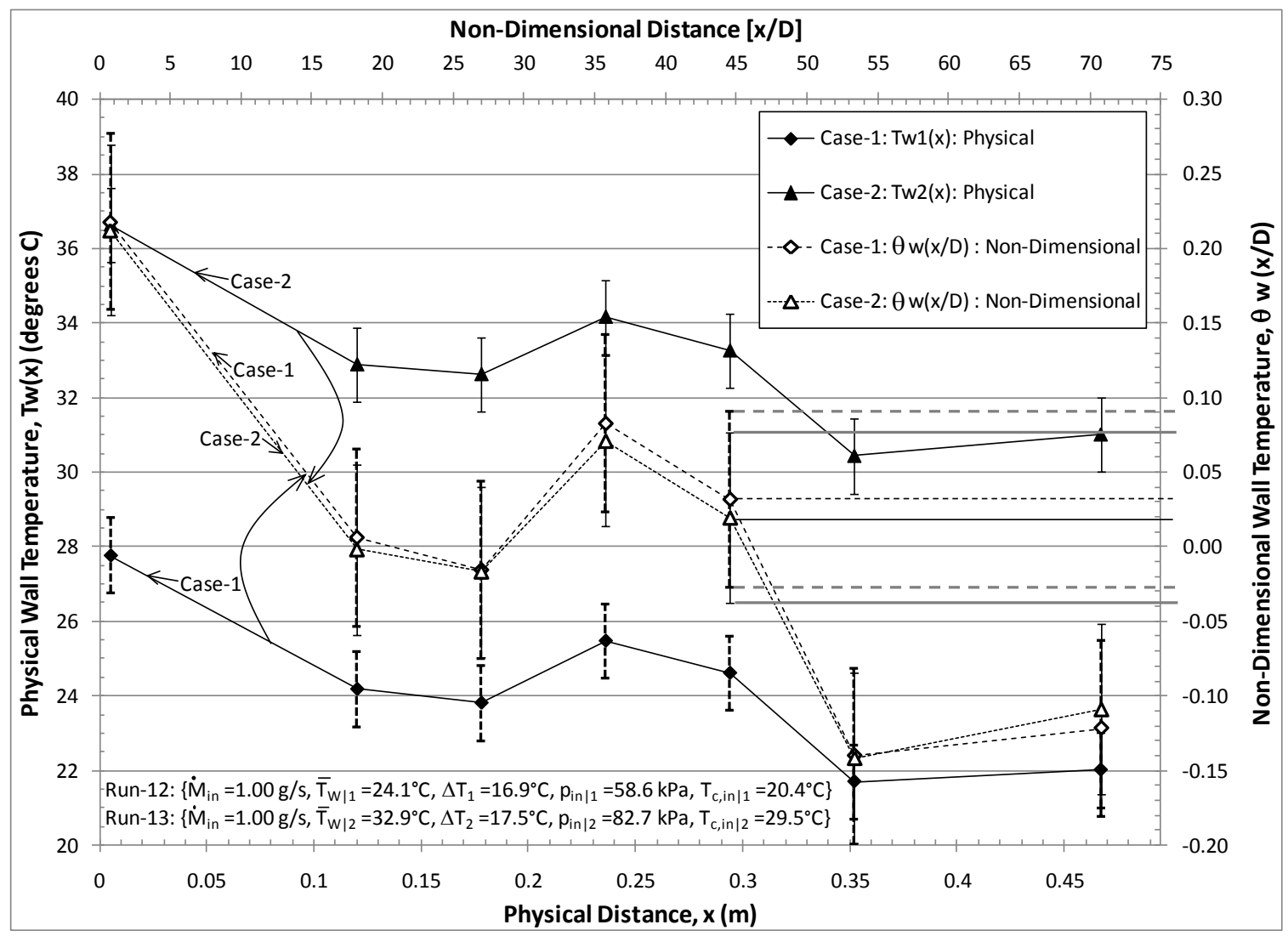

Figure 6.1: The figure shows two different condensing-surface temperature variations $T_{\mathrm{w} 1}(x)$ and $T_{\mathrm{w} 2}(x)$ corresponding to runs 12 and 13 in Table 5.1. It also shows corresponding non-dimensional temperatures $\theta_{W}(\widetilde{\mathbf{x}})$ with respect to nondimensional $\tilde{\mathbf{x}}=\mathbf{x} / \mathbf{D}$.

\subsection{Experimental Range and Results}

The experimental results given in Table 5.1 for the fully condensing flows show key details of different and representative flow runs. These results were obtained by the flow loop arrangement in Figure 3.28 and the procedures 1 and 2 described in section 5.1. The experimental runs reported in Table 5.1 cover only a portion of the non-dimensional parameter space $\left\{\tilde{x}, \operatorname{Re}_{i n}, G p \equiv\left(\left(\rho_{22} g_{x} D_{3}\right) / \mu_{22}\right), J a / \operatorname{Pr}_{1}, \rho_{2} / \rho_{1}, \mu_{2} / \mu_{1}\right\}$ that governs this in-tube problem. With distance $\mathrm{x}$ from the inlet satisfying the constraints $0 \leq \mathrm{x} \leq \mathrm{x}_{\mathrm{FC}}$ for 
full condensation cases considered here, the remaining non-dimensional parameters cover the zones shown in Figures $6.2-6.3$. The ranges of the non-dimensional numbers involved in Figures $6.2-6.3$ are:

$$
\begin{aligned}
& 0.0025<\rho_{2} / \rho_{1}<0.11 \\
& 0.015<\mu_{2} / \mu_{1}<0.025 \\
& 471000<\mathrm{Gp}<9510000 \\
& 0.004<\mathrm{Ja} / \mathrm{Pr}_{1}<0.069
\end{aligned}
$$

It should be noted that our ability to cover a limited range of $\mu_{2} / \mu_{1}$ and $\rho_{2} / \rho_{1}$ values in Figure 6.3 results from the fact that $\Delta \mathrm{T} \equiv \mathrm{T}_{\text {Sat }}\left(\mathrm{p}_{\mathrm{in}}\right)-\overline{\mathrm{T}}_{\mathrm{W}}$ is systematically changed by changing the inlet pressure $\mathrm{p}_{\mathrm{in}}$ and the representative vapor properties change when $\mathrm{T}_{\text {Sat }}\left(\mathrm{p}_{\text {in }}\right)$ changes.

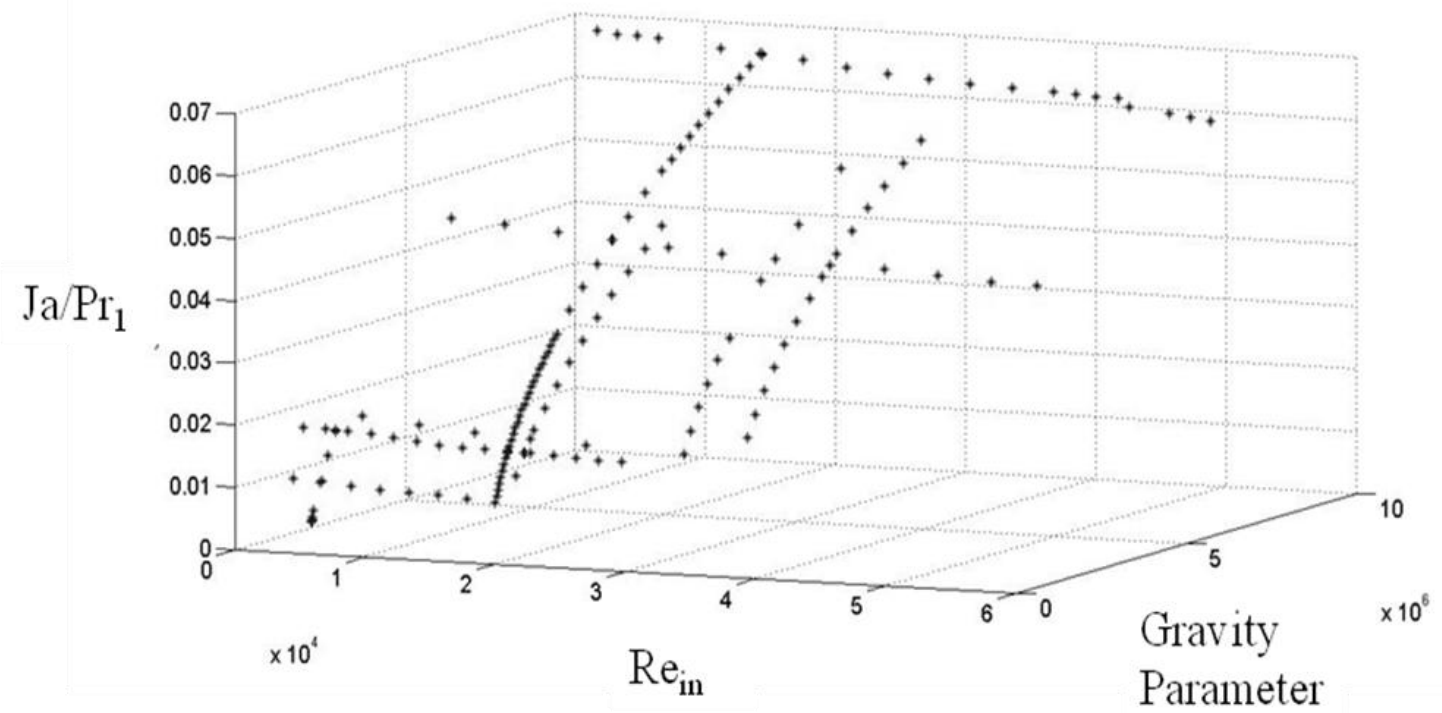

Figure 6.2: The investigated full and partial condensation flow cases cover the parameter space $\left\{\operatorname{Re}_{\text {in }}, \mathrm{Gp}, \mathrm{Ja} / \mathrm{Pr}_{1}\right\}$ above. 


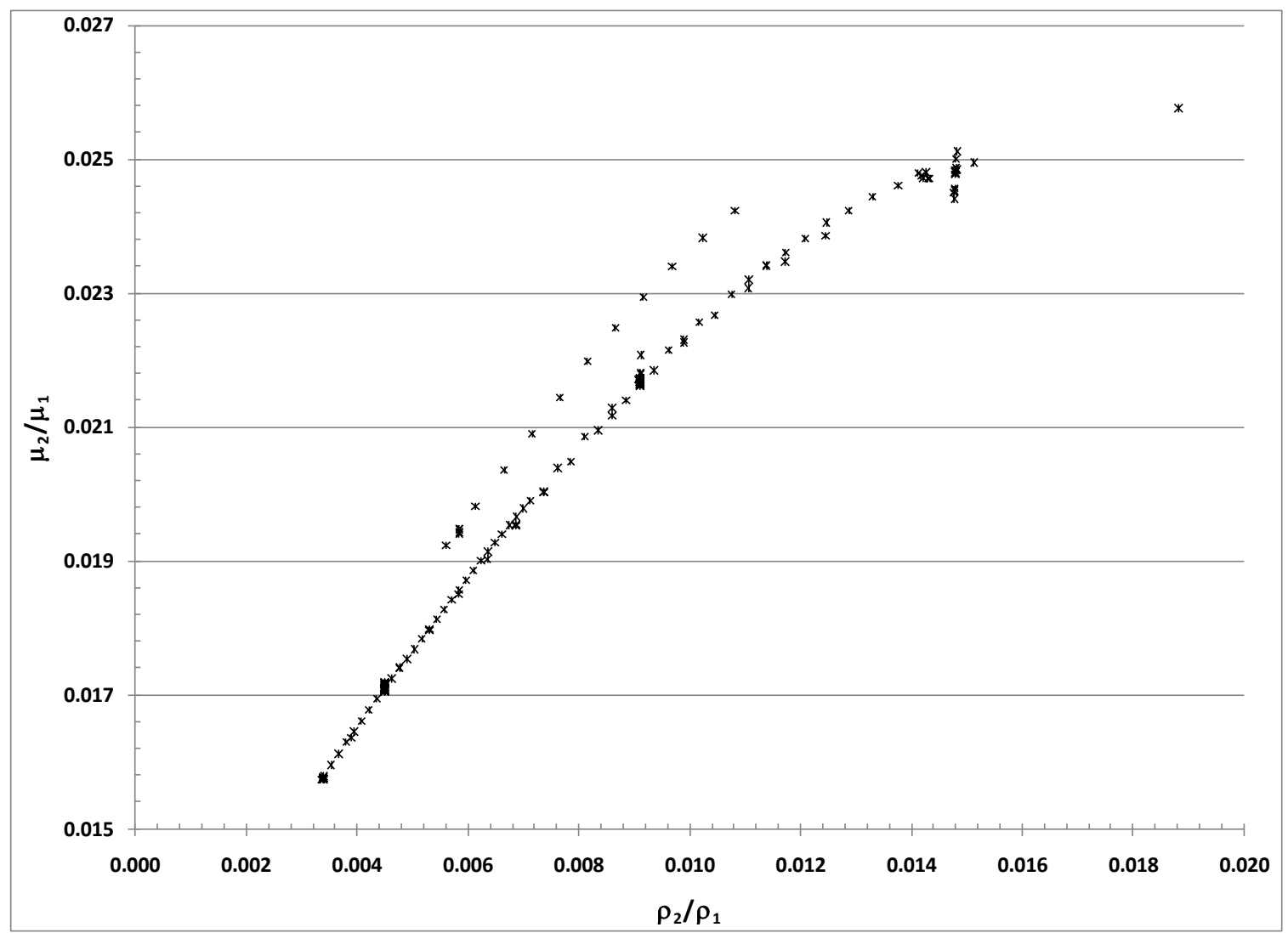

Figure 6.3: The investigated full and partial condensation flow cases cover the parameter space $\left\{\rho_{2} / \rho_{1}, \mu_{2} / \mu_{1}\right\}$ space above.

It was observed that, for the chosen and reported values of $\dot{\mathrm{M}}_{\text {in }}$ and $\Delta \mathrm{T} \equiv$ $\mathrm{T}_{\text {Sat }}\left(\mathrm{p}_{\mathrm{in}}\right)-\overline{\mathrm{T}}_{\mathrm{W}}$, the flow self-selected an effective point of full condensation whose distance $\mathrm{x}_{\mathrm{FC}}$ from the inlet was such that $0<\mathrm{x}_{\mathrm{FC}}<\mathrm{L}$ and the test-section was filled with liquid downstream of the point/zone of full condensation (in the video, unlike the still picture in Figure 5.3, the upper level of liquid that filled the tube was above the green light and was quite visible). Most gravity driven vertical tube flows visually appeared to be annular wavy up to some point $\mathrm{x}_{\mathrm{A}}$ close to the point $\mathrm{x}_{\mathrm{FC}}\left(>\mathrm{x}_{\mathrm{A}}\right)$ of full condensation. The length $\left(\mathrm{x}_{\mathrm{FC}}-\mathrm{x}_{\mathrm{A}}\right)$ of the non-annular zone could not be quantified but appeared small and somewhat dependent on flow conditions. This length $\mathrm{x}_{\mathrm{FC}}$ is typically estimated (by extrapolation of the computationally obtained ${ }^{6}$ values of the 'quality' curve with $\mathrm{x}-$ beyond $\mathrm{x}_{\mathrm{A}}$ to $\mathrm{x}_{\mathrm{FC}}$ ) to cover points where at least 90 to $100 \%$ of the incoming vapor mass 
flow rate has already condensed. The experimental results given in Table 5.1 for these "self-selected/natural" fully condensing flows show a hydrostatic component in absolute pressure readings at tranducer loactions below the point of full condensation. For most cases considered here, $\mathrm{x}_{\mathrm{FC}}<\mathrm{x}_{9}<\mathrm{L}$, and therefore there is always a hydrostatic component of pressure at location - $\mathrm{x}_{9}$ in Figure 3.27 This implies:

$\mathrm{p}_{\mathrm{in}}-\mathrm{p}_{\mathrm{x} 9}=\left(\mathrm{p}_{\mathrm{in}}-\mathrm{p}_{\mathrm{X}_{\mathrm{FC}}}\right)+\left(\mathrm{p}_{\mathrm{X}_{\mathrm{FC}}}-\mathrm{p}_{\mathrm{x} 9}\right) \cong\left(\mathrm{p}_{\mathrm{in}}-\mathrm{p}_{\mathrm{X}_{\mathrm{FC}}}\right)+\rho \mathrm{g}\left(\mathrm{x}_{\mathrm{FC}}-\mathrm{x}_{9}\right)$

Because both the reported experiments (Figure 6.4) and associated theory ${ }^{6}$ confirm that, for most cases, the pressure differences in the two-phase (mostly) annular region is negligible compared to the hydrostatic pressure (i.e. $\left|p_{\text {in }}-p_{\mathrm{x}_{\mathrm{FC}}}\right| \ll$ $\left.\left|\rho g\left(x_{\mathrm{FC}}-\mathrm{x}_{9}\right)\right|\right)$, Equation (6.2) simplifies to:

$$
\mathrm{p}_{\mathrm{in}}-\mathrm{p}_{\mathrm{x} 9} \cong \rho \mathrm{g}\left(\mathrm{x}_{\mathrm{FC}}-\mathrm{x}_{9}\right)
$$




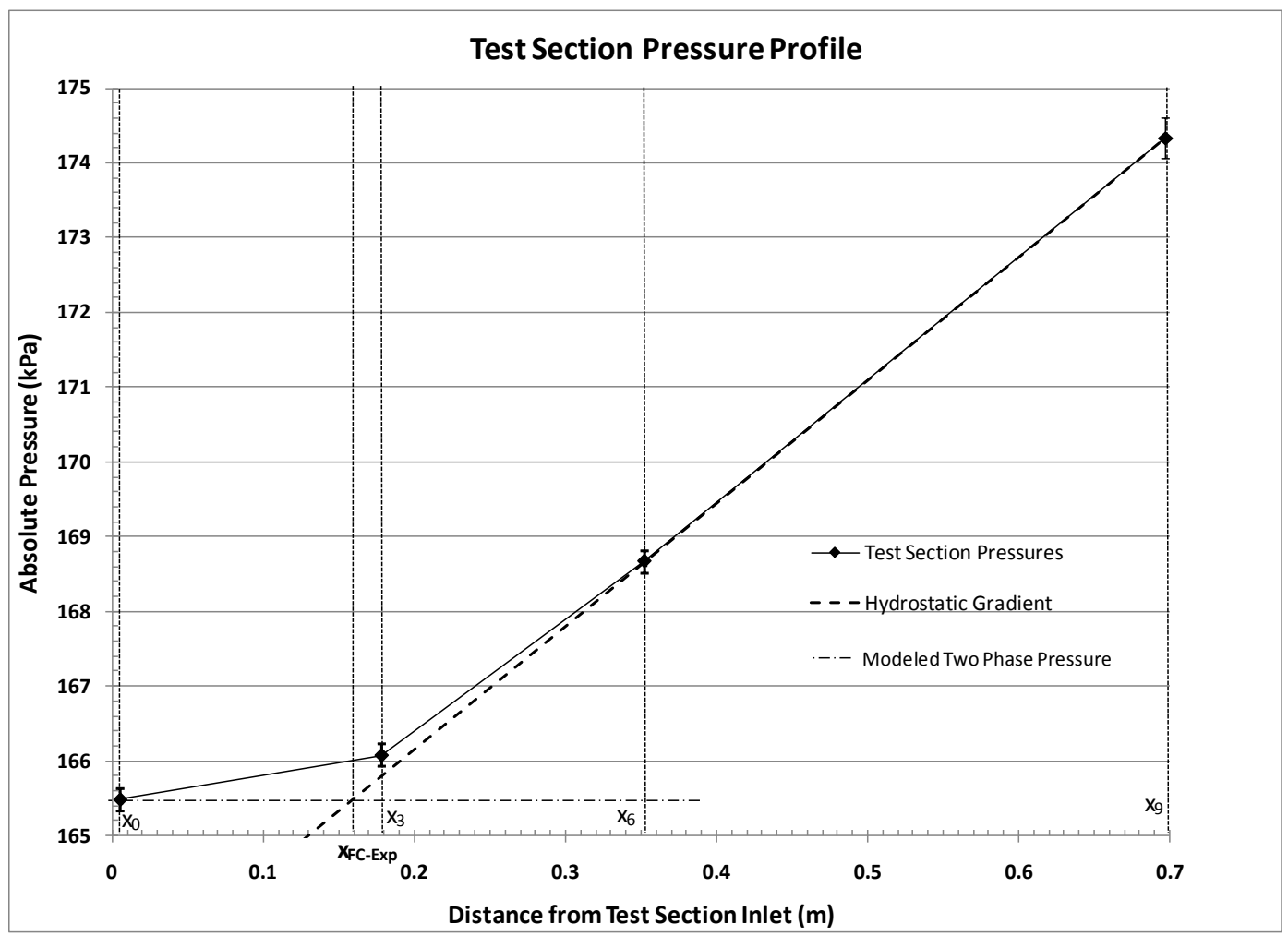

Figure 6.4: For a representative case (run 14 in Table 5.1), the plot shows testsectional pressure variation with distance $x$. The measurements are at locations $x_{0}$, $x_{3}, x_{6}$, and $x_{9}$ marked in Figure 3.27. The value of $x_{F C}$ is marked to indicate its estimated value.

Because the left side of Equation (6.3) is available from the experimental results, Equation (6.3) is used to obtain experimental estimates for $\mathrm{x}_{\mathrm{FC}}$, the distance between the inlet and the effective point of full condensation. Furthermore the computational solution approach described in the companion paper $^{6}$ gives - under the assumption of nearly smooth interface, steady laminar vapor flow (in the near interface zone) and laminar condensate flow - direct theoretical estimates for $\mathrm{x}_{\mathrm{FC}}$ and $\left(\mathrm{p}_{\mathrm{in}}-\mathrm{px}-\mathrm{FC}\right)$ values. Cases for which the prediction tool in Mitra ${ }^{6}$ does not allow (or is not valid) one to go right up to $100 \%$ condensation, the theoretical estimate for $\mathrm{x}_{\mathrm{FC}}$ is obtained by extrapolating from the theoretically obtained distances for $80-90 \%$ condensation of the incoming vapor. Although predictions of $\left|\left(\mathrm{p}_{\mathrm{in}}-\mathrm{pX}-\mathrm{FC}\right)\right|$ is off, its order of magnitude is correct and, therefore it is found that the right side of Equation (6.3) correctly approximates the right side of Equation (6.2). 
For fully condensing flows, the experimental value of the average heat-transfer coefficient $\overline{\mathrm{h}}$ (or $\overline{\mathrm{h}}_{\text {Exp }}$ ) is obtained from Equation (6.4) below. For this, the experimental estimates of $\dot{\mathrm{M}}_{\mathrm{in}}, \mathrm{xFC}$, and $\Delta \mathrm{T} \equiv \mathrm{T}_{\text {Sat }}\left(\mathrm{p}_{\mathrm{in}}\right)-\overline{\mathrm{T}}_{\mathrm{W}}$ are used in Equation (6.4).

$$
\dot{\mathrm{Q}}_{\mathrm{out}} \approx \dot{\mathrm{M}}_{\mathrm{in}} \mathrm{h}_{\mathrm{fg}}=\left(\pi \mathrm{D} \cdot \mathrm{x}_{\mathrm{FC}} \cdot \overline{\mathrm{h}}\right) \Delta \mathrm{T}
$$

The theoretical value of the average heat-transfer coefficient $\bar{h}\left(\right.$ or $\left.\bar{h}_{\text {Sim }}\right)$ is obtained by employing the computationally obtained values for the distance $\mathrm{x}_{\mathrm{FC}}$ in Equation (6.4). The resulting value of $\overline{\mathrm{h}}_{\text {Sim }}$ is found to be equivalent, ${ }^{6}$ or nearly the same, as the one obtained from the relationship:

$$
\overline{\mathrm{h}} \cong \frac{\mathrm{k}_{1}}{\mathrm{x}_{\mathrm{FC}}} \cdot \int_{0}^{\mathrm{x}_{\mathrm{FC}}} \frac{1}{\Delta(\mathrm{x})} \cdot \mathrm{dx}
$$

where the film thickness $\Delta(\mathrm{x}) \equiv \mathrm{D} \cdot \delta(\mathrm{x})$ and the expression on the right of Equation (6.5) is evaluated by the computational solution approach described in Mitra. ${ }^{6}$

As shown in Figures 6.5-6.6, whenever the laminar vapor/laminar condensate assumption is adequate, there is an excellent agreement (within $3-4 \%$ ) between theoretical and experimental estimates of $\mathrm{x}_{\mathrm{FC}}$. Equivalently, because of Equation (6.3) we also have an agreement between experimental and theoretical estimates of $\Delta \mathrm{p} \equiv\left(\mathrm{p}_{\mathrm{x} 9}-\mathrm{p}_{\mathrm{in}}\right)$. In Figures 6.5-6.6, the reported plots show the functional dependence structure of $\mathrm{x}_{\mathrm{FC}}=$ $\mathrm{X}_{\mathrm{FC}}\left(\dot{\mathrm{M}}_{\mathrm{in}}, \Delta \mathrm{T}\right)$ as one of the two variables $\left(\dot{\mathrm{M}}_{\mathrm{in}}\right.$ or $\left.\Delta \mathrm{T}\right)$ is varied while the other is held fixed. Figures 6.5-6.6 show the cases for which the experimentally calculated $\mathrm{x}_{\mathrm{FC}}$ starts becoming significantly smaller than the theoretically calculated $\mathrm{x}_{\mathrm{FC}}$ at larger values of $\dot{\mathrm{M}}_{\text {in }}$ and $\Delta \mathrm{T}$. Therefore, Figures 6.5-6.6, provide us with a good opportunity to experimentally obtain and develop a quantitative criteria as to when the near interface region of the vapor flow starts interacting strongly with laminar waviness or turbulence of the condensate in the near interface region. A reasonable procedure for quantifications of these effects, that appear to be the most probable cause (given the videos show the annularity of these flows) for theory and experiment to deviate from one another, is described in section 7 . 


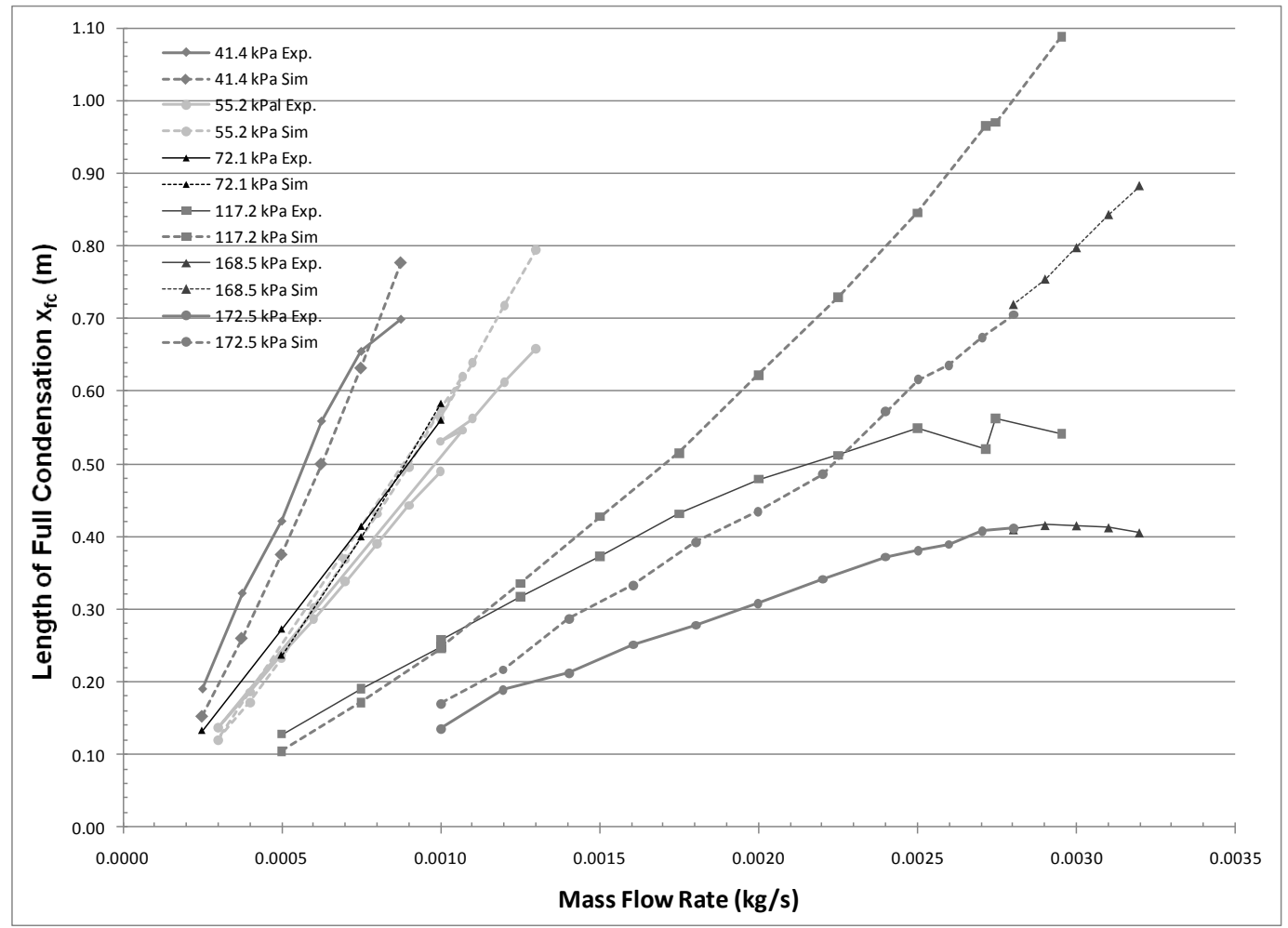

Figure 6.5: The comparison of theoretically and computationally obtained values of $\mathrm{x}_{\mathrm{FC}}$ as a function of $\dot{\mathrm{M}}_{\mathrm{in}}$. Here the the dashed lines indicates the simulation results and the solid lines indicate the experimental results. 


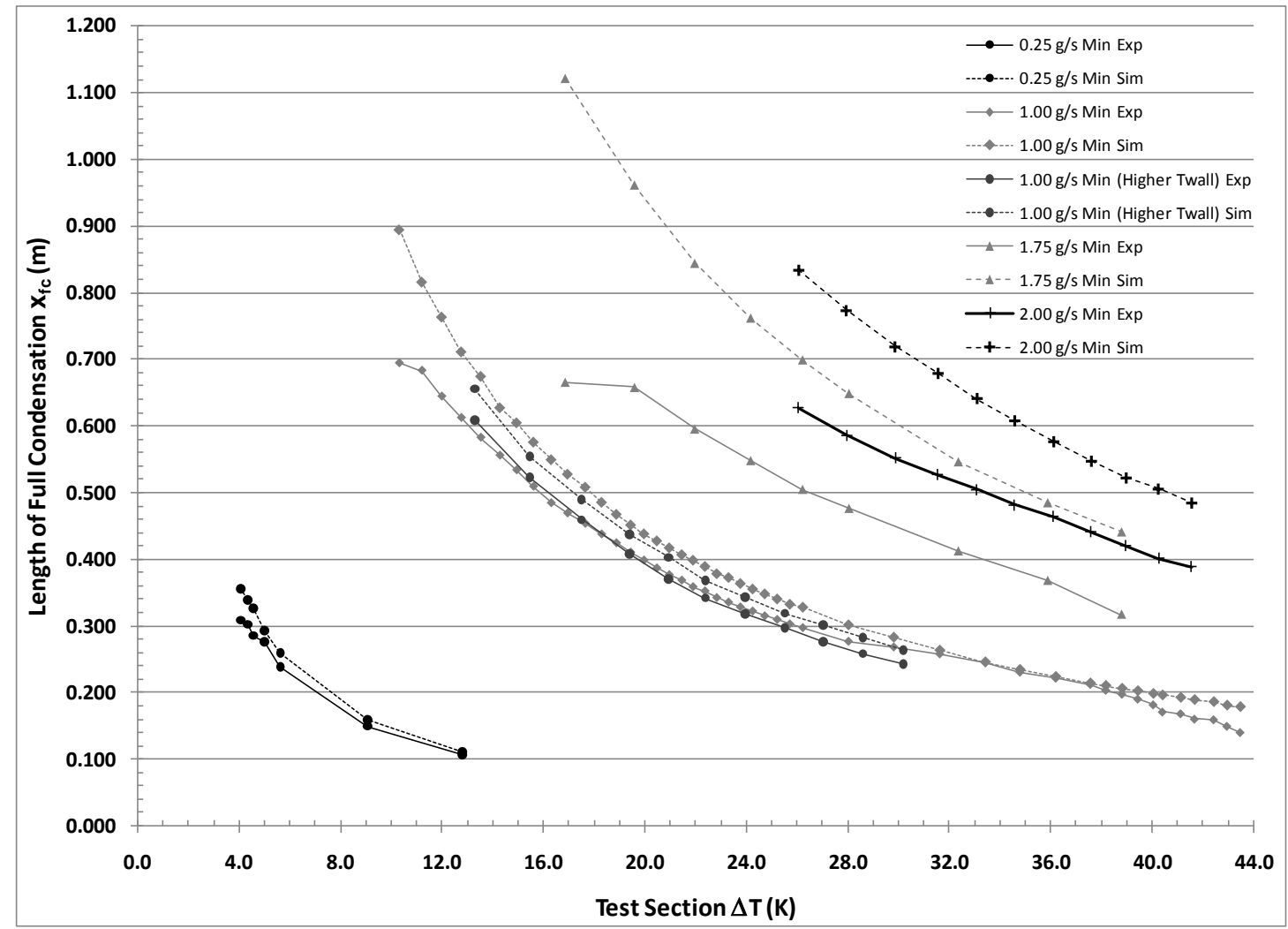

Figure 6.6: The comparison of theoretically and computationally obtained values of $\mathrm{x}_{\mathrm{FC}}$ as a function of $\Delta \mathrm{T}$. Here the dashed lines indicate the simulation results and the solid lines indicate the experimental results. 


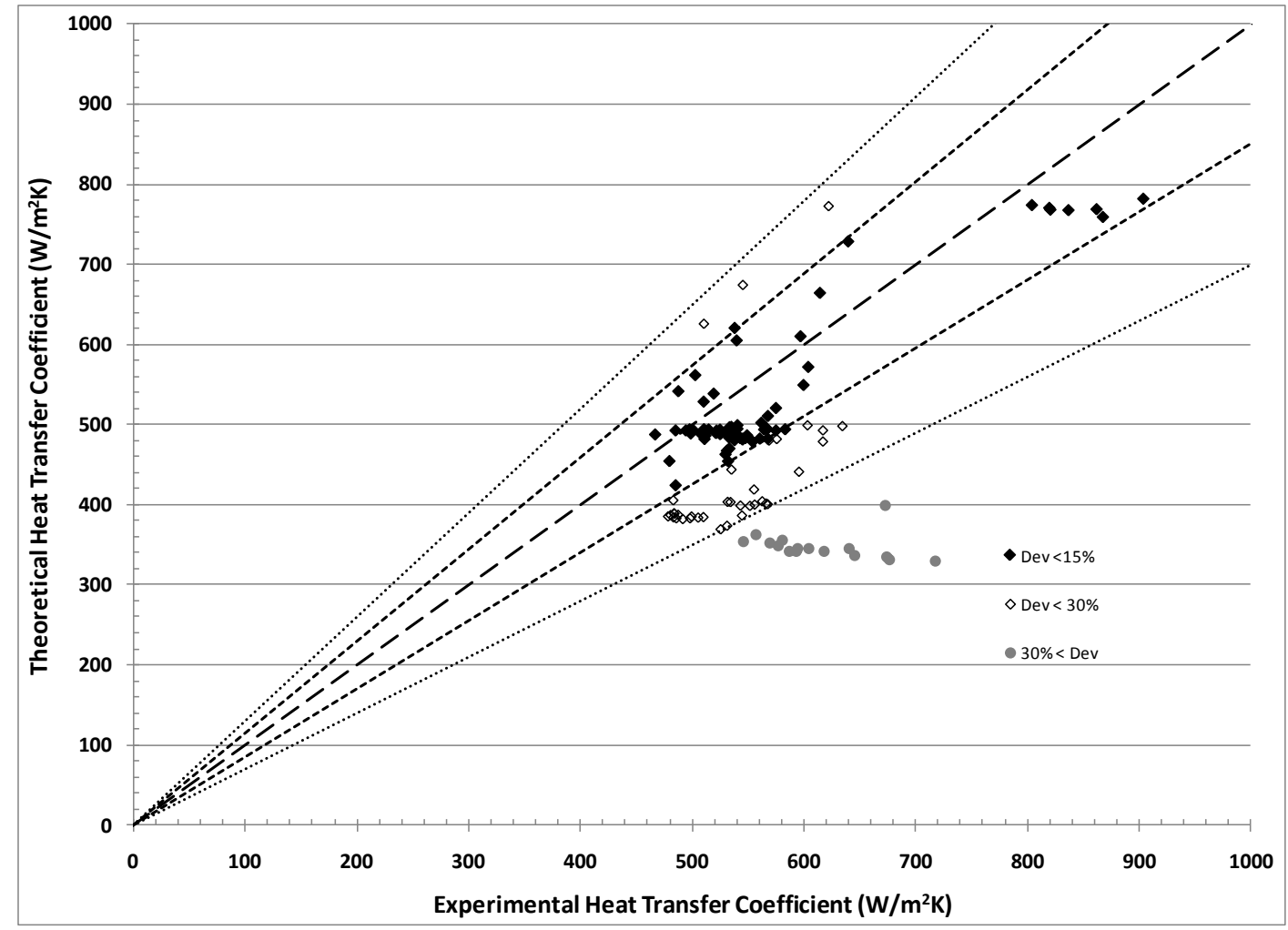

Figure 6.7: Comparison of experimentally and computationally obtained values of average heat transfer coefficients for fully condensing flows.

The full condensation runs/cases associated Figures 6.2-6.3 also allow a comparison of theoretically and experimentally obtained values of the average heattransfer coefficient $\bar{h}$. These comparisons are shown in Figure 6.7. 


\section{Effects of interactions between near-interface vapor flow and condensate flows' interfacial waviness}

\subsection{Observed Deviations between Experimental and Theoretical Results}

As seen in Figures 7.1-7.2, there are significant numbers of experimental data points for fully condensing flows where the experimentally measured values of the heat transfer coefficients are significantly more than the idealized theoretical estimates. For convenience of analysis, we have sorted the data points based on their deviation from the idealized theory and defined the measure as: Deviation $\equiv \frac{\overline{\mathrm{h}}_{\mathrm{Exp}}-\overline{\mathrm{h}}_{\mathrm{Th}}}{\overline{\mathrm{h}}_{\mathrm{Exp}}} \times 100$. The sorting in Figure 7.1 is done in " $\mathrm{Ja} / \mathrm{Pr}_{1}-\mathrm{Re}_{\mathrm{in}}$ " plane and in Figure 7.2 in " $\mathrm{Ja} / \mathrm{Pr}_{1}-\mathrm{Re}_{\delta \mid \mathrm{x}=\mathrm{x}_{\mathrm{FC}}}$ (三 $\left.\frac{4 \dot{\mathrm{M}}_{\mathrm{L}}\left(\mathrm{x}_{\mathrm{FC}}\right)}{\pi \mathrm{D} \mu_{1}}\right)$ " plane. A pictorial depiction of this sorting, as shown in Figures 7.1-7.2, is in the following three groups: (i) experimental values of $\overline{\mathrm{h}}$ that are within $15 \%$ (represented by filled diamond points), (ii) experimental values of $\overline{\mathrm{h}}$ that are between $15 \%-30 \%$ above the correlated or theoretical values (represented by hollow diamond points), and (iii) experimental values of $\overline{\mathrm{h}}$ that are more than $30 \%$ above the correlated or theoretical values (represented by the filled circular points). These experimentally obtained data are also the same for which, in Figures 6.4-6.5, the indirectly measured experimental values of $\mathrm{x}_{\mathrm{FC}}$ are smaller than the predicted values of $\mathrm{x}_{\mathrm{FC}}$. The fact that the experimental heat transfer rate is higher and the point of full condensation is smaller is understandable. Near the inlet, despite turbulence of the vapor in the core regions, the condensate is thin, laminar, and nearly smooth (except for vibration induced waves). The large value of interfacial mass-flux and associated large bending of vapor stream lines at small distances from the inlet (see, e.g., stream line patterns in Phan $^{31}$ ) makes the "near interface" vapor flow zone laminar despite turbulence in the core regions. However, for these gravity driven condensate flows, the condensate accelerates and by a certain downstream 
distance, the laminar condensate motion develops significant instability induced (different from wall noise induced) interfacial waves and, further downstream, the condensate flow becomes turbulent - as is the also the case for the gravity driven Nusselt problem. ${ }^{2}$ At such downstream distances, despite laminarization of the slowing vapor in the core regions, the near interface vapor flow regions can become turbulent due to the accelerating condensate flow becoming turbulent at $x$ locations where $\operatorname{Re}_{\delta}(x)\left(\equiv \frac{4 \dot{\mathrm{M}}_{\mathrm{L}}(\mathrm{x})}{\pi \mathrm{D} \mu_{1}}\right)$ is sufficiently large. Note that Incropera ${ }^{41}$ suggests that the order of magnitude of $\operatorname{Re}_{\delta}$ values where gravity driven laminar condensate becomes wavy is 30 to 100 and where it becomes turbulent is 500 to 1000 .

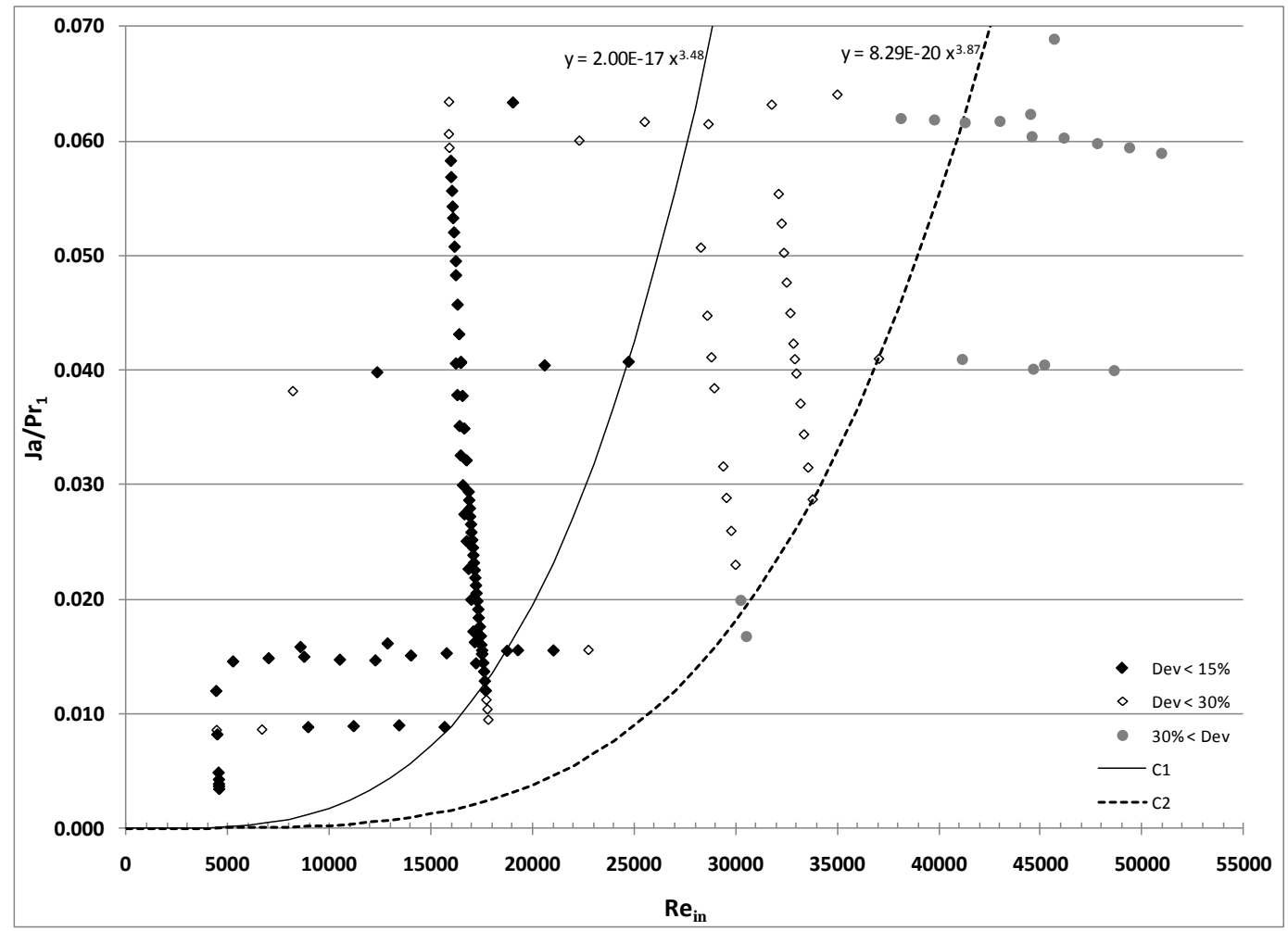

Figure 7.1: The plot shows deviation levels (between theory and experiments) with respect to the variables $\mathrm{Ja} / \mathrm{Pr}_{1}$ (representing $\Delta \mathrm{T}$ ) and the inlet Reynolds number Rein (representing $\dot{M}_{\mathrm{in}}$ ). The solid black diamond points show less than $15 \%$ deviation from the idealized theory. The hollow diamond points show experimental heat transfer coefficient values higher by $15 \%-30 \%$ and hollow circular points show that the experimental heat transfer values were greater than $30 \%$ with respect to the idealized theoretical estimates. 


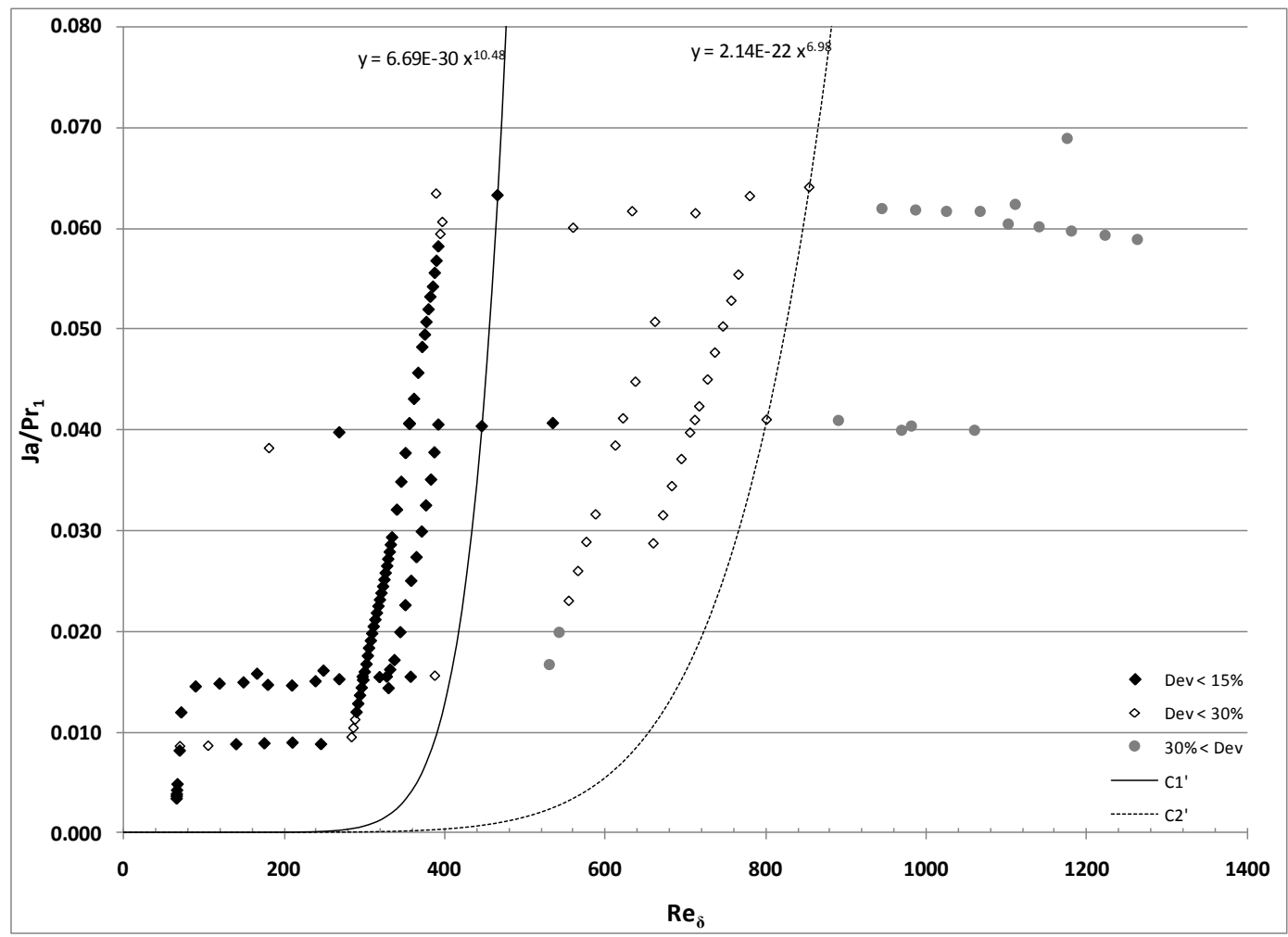

Figure 7.2: The plot shows deviation levels (between theory and experiments) with respect to the variables $\mathrm{Ja} \mathrm{Pr}_{1}$ (representing $\Delta \mathrm{T}$ ) against the condensate film's Reynolds number $\operatorname{Re}_{\delta}$ at $x=x_{F C}$. The solid black diamond points show less than $15 \%$ deviation from the idealized theory. The hollow diamond points show experimental heat transfer coefficient values higher by $15 \%$ - 30\% and hollow circular points show that the experimental heat transfer values were greater than $30 \%$ with respect to the idealized theoretical estimates.

The curves C1 (and C2) in Figure 7.1 suggests that the critical inlet Reynolds number - which determines whether or not near-interface laminarity or turbulence of the vapor is possible over the length of interest $\left(0 \leq \mathrm{x} \leq \mathrm{x}_{\mathrm{FC}}\right)$ - also depends on the temperature-difference parameter $\mathrm{Ja} / \mathrm{Pr}_{1}$ which is known to control the interfacial mass transfer rates (see Equation (6) in Mitra ${ }^{6}$ ). Similarly curves $\mathrm{C}_{1}{ }^{\prime}\left(\right.$ and $\left.\mathrm{C}_{2}{ }^{\prime}\right)$ in Figure 7.2 suggests that the critical condensate Reynolds number $\operatorname{Re}_{\delta \mid \mathrm{x}=\mathrm{x}_{\mathrm{FC}}}\left(\equiv \frac{4 \dot{\mathrm{M}}_{\mathrm{L}}\left(\mathrm{x}_{\mathrm{FC}}\right)}{\pi \mathrm{D} \mu_{1}}=\frac{4 \dot{\mathrm{M}}_{\mathrm{in}}}{\pi \mathrm{D} \mu_{1}}\right)-$ which determines at what distance $\mathrm{x}$ relative to $\mathrm{x}_{\mathrm{FC}}$ the laminar condensate becomes significantly wavy and/or significantly turbulent - also depends on the average interfacial mass transfer rate modeled by the parameter $\mathrm{Ja} / \mathrm{Pr}_{1}$. This dependence of critical values of 
$\operatorname{Re}_{\text {in }}$ or $\operatorname{Re}_{\delta \mid x=x_{F C}}$ on interface mass transfer rate (as modeled by $\mathrm{Ja} / \mathrm{Pr}_{1}$ ) is expected because vapor lines bend and pierce the interface (see, e.g., Narain et al. ${ }^{30}$ ) with significant reduction in the $\mathrm{x}$ - component of the vapor speed in the near interface region. The extent of reduction in the $\mathrm{x}$-component of vapor speed by the time vapor reaches the interface also depends on the value of $\operatorname{Re}_{\delta}(\mathrm{x})$ - a measure of the increasing inertia of the condensate.

By reprocessing the results in Figures 7.1-7.2 in terms of the parameters used for the $\mathrm{x}$-axes in Figures 7.3-7.4, we arrive at the following results for FC-72 flows' annular condensation inside vertical tubes:

(i) The effects of near-interface vapor turbulence and near-interface condensate waviness are small (in the sense that the laminar/laminar smooth-interface model ${ }^{6}$ for these flows are adequate) provided

$$
\operatorname{Re}_{\text {in }}<60000\left(\frac{\mathrm{Ja}}{\mathrm{Pr}_{1}}\right)^{0.2718}
$$

and

$$
\operatorname{Re}_{\delta \mid \mathrm{x}=\mathrm{x}_{\mathrm{FC}}}<700\left(\frac{\mathrm{Ja}}{\mathrm{Pr}_{1}}\right)^{0.668}
$$

(ii) The effects of near-interface vapor turbulence and near-interface condensate waviness enhance the average heat transfer coefficient $\bar{h}$ by a factor between 1.15 and 1.3 provided

$$
60000\left(\frac{\mathrm{Ja}}{\operatorname{Pr}_{1}}\right)^{0.2718} \leq \mathrm{Re}_{\mathrm{in}} \leq 88000\left(\frac{\mathrm{Ja}}{\operatorname{Pr}_{1}}\right)^{0.2718}
$$

and $700\left(\frac{\mathrm{Ja}}{\mathrm{Pr}_{1}}\right)^{0.1145} \leq \operatorname{Re}_{\delta \mid \mathrm{x}=\mathrm{x}_{\mathrm{FC}}} \leq 1250\left(\frac{\mathrm{Ja}}{\mathrm{Pr}_{1}}\right)^{0.1145}$

(iii) The effects of near-interface vapor turbulence and near-interface condensate waviness enhance the average heat transfer coefficient $\bar{h}$ by a factor greater than 1.3 provided 


$$
\mathrm{Re}_{\text {in }}>88000\left(\frac{\mathrm{Ja}}{\mathrm{Pr}_{1}}\right)^{0.2718}
$$

$$
\text { and } \quad \operatorname{Re}_{\delta \mid \mathrm{x}=\mathrm{x}_{\mathrm{FC}}}>1250\left(\frac{\mathrm{Ja}}{\mathrm{Pr}_{1}}\right)^{0.1145}
$$

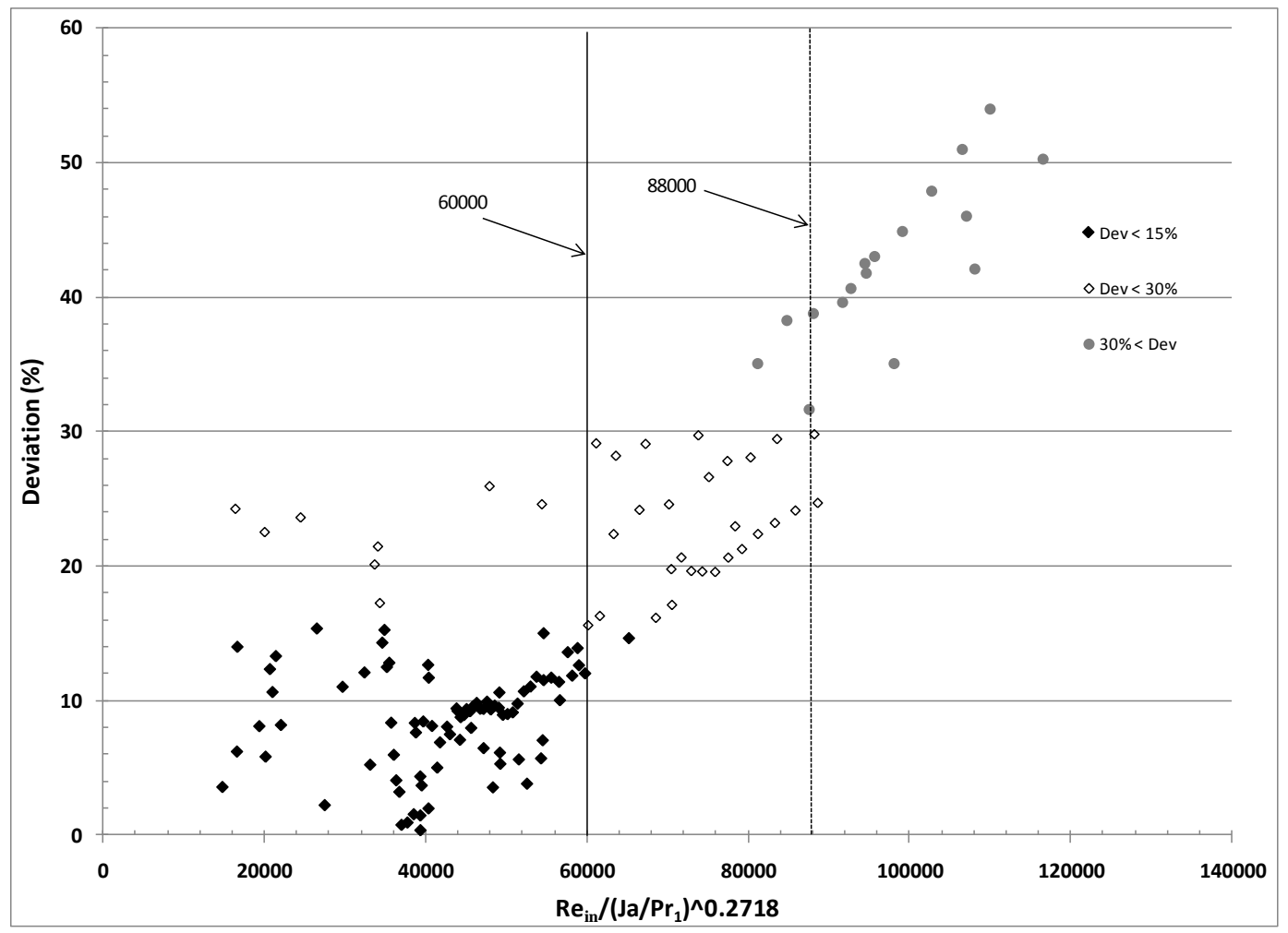

Figure 7.3: Plot of deviation against inlet parameter $\operatorname{Re}_{\text {in }} /\left(\mathrm{Ja} / \mathrm{Pr}_{1}\right)^{0.2718}$. The solid black diamond points show less than $15 \%$ deviation from the idealized theory. The hollow diamond points show experimental heat transfer coefficient values higher by $15 \%-30 \%$ and $t$ he hollow circular points show that the experimental heat transfer values were greater than $30 \%$ with respect to the idealized theoretical estimates. 


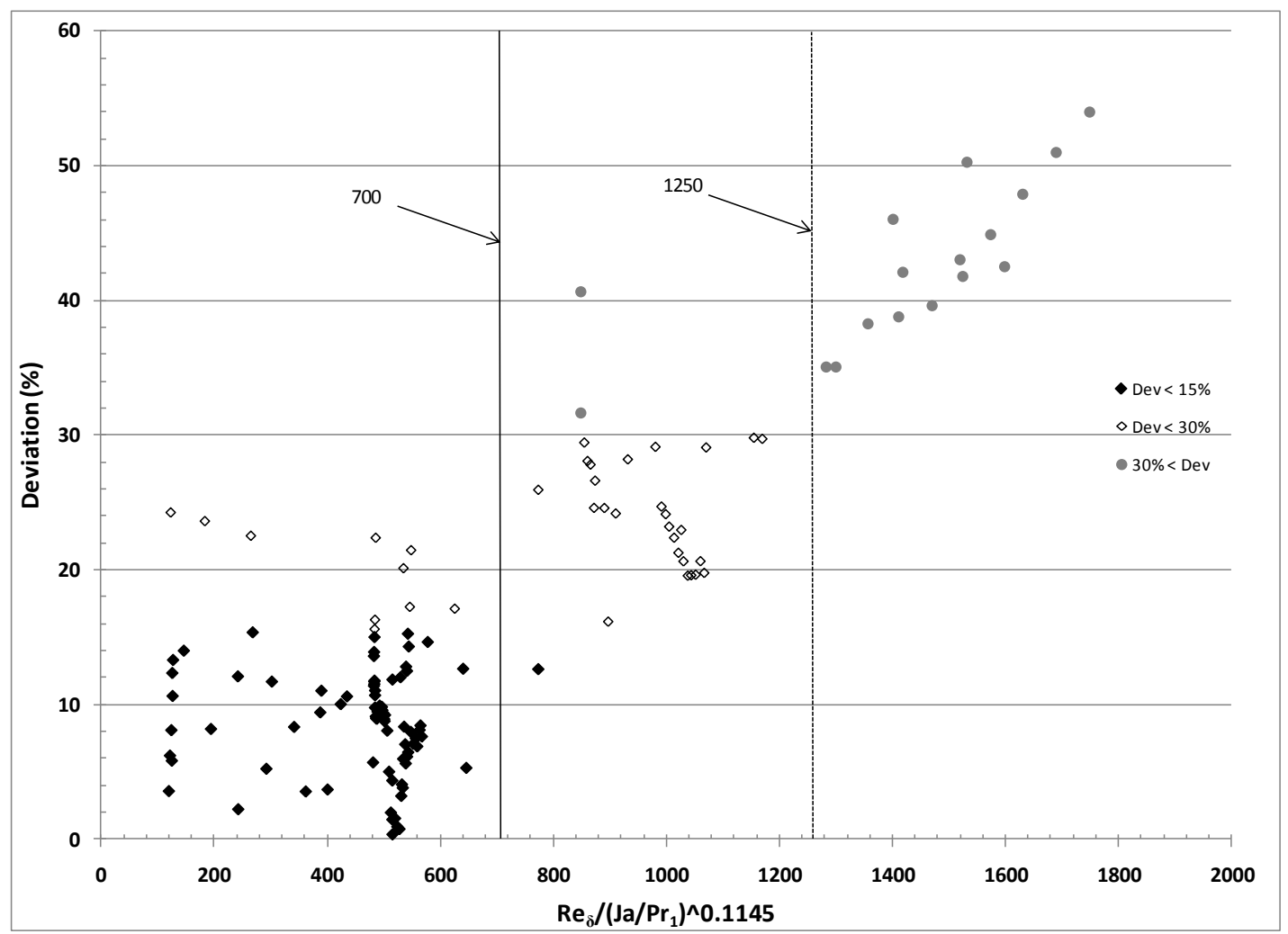

Figure 7.4: Plot of discrepancy against inlet parameter $\left(\operatorname{Re}_{\delta \mid x=x_{F C}}\right) /\left(J a / P r_{1}\right)^{0.1145}$ at $x=x_{F C}$. The solid black diamond points show less than $15 \%$ deviation from the idealized theory. The hollow diamond points show experimental heat transfer coefficient values higher by $15 \%-30 \%$ and the hollow circular points show that the experimental heat transfer values were greater than $30 \%$ with respect to the idealized theoretical estimates.

\subsection{Reasons for Deviations and Suggested Modeling for}

\section{Wavy and Turbulent Annular Flows}

Based on the above results, it is likely that, as and when one has access to experimentally measured "local" values of heat transfer coefficient $h_{x}$, or heat flux $\mathrm{q}_{\mathrm{w}}^{\prime \prime}(\mathrm{x})$, then one could use - in conjunction with the existing steady ${ }^{6}$ and a full unsteady simulation capability being developed by our group (as in Kulkarni ${ }^{32}$ ) - a local interfacial vapor Reynolds number $\operatorname{Re}_{\mathrm{VL}}(\mathrm{x})$ to characterize local transition from smooth interface steady laminar/laminar conditions to significant interfacial waviness without turbulence 
as well as significant waviness with turbulence. This number is defined here as $\operatorname{Re}_{\mathrm{VL}}(\mathrm{x}) \equiv \rho_{2}\left\{\mathrm{Uu}_{\mathrm{f}}(\mathrm{x})\right\}^{2} / \tau^{\mathrm{i}}$ where, as in Mitra, ${ }^{6}\left\{\mathrm{Uu}_{\mathrm{f}}(\mathrm{x})\right\}$ and $\tau^{\mathrm{i}}$ are, respectively, timeaveraged mean of the physical values of interfacial speed and shear stress. Because the condensate continues to speed up under gravity, the same number $\operatorname{Re}_{\mathrm{VL}}(\mathrm{x})$ can also be used to characterize subsequent transition to near-interface vapor/liquid turbulence. This parameter $\operatorname{Re}_{\mathrm{VL}}(\mathrm{x})$ is also the reciprocal of the much sought after interfacial friction factor $\mathrm{f}(\mathrm{x}) \equiv \tau^{\mathrm{i}} / \rho_{2}\left\{\mathrm{Uu}_{\mathrm{f}}(\mathrm{x})\right\}^{2}$ whose non-dimensional definitions as well as models vary in the literature (see Narain et al. ${ }^{42}$ ).

From the one-dimensional smooth-interface laminar/laminar theory presented in Mitra, ${ }^{6}$ we know that the flow is predictable in terms of three variables viz., nondimensional interfacial speed $\mathrm{u}_{\mathrm{f}}(\mathrm{x})$, non-dimensional film thickness $\delta(\mathrm{x})$, and nondimensional pressure gradient $\mathrm{d} \pi(\mathrm{x}) / \mathrm{dx}$. This is done in Mitra ${ }^{6}$ with the help of an appropriate approximate model for friction factor $f$ and, concurrently, a model for the vapor momentum flux (with the interfacial shear from the vapor profile preferably matching the value from the interfacial shear model) through their known explicit functional dependence on the non-dimensional variables: $\mathrm{u}_{\mathrm{f}}(\mathrm{x}), \delta(\mathrm{x})$, and $\mathrm{d} \pi(\mathrm{x}) / \mathrm{dx}$. The approximate explicit analytical model for $\mathrm{f}(\mathrm{x})$ in the 1-D approach ${ }^{6}$ is easily obtained from using the thin film, laminar/laminar flow, and negligible inertia assumptions leading to condensate profile given by Equation (7) of Mitra. ${ }^{6}$ Utilizing this profile and setting $\tau^{\mathrm{i}}$ $\left(\equiv \rho_{2} \mathrm{U}^{2} \cdot \mathrm{u}_{\mathrm{f}}^{2}(\mathrm{x}) \cdot \mathrm{f}(\mathrm{x})\right)$ equal to its value in terms of interfacial velocity gradient $\tau^{\mathrm{i}} \equiv$ $\mu_{1} \mathrm{U} / \mathrm{D} \cdot \partial \mathrm{u}_{1} /\left.\partial \mathrm{y}\right|^{\mathrm{i}}$, one obtains an explicit model for $\mathrm{f}(\mathrm{x}) \equiv 1 / \operatorname{Re}_{\mathrm{V}}(\mathrm{x})$. The resulting explicit model/relationship for the friction factor $\mathrm{f}(\mathrm{x})$ is:

$$
u_{f}^{2}(x) \cdot f(x)=\left[u_{f}(x)-\left\{\left(-d \pi(x) / d x+\rho_{1} / \rho_{2} \cdot F_{x}^{-1}\right) \cdot \operatorname{Re}_{i n}\right\} \delta^{2}(x) \cdot(1 / 2) \cdot\left(\mu_{2} / \mu_{1}\right)\right] \cdot\left[\frac{2}{\delta(x)} \cdot \frac{\mu_{1}}{\mu_{2}}\right]
$$

This functional dependence for $\mathrm{f}(\mathrm{x})$ exhibits the general dependence on the three $\mathrm{x}$-dependent non-dimensional flow variables of $\mathrm{u}_{\mathrm{f}}(\mathrm{x}), \delta(\mathrm{x})$, and $\mathrm{d} \pi / \mathrm{dx}(\mathrm{x})$ along with dependence on the non-dimensional constant parameters: $\rho_{2} / \rho_{1}, \mu_{2} / \mu_{1}, \operatorname{Re}_{\text {in }}$, and Fr-1x. This formulation as well as the model for $\mathrm{f}(\mathrm{x}) \equiv 1 / \operatorname{Re}_{\mathrm{VL}}(\mathrm{x})$ can also be equivalently obtained in terms of three other suitable variables, such as: non-dimensional interfacial speed $\mathrm{u}_{\mathrm{f}}(\mathrm{x})$, non-dimensional film thickness $\delta(\mathrm{x})$, and non-dimensional local condensate 
Reynolds number $\operatorname{Re}_{\delta}(\mathrm{x}) \equiv 4 \dot{\mathrm{M}}_{\mathrm{L}}(\mathrm{x}) / \pi \mathrm{D} \mu_{1}$ (where $\dot{\mathrm{M}}_{\mathrm{L}}(\mathrm{x})$ is the physical value of the local condensate mass flow rate).

For the gravity dominated flow runs (as defined in Mitra ${ }^{6}$ ) that are experimentally considered in Figures 6.4 - 7.2 above, the condensate motion is approximately characterized by the Nusselt solution ${ }^{2}$ for a range of inlet flow rates and one can either use the 1-D theory in Mitra ${ }^{6}$ or use the single degenerate ordinary differential equation in $\delta(\mathrm{x})$ (given in Nusselt ${ }^{2}$ ) to obtain the Nusselt solution that yields $\delta(\mathrm{x})$ as well as $\mathrm{u}_{\mathrm{f}}(\mathrm{x})$ and $\operatorname{Re}_{\delta}(\mathrm{x})$. In this degenerate gravity dominated limit, vapor momentum balance is completely independent of the condensate motion (and need not be solved if the interest is in the condensate motion alone) and vapor mass balance yields the variations in the average value of the vapor speed. This degeneracy for gravity dominated flows arise from the fact that interfacial shear $\tau^{\mathrm{i}}$ or $\mathrm{u}_{\mathrm{f}}^{2}(\mathrm{x}) \cdot \mathrm{f}(\mathrm{x})$ is nearly zero relative to wall shear. Yet one can use the full 1-D solution scheme (in Mitra $^{6}$ ) to obtain the still negligible values of $\mathrm{u}_{\mathrm{f}}^{2}(\mathrm{x}) \cdot \mathrm{f}(\mathrm{x})$ up to a certain $\mathrm{x}=\mathrm{x}^{*}$ and this is done and resulting values of a gradually increasing $\operatorname{Re}_{\mathrm{VL}}(\mathrm{x})=1 / \mathrm{f}(\mathrm{x})$ is schematically (i.e. not to scale) shown in Figure 7.5. However, downstream of a certain $\mathrm{x}=\mathrm{x}^{*}$, finite amplitude instability induced waves develop. ${ }^{6,41}$ In the zone $\mathrm{x}>\mathrm{x} *$, interfacial shear $\tau^{\mathrm{i}}$ or $\mathrm{u}_{\mathrm{f}}^{2}(\mathrm{x}) \cdot \mathrm{f}(\mathrm{x})$ is significantly non-zero and should not be ignored. The value of $x^{*}$ itself can be obtained by more detailed experiments or by the unsteady computational approaches described in Narain ${ }^{30}$ and Kulkarni. ${ }^{32}$ Once $\mathrm{x}^{*}$ is obtained, one can still use the full 1-D solution scheme ${ }^{6}$ to obtain the still negligible values of $\mathrm{u}_{\mathrm{f}}^{2}\left(\mathrm{x}^{*}\right) \cdot \mathrm{f}\left(\mathrm{x}^{*}\right)$. If one has to match the negligible shear behavior for $\mathrm{x} \approx \mathrm{x}^{*}$ to the wave-induced non-negligible shear behavior for $\mathrm{x}>\mathrm{x}$, one must discard the Nusselt model for the condensate velocity profile and use the one given by Equation (7) in Mitra. ${ }^{6}$ For $\mathrm{x}>\mathrm{x}^{*}$, one can set $\mathrm{u}_{\mathrm{f}}{ }^{2}(\mathrm{x}) \cdot \mathrm{f}(\mathrm{x})=\mathrm{w}(\mathrm{x}) \cdot \mathrm{u}_{\mathrm{f}}{ }^{2}\left(\mathrm{x}^{*}\right) \cdot \mathrm{f}\left(\mathrm{x}^{*}\right)$ where $\mathrm{w}(\mathrm{x})>1$ is an empirically/computationally knowable function of $\mathrm{x}$ that can be determined to model the wave-enhanced interfacial shear so as to make the predicted mean values of the flow variables (such as mean film thickness and wall heat-flux) agree with their experimentally measured values for $x>x^{*}$. Finding " $w(x)$ " or " $f(x)$ " this way will be far superior to ad hoc modeling of interfacial shear. ${ }^{42}$ 


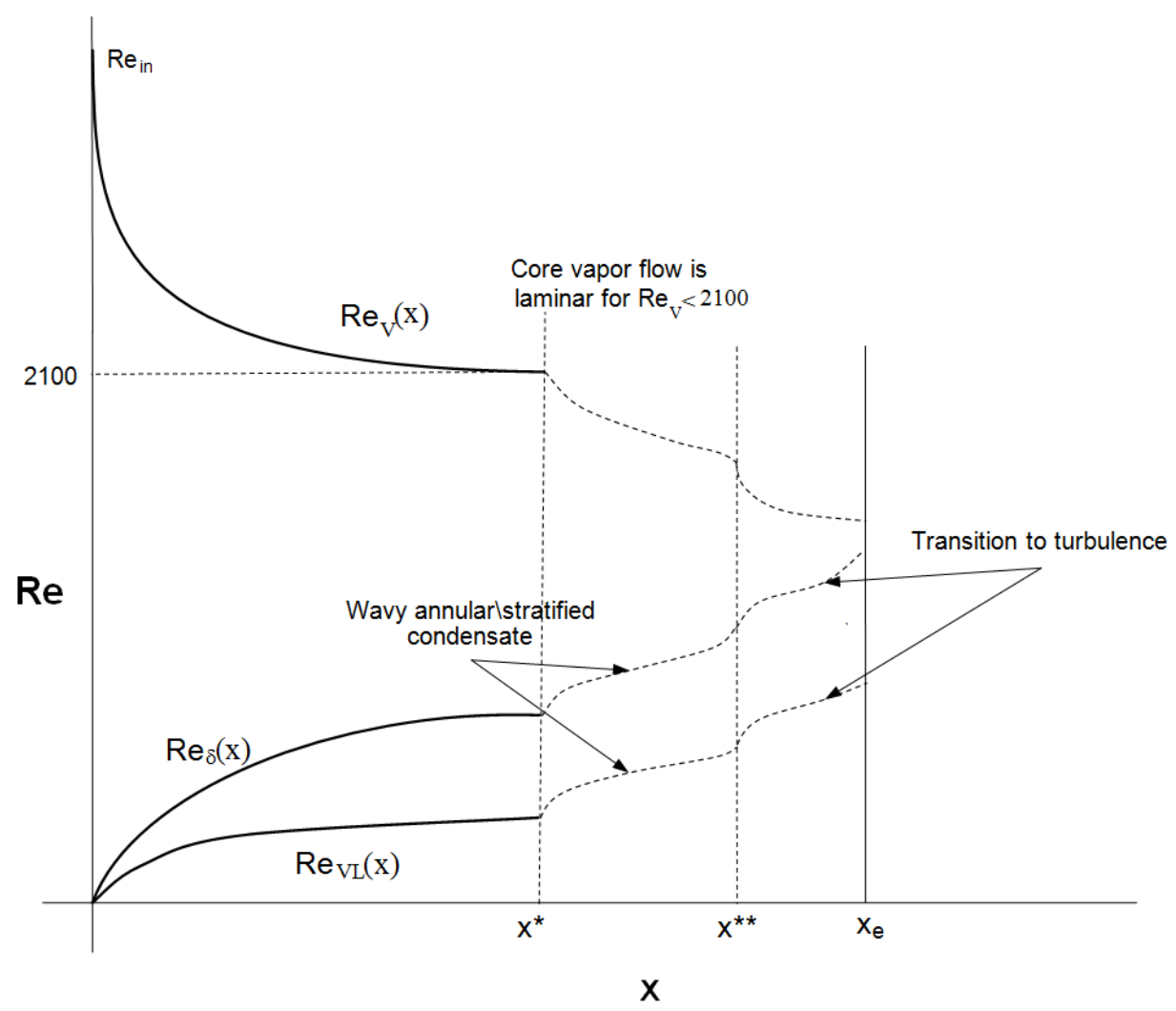

Figure 7.5: For modeling heat transfer enhancement greater than $15 \%$, the figure shows the schematic of variations, with distance $x$, for the near interface vapor turbulence parameter $\operatorname{Re}_{\mathrm{VL}}(\mathrm{x})$, vapor flow $\operatorname{Reynolds}$ number $\operatorname{Re}_{\mathrm{V}}(\mathrm{x})$, and the condensate Reynolds number $\operatorname{Re}_{\delta}(\mathbf{x})$.

The knowledge of $\mathrm{u}_{\mathrm{f}}^{2}(\mathrm{x}) \cdot \mathrm{f}(\mathrm{x})$ from 1-D theory ${ }^{6}$ for $\mathrm{x}<\mathrm{x}^{*}$ along with its modification $\mathrm{u}_{\mathrm{f}}^{2}(\mathrm{x}) \cdot \mathrm{f}(\mathrm{x})=\mathrm{w}(\mathrm{x}) \cdot \mathrm{u}_{\mathrm{f}}^{2}\left(\mathrm{x}^{*}\right) \cdot \mathrm{f}\left(\mathrm{x}^{*}\right)$ for $\mathrm{x}>\mathrm{x}^{*}$, can be used to express the pressure gradient $\mathrm{d} \pi(\mathrm{x}) / \mathrm{dx}$ as a function of $\mathrm{u}_{\mathrm{f}}(\mathrm{x})$ and $\delta(\mathrm{x})\left(\right.$ or $\left.\operatorname{Re}_{\delta}(\mathrm{x})\right)$ for $\mathrm{x}>\mathrm{x} *$. This suggested modification of the 1-D scheme for $\mathrm{x}>\mathrm{x} *$ would only allow two unknown independent variables ( say $\mathrm{u}_{\mathrm{f}}(\mathrm{x})$ and $\delta(\mathrm{x})$ or $\mathrm{u}_{\mathrm{f}}(\mathrm{x})$ and $\operatorname{Re}_{\delta}(\mathrm{x})$ ) in the modeling and solution for $\mathrm{x}>\mathrm{x}^{*}$. This is a natural outcome of using an empirically obtained function $\mathrm{w}(\mathrm{x})$ to replace one of the unknowns ( formulation and solution (not done here) of the problem for $\mathrm{x}>\mathrm{x} *$ in terms of the two chosen variables (say $\mathrm{u}_{\mathrm{f}}(\mathrm{x})$ and $\operatorname{Re}_{\delta}(\mathrm{x})$ ) can be used to show that, as $\mathrm{x}$ approaches $\mathrm{x}^{*}$ in Figure 7.5, the value of $\operatorname{Re}_{\mathrm{VL}}(\mathrm{x})$ approaches a certain critical constant value of $\left.\mathrm{Re}_{\mathrm{VL}}\right|_{\mathrm{Cr}-1}$. 
The trends of $\operatorname{Re}_{\mathrm{VL}}(\mathrm{x}), \operatorname{Re}_{\delta}(\mathrm{x}), \mathrm{Re}_{\mathrm{in}}(\mathrm{x})$, in Figure 7.5 for $\mathrm{x}<\mathrm{x} *$ is for a specific gravity dominated flow situation and is representative (though not to scale) of the trends obtained by the solution scheme described in Mitra ${ }^{6}$. The trends in Figure 7.5 for the laminar/laminar wavy zone over $\mathrm{x}^{*} \leq \mathrm{x} \leq \mathrm{x} * *$ and the turbulent/turbulent wavy zone for $\mathrm{x}$ $\geq \mathrm{x}^{* *}$ are entirely schematic and need to be obtained with the help of sufficient experimental input and the modeling approach suggested in the previous paragraph. In Figure 7.5, the suggested trend of the parameter $\operatorname{Re}_{\mathrm{VL}}(\mathrm{x})$ for $\mathrm{x}<\mathrm{x}^{*}$ denotes nearly smooth interface steady laminar/laminar conditions, $\operatorname{Re}_{\mathrm{VL}}(\mathrm{x})>\left.\operatorname{Re}_{\mathrm{VL}}\right|_{\mathrm{Cr}-1}$ for $\mathrm{x}>\mathrm{x} *$ denotes significant laminar/laminar waviness in the near interface zone, and $\operatorname{Re}_{\mathrm{VL}}(\mathrm{x})>$ $\left.\operatorname{Re}_{\mathrm{VL}}\right|_{\mathrm{Cr}-2}$ for $\mathrm{x}>\mathrm{x} * *$ denotes significant turbulent/turbulent waviness in the near interface zone. The above suggested developments for gravity dominated flows will also yield proper models for the interfacial shear $\tau^{\mathrm{i}}$ (or $\mathrm{f}$ ) and would make the existing models and one dimensional analysis much more reliable outside the currently available ${ }^{6}$ laminar/laminar smooth interface zone.

With the above understanding of $\operatorname{Re}_{\mathrm{VL}}(\mathrm{x})$, we see that the parameter zone characterized by Equation (7.1) above is one for which the ratio $\mathrm{x} / \mathrm{x}_{\mathrm{FC}}$ dominates the ratio $\left(\mathrm{x}_{\mathrm{FC}}-\mathrm{x}^{*}\right) / \mathrm{x}_{\mathrm{FC}}$, the parameter zone characterized by Equation (7.2) above is one for which the ratios $\left(\mathrm{x}_{\mathrm{FC}}-\mathrm{x}^{*}\right) / \mathrm{x}_{\mathrm{FC}}$ and $\mathrm{x} * / \mathrm{x}_{\mathrm{FC}}$ are comparable in magnitude, and the parameter zone characterized by Equation (7.3) above is one for which the ratio $\left(\mathrm{x}_{\mathrm{FC}}-\right.$ $\left.\mathrm{x}^{*}\right) / \mathrm{x}_{\mathrm{FC}}$ starts dominating the ratio $\mathrm{x} / \mathrm{x}_{\mathrm{FC}}$.

It is reiterated that the above described synthesis of theory with experiments require experimental data on distances where transition to waviness and turbulence occur, mean local values of heat-flux in the wavy and turbulent condensate zone, etc. for different working fluids. As and when such a synthesis is achieved, one should be able to replace the numerical multipliers and exponents appearing in Equations (7.1) - (7.3) by multipliers and exponents that are functions of $G_{P}, \rho_{2} / \rho_{1}$, and $\mu_{2} / \mu_{1}$. Such a generalization of Equations (7.1) - (7.3), along with heat transfer co-efficient values obtained from a one dimensional theory (see Mitra ${ }^{6}$ ), will yield more reliable estimates of vertical in-tube 
condensation heat-transfer coefficients (for different working fluids) in the wavy and turbulent regimes. 


\section{Remarks on comparisons with well known correlations and recommendations}

As seen from the theory ${ }^{6,32}$ and notations defined in section - 3, the nondimensional numbers that affect these condensing flows can be represented by the set $\left\{\tilde{\mathrm{x}}=\mathrm{x} / \mathrm{D}, \mathrm{Re}_{\mathrm{in}}, \mathrm{G}_{\mathrm{P}}, \mathrm{Fr}_{\mathrm{y}}^{-1}, \mathrm{Ja} / \operatorname{Pr}_{1}, \rho_{2} / \rho_{1}, \mu_{2} / \mu_{1}\right\}$. Well known experimental correlations, ${ }^{2,19-}$ ${ }^{24}$ including those listed in Table 8.1, often replace the parameter set $\left\{\widehat{x} \equiv x / D, R_{i n}\right.$, $\left.\mathrm{Ja} / \operatorname{Pr}_{1}\right\}$ by $\left\{\operatorname{Re}_{\delta}(\mathrm{x}), \operatorname{Re}_{\mathrm{in}}, \mathrm{X}(\mathrm{x})\right\}$ where the condensate's film Reynolds number is $\operatorname{Re}_{\delta}(\mathrm{x}) \equiv 4 \dot{\mathrm{M}}_{\mathrm{L}}(\mathrm{x}) / \pi \mathrm{D} \mu_{1}$ and the local vapor quality is $\mathrm{X}(\mathrm{x}) \equiv \mathrm{Z}(\mathrm{x}) \equiv \dot{\mathrm{M}}_{\mathrm{V}}(\mathrm{x}) / \dot{\mathrm{M}}_{\text {in }}$. As a result of the above choices, one finds that most of the existing correlations, ${ }^{14-27}$ directly or indirectly use the non-dimensional parameter set: $\left\{X(x), \operatorname{Re}_{\delta}(x), \operatorname{Re}_{i n}, G_{P}, \rho_{2} / \rho_{1}, \mu_{2} / \mu_{1}\right\}$. One significant drawback of this choice of parameters is that even when a heat transfer correlation provides a reasonable order of magnitude estimate, the correlation itself is not useful for estimating the length of a condenser for a given heat load unless the correlation is supplemented by experimentally measured or analytically/computationally obtained (as is the case here) axial variation in quantities such as $\mathrm{X}(\mathrm{x}), \mathrm{Re}_{\delta}(\mathrm{x})$, etc. This drawback is not present for the explicit correlations (involving $\mathrm{x}$ ) presented in this thesis and Mitra ${ }^{6}$ for annular wavy gravity driven flows. 
Table 8.1: Representative coverage of the parameter space under different well known empirical or semi-empirical correlations.

\begin{tabular}{|c|c|c|c|c|c|c|c|}
\hline \multirow[t]{2}{*}{ Correlations } & \multicolumn{2}{|c|}{ Low $G_{p}$} & \multirow{2}{*}{$\begin{array}{l}\text { High } \\
G_{p}\end{array}$} & \multirow{2}{*}{$\begin{array}{l}\text { Low } \\
\operatorname{Re}_{\delta}\end{array}$} & \multirow{2}{*}{$\begin{array}{r}\text { High } \\
\operatorname{Re}_{\delta}\end{array}$} & \multirow{2}{*}{$\begin{array}{l}\text { Low } \\
\operatorname{Re}_{\text {in }}\end{array}$} & \multirow{2}{*}{$\begin{array}{l}\mathrm{High} \\
\mathrm{Re}_{\text {in }}\end{array}$} \\
\hline & Very Low & $\begin{array}{l}\text { Moderately } \\
\text { Low }\end{array}$ & & & & & \\
\hline $\begin{array}{l}\text { Proposals } \\
\text { based on this } \\
\text { paper }\end{array}$ & & & & & & & \\
\hline $\begin{array}{c}\text { Cavallini } \\
\text { [1974] }\end{array}$ & & & & & & & \\
\hline Shah [1979] & & & & & & & \\
\hline $\begin{array}{c}\text { Dobson \& } \\
\text { Chato[1998] }\end{array}$ & & & & & & & \\
\hline $\begin{array}{c}\text { Azer et.al } \\
\text { [971] }\end{array}$ & & & & & & & \\
\hline $\begin{array}{c}\text { Travis et.al } \\
\text { [1973] }\end{array}$ & & & & & & & \\
\hline $\begin{array}{l}\text { Soliman et.al } \\
\text { [1968] }\end{array}$ & & & & & & & \\
\hline $\begin{array}{c}\text { Cavallini } \\
\text { [2003] }\end{array}$ & & & & & & & \\
\hline
\end{tabular}

In actual practice, for a given fluid, the fluid parameter $\rho_{2} / \rho_{1}$ and $\mu_{2} / \mu_{1}$ do not affect the flow as much as the other parameters. Of these remaining parameters, the set $\left\{\mathrm{Re}_{\mathrm{in}}, \mathrm{G}_{\mathrm{p}}, \mathrm{Re}_{\delta}\right\}$ have a profound impact on the flow physics in the sense that together they determine: (i) certain well defined low to high ranges of $\mathrm{Re}_{\text {in }}$ for which the core vapor flow is turbulent over a significant length of the flow and it affects the pressuredifference across the two-phase region, (ii) certain well defined low, high, and intermediate ranges of values for $\mathrm{G}_{\mathrm{P}}{ }^{6}$ decides whether the flow is shear driven, gravity driven, or driven by a combination of shear and gravitational forces, and (iii) certain well defined low to high ranges of $\operatorname{Re}_{\delta}$ (also discussed in Equations (7.1) - (7.3)) determine whether or not the near-interface region of the condensate flow exhibits sufficient waviness (with or without turbulence).

The above discussion suggests that the parameters $\left\{\mathrm{Re}_{\mathrm{in}}, \mathrm{G}_{\mathrm{P}}, \mathrm{Re}_{\delta}\right\}$ in the header of Table 8.1 determine, loosely speaking, at least eight distinct pairs of permutations of these three parameters (e.g. \{high, low, low $\}$ ) that define different flow physics groups each of which require separate experimental and modeling attention. Of these, for purely 
shear driven flows, one typically does not need to consider high $\mathrm{Re}_{\delta}$ cases involving condensate turbulence as the condensate flows' $\mathrm{Re}_{\delta}$ is seldom as high as those for gravity driven flows (which may, see Incropera ${ }^{41}$, high $\mathrm{Re}_{\delta}$ in the range of 500-1000).

As seen in Table 8.1, the popular correlations in the literature, ${ }^{19-24}$ etc.) are developed over multiple flow physics groups because they attempt an ambitious synthesis of experimental data obtained for flows in vertical tubes, horizontal tubes, and horizontal to inclined channels. Even when an attempt is made (as in Cavallini ${ }^{24}$ ) to classify and propose different correlations for different flow regimes (annular, stratified, plug/slug, etc.), the correlations for annular flow rely heavily on horizontal tube data. Now horizontal tube annular flows require shear forces to dominate the effects of azimuthal component of gravity vector which requires relatively large $\mathrm{Re}_{\mathrm{in}}$ values (see $\mathrm{J}_{\mathrm{G}}>2.5$ criteria in Cavallini ${ }^{24}$ ) in an altogether different $\left\{\operatorname{Re}_{\text {in }}, G_{P}\right\}$ space as compared to vertical in-tube annular wavy flows considered here. Unlike high $\mathrm{Re}_{\text {in }}$ and low $\mathrm{G}_{\mathrm{p}}$ three dimensional flows in the correlations given in Cavallini, ${ }^{24}$ the flows considered here involve low $\mathrm{Re}_{\mathrm{in}}$ and high $\mathrm{G}_{\mathrm{p}}$ values that allow two-dimensional annular flows. As a result of the aforementioned reasons, even where the agreement between the experimentally obtained heat transfer coefficients in this paper and those obtained from related theoretical correlations ${ }^{6}$ are found to be good, the values obtained from other correlations of Shah, ${ }^{19}$ Cavallini,,${ }^{20,24}$ Dobson-Chato, ${ }^{21}$ Azer, ${ }^{23}$ Soliman ${ }^{22}$ and Travis ${ }^{43}$ are not as good (see Figure 8.1). The existing correlations can, at best, only provide an order of magnitude estimate of the average heat transfer coefficient. If higher accuracy correlations need to be developed, one must seek correlations for the specific physics based subgroups. 


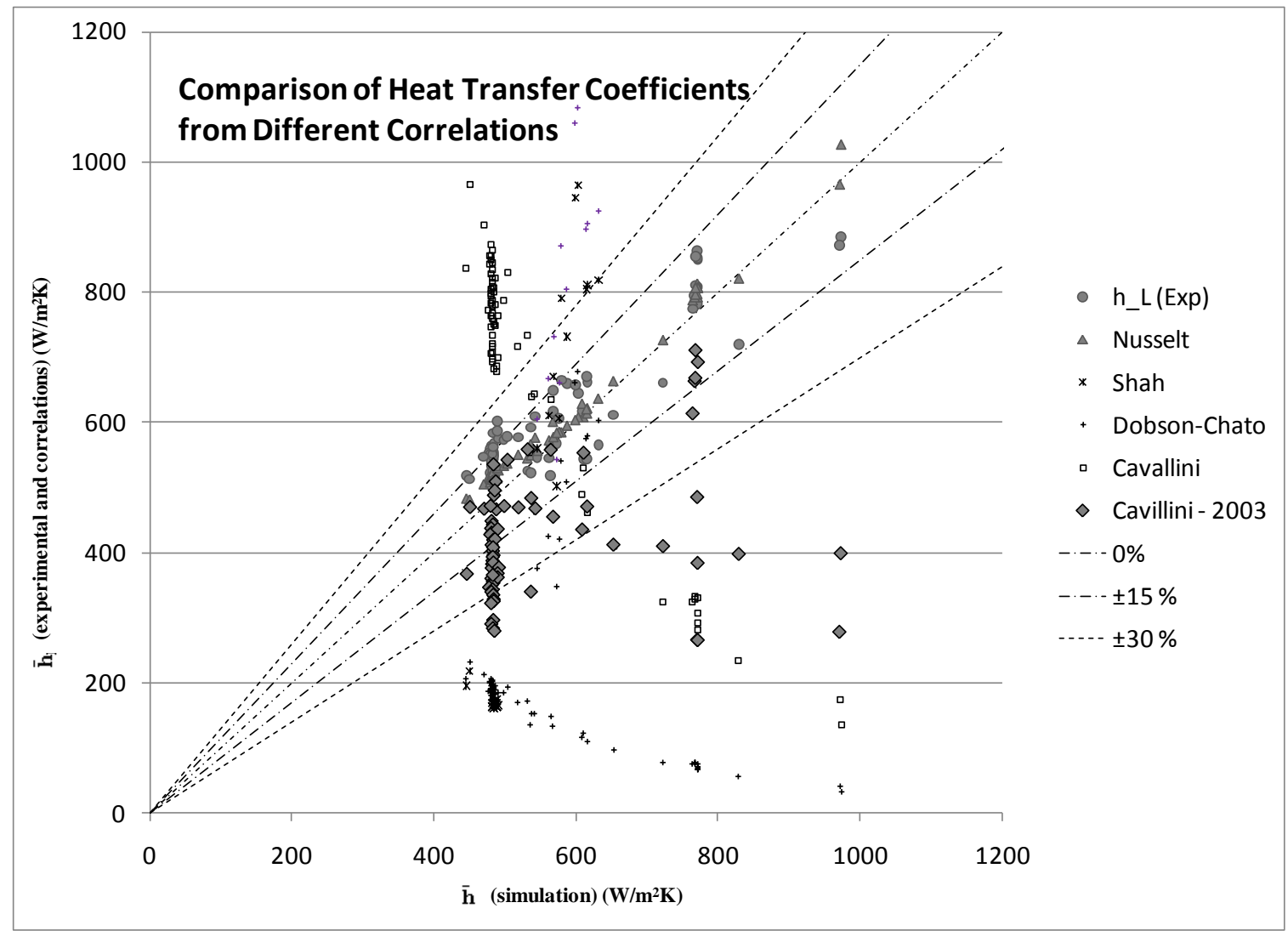

Figure 8.1: The figure shows a comparison of experimentally obtained heat transfer coefficient with heat transfer coefficients obtained from evaluating different correlations with the help of our simulation tool's predictions. ${ }^{6}$ The figure limits itself to assessing the efficacy of various correlations for the gravity dominated flows considered here.

As an example, the experiments and analysis ${ }^{6}$ are synthesized here to propose correlations that limit themselves (see the first row of Table 8.1) to a clear and sharp categorization of the boundaries among shear, gravity and mixed flow regimes within laminar vapor (low $\mathrm{Re}_{\text {in }}$ ) and laminar condensate (low $\mathrm{Re}_{\delta}$ ) flow regimes. Furthermore, as discussed in section 7, this paper also makes some contribution, through our experimental results, to define the boundary of this annular wavy flow regime where an assumption of smallness of wave effects and near-interface "laminarity" of the vapor and the condensate flows can be considered to be adequate. 
In Figures 7.1-7.2, most of the experimental data, that agree well (i.e. within 15\%) with the theoretical model in Mitra, ${ }^{6}$ are found to correspond to gravity dominated flows for which either the Nusselt correlations ${ }^{2}$ for high $G_{P}$ or "near" Nusselt correlations for moderate to high $G_{P}$ are adequate. As a result, for the data in the range specified by Equation (6.1), the following correlations can be used:

$$
\begin{aligned}
& \mathrm{q}_{\mathrm{w}}^{\prime \prime}(\mathrm{x})=\mathrm{h}_{\mathrm{x}} \Delta \mathrm{T} \\
& \mathrm{Nu}_{\mathrm{x}}=\mathrm{h}_{\mathrm{x}} \mathrm{D} / \mathrm{k}_{1} \cong 1 / \delta
\end{aligned}
$$

where, if $\mathrm{G}_{\mathrm{P}}$ is large and in the gravity dominated zone defined in Mitra, ${ }^{6}$ we have

$$
\mathrm{Nu}_{\mathrm{x}}=\left[4\left(\frac{\mathrm{Ja}}{\mathrm{Pr}_{1}}\right)\left(\frac{\tilde{\mathrm{x}}}{\mathrm{G}_{\mathrm{P}}}\right)\right]^{-1 / 4}
$$

and, if $G_{P}$ is in the moderate to large $G_{P}$ zone defined in Mitra, ${ }^{6}$ we have

$$
\mathrm{Nu}_{\mathrm{x}}=\left[\frac{0.748 \hat{\mathrm{x}}^{0.35}\left(\mathrm{Ja} / \mathrm{Pr}_{1}\right)^{0.361}\left(\rho_{2} / \rho_{1}\right)^{0.238}}{\operatorname{Re}_{\mathrm{in}}{ }^{0.353}\left(\mu_{2} / \mu_{1}\right)^{0.595}}\right]^{-1}
$$

For reasons discussed above, unlike the Shah, ${ }^{19}$ Cavallini, ${ }^{20}$ Cavallini, ${ }^{24}$ DobsonChato, ${ }^{21}$ Azer, ${ }^{23}$ Soliman $^{22}$ and Travis ${ }^{43}$ correlations in Figure 8.1, the specialized correlations given in Equations (8.1) - (8.4) - and restricted by Equations (6.1) and (7.1) are superior for this specific gravity driven annular wavy flow regime (also see Table 8.1). 


\section{Experimental results on differences between gravity and shear driven flows' boundary condition sensitivities}

\subsection{Background for Boundary-Condition Sensitivity Results}

New and careful theoretical and computational investigations ${ }^{6,32}$ show that purely shear driven flows exhibit a certain supercritical parabolic sensitivity to inlet pressure fluctuations. This sensitivity leads to quasi steady realization of condensing flows that have different independent impositions of pressures with suitable time variations (whether they are steady in the mean or not) is possible at the inlet and the exit while all other conditions (mass flow rate, condensing-surface thermal boundary condition associated with the cooling approach, etc.) remain quasi-steady at the same mean values. For purely shear driven quasi-steady flows, this parabolic-sensitivity has been demonstrated and it leads to different steady-in-the-mean pressure-difference impositions (through concurrent control of inlet and exit pressures in the presence of inlet pressure fluctuation). As a result of this sensitivity, the flow realizations (including heat transfer rates and condensing-surface temperatures) significantly change ${ }^{44,45}$ in response to different quasi-steady pressure-difference impositions. This thesis reports and summarizes our experimental finding that similar supercritical parabolic sensitivity does not exist for gravity dominated flows. That is, 'non-natural' elliptic pressure-difference impositions (different from self-selected, or "natural" pressure-difference) for the same inlet mass flow rate and coolant flow conditions could not be imposed for experimental realizations of gravity dominated flows in closed loop systems considered here. Whenever such non-natural pressure-difference and inlet pressure fluctuations are experimentally imposed on a vertical tube condenser, unlike the shear driven case in Kulkarni ${ }^{32}$ the flow variables within the test-section do not make direct adjustments but 
they may do so only because the other mechanical boundary condition (namely the quasisteady mass flow rate) also changes.

For the gravity dominated in-tube vertical annular flows considered here (see definition of gravity dominated in Mitra ${ }^{6}$ ), the condensate motion and the associated film thickness (interface location) is completely determined by gravity as they must follow the Nusselt solution. ${ }^{2}$ This makes the coupling between liquid motion and vapor motion unidirectional in the sense that the liquid motion dictates and achieves the kind of vapor motion that must be there in order to achieve the Nusselt ${ }^{2}$ type behavior for the condensate motion. Under these conditions, computational simulations (of the type reported in Kulkarni ${ }^{32}$ ) also fail to show that imposition of different quasi-steady exit pressure conditions is possible if the inlet conditions (i.e. mass flow rate $\dot{\mathrm{M}}_{\text {in }}$ and pressure $p_{\text {in }}$ at the inlet of the test section in Figure 9.1) as well as the condensing-surface cooling approach are kept steady/quasi-steady.

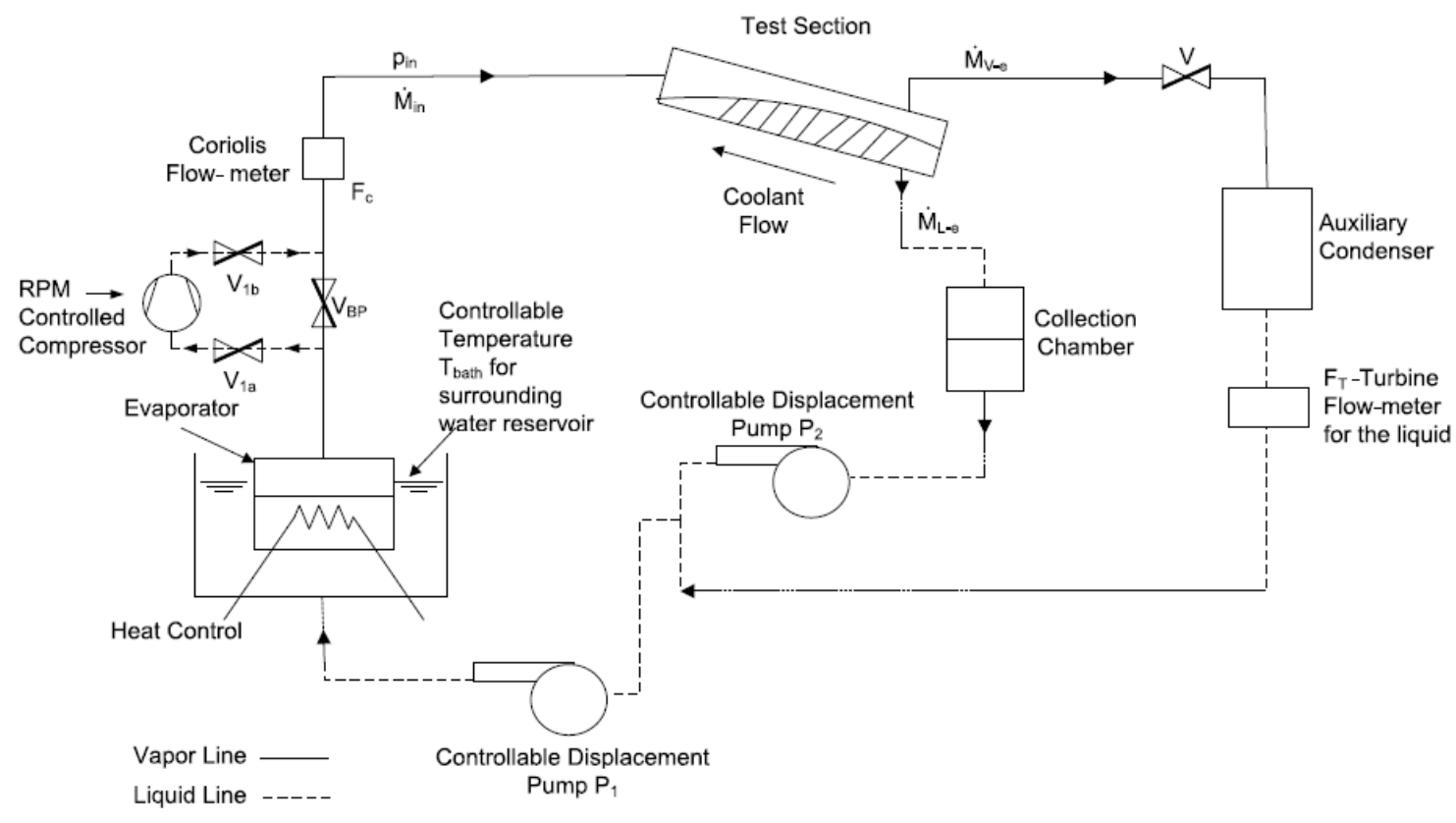

Figure 9.1: Flow loop arrangement for investigation of various boundary-condition sensitivities of internal partially or fully condensing flows (gravity or shear driven). 
In the next two sub-sections, we describe the experimental procedure and results for boundary condition sensitivity of gravity dominated flows.

\subsection{Procedure for Imposition of "Non-Natural" Pressure- difference for Vertical In-tube Flows}

For describing the experimental approach needed to assess the elliptic-sensitivity effect for fully condensing gravity driven flows, the flow loop in Figure 3.28 has been slightly modified, and this version is schematically shown in Figure 9.1. This set up is similar to the one used for shear driven flows, ${ }^{32}$ except that, for the reported experimental results, the evaporator does not have the water bath within which the evaporator in Figure 9.1 is immersed. The test-section in Figure 9.1 is the vertical tube test-section in Figure 3.23. In addition, there is an option to use a controllable compressor between the evaporator and the inlet of the test-section. Since the compressor is in a bypass loop, if the mass flow rate $\dot{\mathrm{M}}_{\text {in }}$ is fixed, the degree to which the compressor contributes energy and adjusts the mean value and fluctuation content of the inlet pressure $p_{\text {in }}$ of the vapor as it enters the test-section is adjusted by the control of the compressor's rotational speed (rpm) and through the level of opening/closing of the valve $\mathrm{V}_{\mathrm{BP}}$ in Figure 9.1.

First the self-sought "natural" pressure-difference for fully condensing flows is achieved using a variation of the procedure described in section 5.1. That is, for these fully condensing cases, the valve $\mathrm{V}$ in Figure 9.1 is closed and the pump $\mathrm{P}_{2}$ in Figure 9.1 is removed and eventually attained steady operating values of $\dot{\mathrm{M}}_{\mathrm{in}}, \mathrm{p}_{\mathrm{in}}$, and $\Delta \mathrm{T} \equiv$ $\mathrm{T}_{\mathrm{sat}}\left(\mathrm{p}_{\mathrm{in}}\right)-\overline{\mathrm{T}}_{\mathrm{W}}$ are such that the point of full condensation is within the test-section and the "Collection Chamber" in Figure 9.1 is filled with liquid. The first few steps for the procedure involve: (i) holding fixed the Coriolis mass flow meter $\mathrm{F}_{\mathrm{C}}$ reading of the mass flow rate $\dot{\mathrm{M}}_{\text {in }}$ by manually adjusting and fixing the electrical power supplied to the evaporator heating element, (ii) fixing the inlet pressure $p_{\text {in }}=p_{\text {in }} *$ with the help of the PID control of the rpm of the compressor, and (iii) arriving at one well defined steady condensing surface temperature $\mathrm{T}_{\mathrm{W}}(\mathrm{x})=\left.\mathrm{T}_{\mathrm{W}}(\mathrm{x})\right|_{\mathrm{Na}}$ through control on the primary coolant 
(water that flows along the outside surface of the internal refrigerant tube in the test section) flow rate and its temperature. (iv) The "natural" exit pressure $p_{\text {exit }}=\left.p_{\text {exit }}\right|_{\mathrm{Na}}$ is achieved (and sensed) by using the controllable displacement pump $\mathrm{P}_{1}$ to merely "track"

the liquid pumping rate through it and set it equal to Coriolis meter mass flow rate $\dot{\mathrm{M}}_{\mathrm{in}}$. (v) Then a new PID control is implemented on the pumping rate of pump $\mathrm{P}_{1}$, using feedback from the pressure sensor which measures $p_{\text {exit }}$, to maintain the same exit pressure $\left(\left.\mathrm{p}_{\text {exit }}\right|_{\mathrm{C}-1}=\left.\mathrm{p}_{\text {exit }}\right|_{\mathrm{Na}}\right)$. (vi) Afterwards, attempts are made to change the set point in the pump $\mathrm{P}_{1}$ 's PID control, to achieve various different "non-natural" ( $\neq\left.\mathrm{p}_{\text {exit }}\right|_{\mathrm{Na}}$ ) values of exit pressure $p_{\text {exit }}\left(\left.p_{\text {exit }}\right|_{\mathrm{C}-2},\left.p_{\text {exit }}\right|_{\mathrm{C}-3}\right.$, etc. $)$ while holding the inlet pressure at $\mathrm{p}_{\text {in }}=\mathrm{p}_{\mathrm{in}}{ }^{*}$. It is expected that, if quasi-steady non-natural pressure-difference impositions associated with exit pressure specifications $\left.\mathrm{p}_{\text {exit }}\right|_{\mathrm{C}-2},\left.\mathrm{p}_{\text {exit }}\right|_{\mathrm{C}-3}$, etc. are possible, eventually different quasisteady states should be reached for the fixed heater adjusted steady value of vapor mass flow rate $\dot{\mathrm{M}}_{\text {in }}$ (at the Coriolis-meter $\mathrm{F}_{\mathrm{C}}$ ).

\subsection{The Inability to Impose Quasi-steady "Non-natural" Pressure-Differences at a Fixed Quasi-steady Mass Flow Rate for Gravity Dominated Flows}

In the time duration $t_{1}$ to $t_{1}+20$ min (see Figures 9.2-9.3), the test section boundary conditions were constrained as indicated above such that the total test section pressure drop for case C-1 is in the vicinity of a "natural" case for the indicated mass flow rate $\dot{\mathrm{M}}_{\mathrm{in}}$, inlet pressure $\mathrm{p}_{\mathrm{in}}$, and wall temperature condition $\overline{\mathrm{T}}_{\mathrm{W}}$. Although the Na-1 case itself is not shown in Figures 9.2 and 9.3, many such natural cases have been obtained (including all of the experimental cases for the vertical tube condenser used in Figures 6.1 - 6.7) where it was observed, for representative cases, that long term quasisteady flow in the test-section is achieved along with a long term quasi-steady flow in the rest of the system. Therefore, although the time duration for case $C-1\left(t_{1} \leq t \leq t_{1}+20 \min \right)$ shown in Figures $9.2-9.3$ is not long enough to assure long term system steadiness outside of the test-section, based on our previous experience, it is expected that test- 
section ( $\left.\mathrm{p}_{\mathrm{in}}\right|_{\mathrm{C}-1},\left.\overline{\mathrm{T}}_{\mathrm{W}}\right|_{\mathrm{C}-1},\left.\dot{\mathrm{M}}_{\mathrm{in}}\right|_{\mathrm{C}-1}$, etc.) and other system flow variables would remain quasisteady at their depicted values.

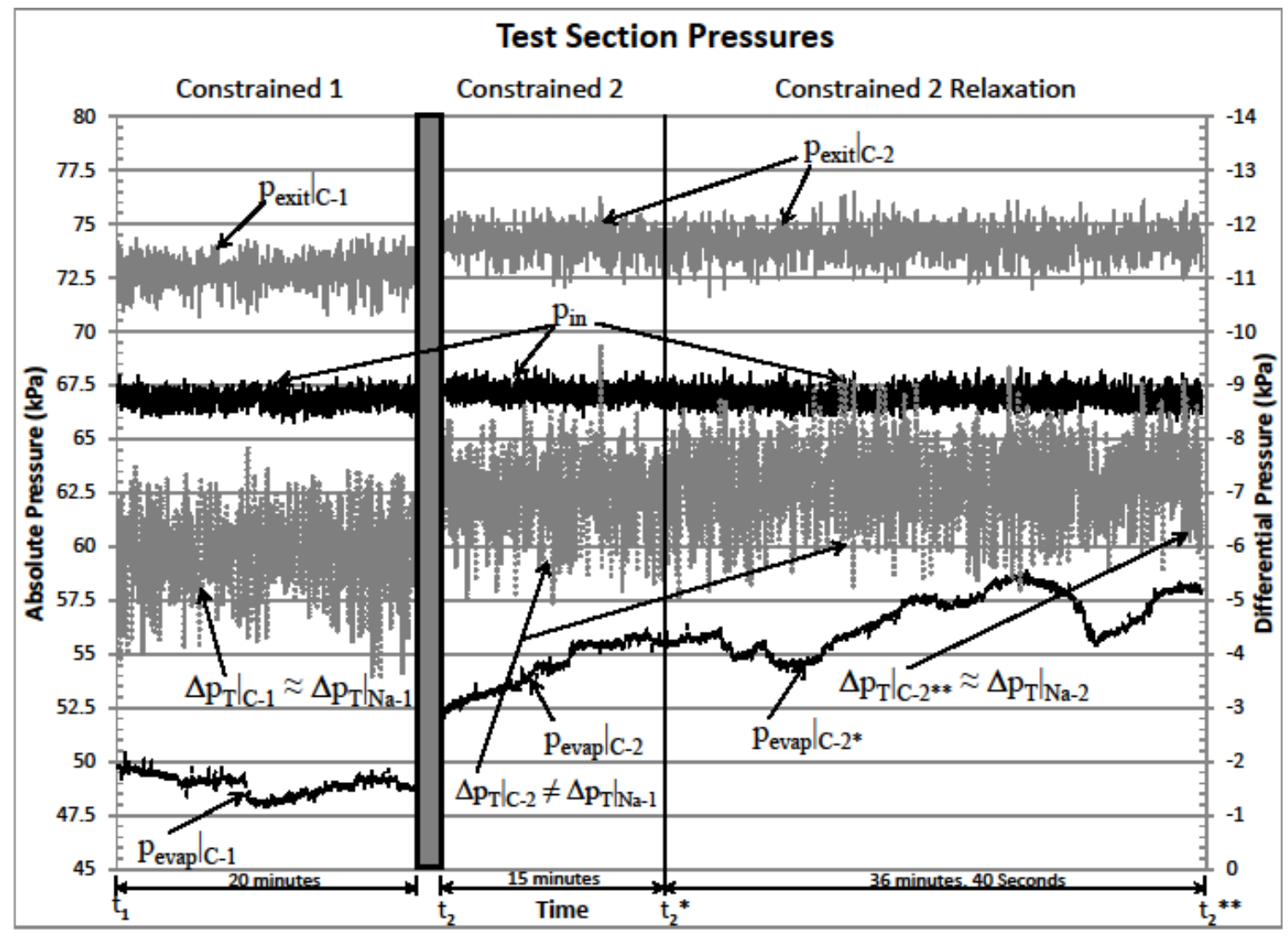

Figure 9.2: Representative experimental time histories for test-section and flow-loop pressures demonstrating inability of gravity driven internal condensing flows to achieve steady state (at a fixed inlet mass flow rate) under imposition of "nonnatural" pressure-difference values. 


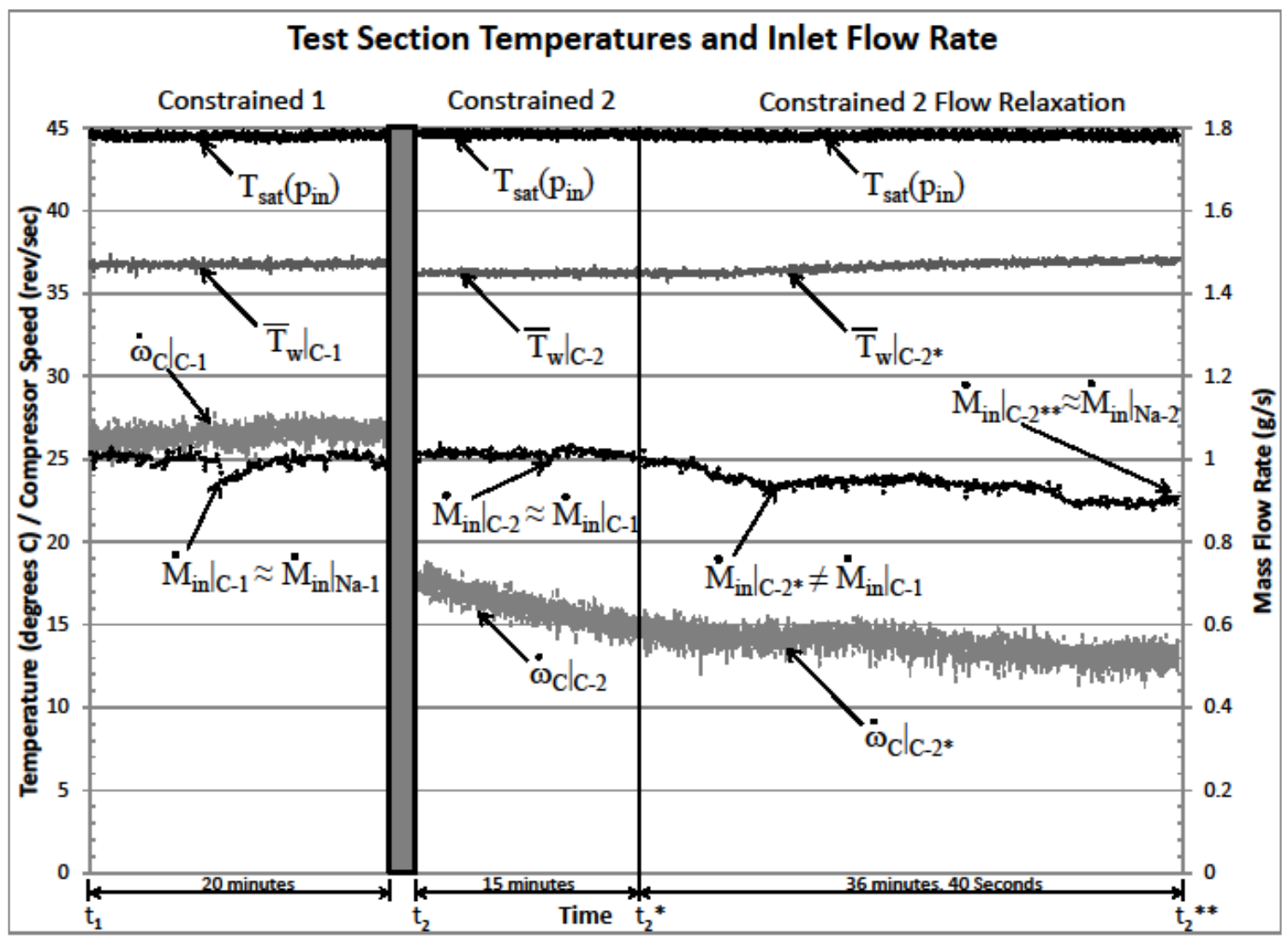

Figure 9.3: Representative experimental time histories for test-section and flow-loop temperatures, inlet flow rate, and compressor speed demonstrating inability of gravity driven internal condensing flows to achieve steady state (at a fixed inlet mass flow rate) under imposition of "non-natural" pressure-difference values. This data corresponds to the same periods of time over which the data in Figure 9.2 were obtained.

Between time $t_{1}+20$ min and time $t_{2}$, the exit pressure $\left(p_{\text {exit }}\right)$ boundary condition was shifted upward from $\left.p_{\text {exit }}\right|_{\mathrm{C}-1}$ to $\left.\mathrm{p}_{\text {exit }}\right|_{\mathrm{C}-2}$ (see Figure 9.2) by changing the set point on the pump $\mathrm{P}_{1}$ 's PID control, which resulted in a temporary slowing down of the liquid pumping rate to allow the level of the liquid in the test section to rise, thereby reducing the length of full condensation (not shown). Due to such an imposition, the inlet pressure 
$\left(\mathrm{p}_{\text {in }}\right)$ would normally rise to compensate for the adjustment and regain a natural $\Delta \mathrm{p}_{\mathrm{T}}$ $\left(\equiv \Delta \mathrm{p}\right.$ ); however, the compressor control on $\mathrm{p}_{\text {in }}$ prevented this from happening (see Figures 9.2-9.3). Instead, between time $t_{1}+20 \mathrm{~min}$ and time $\mathrm{t}_{2}$, the compressor PID control reduced the speed of the compressor, $\dot{\omega} \mathrm{C}$, relieving pressure at the inlet to keep it at the quasi-steady value of $p_{\text {in }}$ shown in Figure 9.2.

Case $\mathrm{C}-2$, from time $\mathrm{t}_{2}$ to time $\mathrm{t}_{2} *$ appears to have achieved a non-natural quasisteady value of $\left.\Delta \mathrm{p}_{\mathrm{T}}\right|_{\mathrm{C}-2} \neq\left.\Delta \mathrm{p}_{\mathrm{T}}\right|_{\mathrm{Na}-1}$ flow with other test section variables showing little to negligible shift in their mean values (note small shift down in wall temperature). However, unlike the case C-1 and Na-1, the flow outside of the test-section did not achieve any steady-state and this is shown (in Figure 9.3) by the unsteady compressor speed $\left.\dot{\omega}_{\mathrm{C}}\right|_{\mathrm{C}-2}$ and the evaporator pressure $\left.\mathrm{p}_{\text {evap }}\right|_{\mathrm{C}-2}$ over this time duration. An outcome of this unsteadiness is that, at time $t_{2}{ }^{*},\left.p_{\text {evap }}\right|_{\mathrm{C}-2}$ has shifted upward (see Figure 9.2) enough that the evaporation thermodynamics inside the evaporator has changed to prevent the evaporator from continuing to supply the mass flow rate of $\left.\left.\dot{\mathrm{M}}_{\text {in }}\right|_{\mathrm{C}-2} \approx \dot{\mathrm{M}}_{\text {in }}\right|_{\mathrm{C}-1}$; therefore, $\left.\dot{\mathrm{M}}_{\mathrm{in}}\right|_{\mathrm{C}-2}{ }^{*}$ reduces between time $\mathrm{t}_{2}{ }^{*}$ and time $\mathrm{t}_{2}{ }^{* *}$. During this time period, the values of $p_{\text {in }}$ and $p_{\text {exit }}$ are held fixed in the mean at $p_{\text {in }}$ and $\left.p_{\text {exit }}\right|_{-2}$, respectively, by the compressor and the liquid pump $\mathrm{P}_{1}$. Note from Figure 9.3 that $\left.\dot{\omega}_{\mathrm{C}}\right|_{\mathrm{C}-2} *$ is still going down between times $\mathrm{t}_{2}{ }^{*}$ and $\mathrm{t}_{2}{ }^{* *}$, but not as quickly as $\left.\dot{\omega}_{\mathrm{C}}\right|_{\mathrm{C}-2}$ between times $\mathrm{t}_{2}$ and $\mathrm{t}_{2}{ }^{*}$. Also note that pevap $\mid \mathrm{C}-2 *$ is still unsteady from time $\mathrm{t}_{2} *$ to time $\mathrm{t}_{2}{ }^{* *}$, although in the mean it is increasing more slowly than $\left.\mathrm{p}_{\text {evap }}\right|_{\mathrm{C}-2}$ between time $\mathrm{t}_{2}$ and time $\mathrm{t}_{2}{ }^{*}$. In addition, $\left.\overline{\mathrm{T}}_{\mathrm{W}}\right|_{\mathrm{C}-2}{ }^{*}$ changes to achieve a new steady value (nearly equal to $\left.\overline{\mathrm{T}}_{\mathrm{W}}\right|_{\mathrm{C}-1}$ at time $\mathrm{t}_{2}{ }^{* *}$ ) consistent with a changed new value of $\left.\dot{\mathrm{M}}_{\text {in }}\right|_{\mathrm{C}-2}{ }^{* *}$. Some time at or beyond time $\mathrm{t}_{2}{ }^{* *}$, the condensing flow in the test section would achieve a new natural case, case N-2 (not shown in Figures 9.2 -9.3) for which both the test-section and the system flow variables will be steady.

The key observation and difference from the shear driven case's ellipticsensitivity ${ }^{32}$ is that it was not possible to have $\dot{\mathrm{M}}_{\text {in }}\left|\mathrm{C}-2 * * \dot{\mathrm{M}}_{\text {in }}\right|_{\mathrm{C}-1}$ (at time $\mathrm{t}_{2}{ }^{* *}$ ) despite the evaporator heater's attempt to do so. In other words, the condensing flow did not readjust to accommodate a different $\Delta \mathrm{p}$ for the same $\dot{\mathrm{M}}_{\mathrm{in}}$. 
From the example reported above and additional experimentation (not reported here for brevity), the flow loop's response as to which mechanical boundary condition variables are shifted (mass flow rate $\dot{\mathrm{M}}_{\mathrm{in}}$, inlet pressure $\mathrm{p}_{\mathrm{in}}$, etc.) and which could be held fixed depended on the procedure used and relative strengths of different portions of the flow loop external to the test-section.

An intermediate response for "mixed" driven flows (see definition of "mixed" driven flow in Mitra $^{6}$ ) is expected and will be demonstrated by us when we redo the experiments in Kulkarni ${ }^{32}$ for slightly inclined channels.

The results presented here and in Mitra ${ }^{6}$ and Kulkarni ${ }^{32}$ correct some of our misunderstandings from Narain ${ }^{28,29}$ in which a non-existent control for fixing inlet pressure - combined with a non-functional sensing of the inlet pressure - caused us to erroneously confirm the incorrect conclusion (based on an earlier CFD code result which has since been corrected in Mitra $^{6}$ and Kulkarni ${ }^{32}$ ) that steady gravity dominated flows also exhibited elliptic-sensitivity. 


\section{Conclusions}

The results presented in this thesis achieved the following:

- Steady gravity driven condensing flows of pure FC-72 considered here were experimentally realized for gravity dominated situations and were found to lead to robust annular/stratified flows.

- The thesis establishes a range of conditions for which the flow is adequately modeled (within 15\%) by the laminar vapor/laminar condensate smooth-interface theory and associated correlations obtained in Mitra et al. ${ }^{6}$

- The thesis described an approach that allowed demarcation of the flow zones where near-interface vapor turbulence and near-interface condensate waviness interact to significantly enhance the heat transfer rates and reduce the length of full condensation as compared to the theory in Mitra. ${ }^{6}$

- The thesis recommends that higher accuracy heat transfer correlations, if desired, must be obtained by analysis and experiments that are specialized for a particular flow physics category of internal condensing flows (eight broad categories have been identified).

- The experimental results on boundary-condition sensitivity show that pure shear driven flows are parabolic with "elliptic-sensitivity" whereas gravity dominated flows are strictly "parabolic". 


\section{References}

1 Fox RW, McDonald RT. Introduction to Fluid Mechanics. 1973.

2 Nusselt W, Die Oberflachenkondensation des Wasserdampfes. Z. Ver. Deut. Ing. 1916.

3 Sparrow JL. A Boundary Layer Treatment of Laminar Film Condensation. Journal of Heat Transfer. 1959;(21):13-18.

4 Rohsenow WM. Heat Transfer and Temperature Distribution in Laminar Film Condensation. Transaction ASME. 1956;(78):1645.

5 Sadasivan JH. Sensible Heat Correction in Laminar Film Boiling and Condensation. Journal of Heat Transfer. 1987;(109):545-547.

6 Mitra S, Narain A, Naik R, Kulkarni SD. A Quasi One-Dimensional Simulation Method and its Results for Steady Annular/Stratified Shear and Gravity Driven Condensing Flows. International Journal of Heat and Mass Transfer. 2011;(54):37613776.

7 Kutateladze SS. Fundamentals of Heat Transfer. Academic Press; 1963.

8 Labuntsov DA. Heat Transfer in Film Condensation of Pure Steam on Vertical Surfaces and Horizontal Tubes. Teploenergetika. 1957;(4):72-80.

9 White FM. Heat and Mass Transfer. Addision-Wesley; 1988.

10 Soliman PJ. Flow Stability and Gravitational Effects in Condenser Tubes. Proceedings. $4^{\text {th }}$ International Heat Transfer Conference. 1970;(6):1-14.

11 Goodykoontz J H, Dorsch RG. Local Heat Transfer Coefficients for Condensation of Steam Vertical Down Flow within a 5/8-inch Diameter Tube. NASA TN D-3326; 1966.

12 Goodykoontz JH, Dorsch RG. Local Heat Transfer Coefficients and Static Pressures for Condensation of High-Velocity Steam within a Tube. NASA TN D-3953; 1967. 
13 Carpenter FG. Heat Transfer and Pressure Drop for Condensing Pure Vapors inside Vertical Tubes at High Vapor Velocities. PhD Thesis, University of Delaware, 1948.

14 Cavallini A, Zechchin R. High Velocity Condensation of R-11 Vapors inside Vertical Tubes. Heat Transfer in Refrigeration. 1971;385-396.

15 Jakob M. Heat Transmission. Wiley; 1949.

16 Akers WW, Rosson HF. Condensation inside a Horizontal Tube. Chemical Engineering Progress Symposium Series. 1960;(56)30:145-150.

17 Koh Y. Film Condensation in a Forced-Convection Boundary-Layer Flow. International Journal Heat Mass Transfer. 1962;(5) Issue 10:941-954.

18 Shekriladze IG, Gomelauri IV. Theoretical Study of Laminar Film Condensation of Flowing Vapor. International Journal Heat Mass Transfer. 1966;(9):581.

19 Shah MM. A General Correlation for Heat Transfer during Film Condensation inside Pipes. International Journal of Heat and Mass Transfer. 1979;(22):547-556.

20 Cavallini A, Smith JR, Zechchin R. A Dimensionless Correlation for Heat Transfer in Forced Convection Condensation. $6^{\text {th }}$ International Heat Transfer Conference. Tokyo, Japan; 1974;(3):309-313.

21 Dobson MK, Chato JC. Condensation in Smooth Horizontal Tubes. ASME Journal of Heat Transfer. 1998;193-213.

22 Soliman M, Schuster JR, Berenson PJ. A General Heat Transfer Correlation for Annular Flow Condensation. ASME Journal of Heat Transfer. 1968;267-276.

${ }^{23}$ Azer NZ, Abis LV, Swearinger TB. Local Heat Transfer Coefficients during Forced Convection Condensation inside Horizontal Tubes. Transactions ASHRAE. 1977;(77):182-201.

${ }^{24}$ Cavallini A, Gensi G, Del Col D, Doretti L, Longo GA, Rossetto L, Zilio C. Condensation Inside and Outside Smooth and Enhanced Tubes - A Review of Recent Research. International Journal of Refrigeration. 2003;(26):373-392.

25 Wu HY, Cheng P. Condensation Flow Patterns in Microchannels. International Journal of Heat and Mass Transfer. 2005;(48):286-297. 
26 Quan XJ, Cheng P, Wu HY. Transition from Annular to Plug/Slug Flow in Condensation in a Microchannel. International Journal of Heat and Mass Transfer. 2008;(51):707-716.

27 Coleman JW, Garimella S. Two-phase Flow Regimes in Round, Square, and Rectangular Tubes during Condensation of Refrigerant R134a. International Journal of Refrigeration. 2003;(26):117-128.

28 Narain A, Kulkarni SD, Mitra S, Kurita JH, Kivisalu M. Internal Condensing Flows in Terrestrial and Micro-Gravity Environments - Computational and Ground Based Experimental Investigations of the Effects of Specified and Unspecified (Free) Conditions at Exit, Interdisciplinary Transport Phenomenon. Annals of New York Academy of Sciences. 2009;(1161):321-360.

29 Narain A, Kurita JH, Kivisalu M, Kulkarni SD, Siemionko A, Ng TW, Kim N, Phan L. Internal Condensing Flows Inside a Vertical Pipe - Experimental/Computational Investigations of the Effects of Specified and Unspecified (Free) Conditions at Exit. ASME Journal of Heat Transfer. 2007;1352-1372.

30 Narain A, Liang Q, Yu G, Wang X. Direct Computational Simulations for Internal Condensing Flows and Results on Attainability/Stability of Steady Solutions, Their Intrinsic Waviness, and Their Noise-Sensitivity. Journal of Applied Mechanics. 2004;(71):69-88.

31 Phan L, Wang X, Narain A. Exit Condition, Gravity, and Surface-Tension Effects on Stability and Noise-sensitivity Issues for Steady Condensing Flows inside Tubes and Channels. International Journal of Heat and Mass Transfer. 2006;(49) Issues 1314:2058-2076.

32 Kulkarni SD, Narain A, Mitra S, Kivisalu M, Hasan MM. Exit-Condition Sensitivity for Shear and Gravity Driven Annular/Stratified Internal Condensing Flows. Accepted for publication in the International Journal of Transport Processes, 2010. 33 Carey VP. Liquid-Vapor Phase-Change Phenomena, Series in Chemical and Mechanical Engineering. Hemisphere Publishing Corporation; 1992. 
${ }^{34}$ Wedekind GL, Bhatt BL. An Experimental and Theoretical Investigation in to Thermally Governed Transient Flow Surges in Two-Phase Condensing Flow. ASME Journal of Heat Transfer. 1977; 99 (4):561-567.

35 Bhatt BL, Wedekind GL. Transient and Frequency Characteristics of Two-Phase Condensing Flows: With and Without Compressibility. ASME Journal of Heat Transfer. 1980; 102 (3):495-500.

36 Bhatt BL, Wedekind GL. A Self Sustained Oscillatory Flow Phenomenon in TwoPhase Condensing Flow Systems. ASME Journal of Heat Transfer. 1980; 102 (4):695-700.

37 Siemonko A. Design, Fabrication, and Operation of a System to Control FC-72 Condensation Inside a Vertical Tube. PhD Thesis, Michigan Technological University, 2006.

38 Kurita JH. Experimental Investigation of Fully Condensing Downward Vapor Flows in a Vertical Tube - Unspecified (Free) Exit Condition Cases. MS Thesis, Michigan Technological University, 2007.

39 Lu Q, Suryanarayana NV. Condensation of a Vapor Flowing inside a Horizontal Rectangular Duct. Journal of Heat Transfer. 1995;(117):418-424.

40 Holman P. Experimental Methods for Engineers. $6^{\text {th }}$ edition: McGraw Hill; 1994.

${ }^{41}$ Incropera FP, Dewitt DP. Fundamentals of Heat and Mass Transfer. $6^{\text {th }}$ edition: Wiley; 2006.

42 Narain A, Yu G, Liu Q. Interfacial Shear Models and Their Required Asymptotic Form for Annular Film Condensation Flows in Inclined Channels and Vertical Pipes. International Journal of Heat and Mass Transfer. 1997;(40):3559 - 3575.

43 Travis DP, Rohsenow WM, Baron AB. Forced Convection Inside Tubes: A Heat Transfer Equation for Condenser Design. ASHRAE Transactions. 1972;(79):157-165.

44 Kivisalu M, Narain A, Mitra S, Naik R. Prediction and Control of Internal Condensing Flows in the Context of their Inlet Sensitivities. Submitted (April 14, 2011) for publication in "Microgravity Science and Technology." Paper number: MGST-S-11-00047. 
45 Kivisalu M, Gorgitrattanagul N, Mitra S, Naik R, Narain A. Shear/Pressure Driven Internal Condensing Flows and their Sensitivity to Inlet Pressure Fluctuations.

Submitted for publication in Proceedings of IMECE 2011, 2011 ASME International Mechanical Engineering Congress and Exposition, November 11-17, 2011, Denver, Colorado, USA. 2011. 


\section{Appendix}

The reported error calculations involve three kinds of variables, namely: (i) measured variables $\mathrm{x}_{\mathrm{Mi}}(\mathrm{i}=1$ to $\mathrm{N} 0)$, (ii) handbook variables $\mathrm{x}_{\mathrm{Hi}}(\mathrm{i}=1$ to $\mathrm{N} 1)$ that report values of various fluid properties, and (iii) calculated variables $x_{\mathrm{Ci}}(i=1$ to $\mathrm{N} 2)$ that depend on other (measured, handbook, or calculated) variables. For the directly measured variables in Tables 5.1 to 8.1 , we have $\mathrm{N} 0=6$ with $\left\{\mathrm{x}_{\mathrm{M} 1} \equiv \dot{\mathrm{M}}_{\mathrm{in}}, \mathrm{x}_{\mathrm{M} 2} \equiv \mathrm{p}_{\mathrm{in}}, \mathrm{x}_{\mathrm{M} 3} \equiv \overline{\mathrm{T}} \mathrm{w}, \mathrm{x}_{\mathrm{M} 4}\right.$ $\left.\equiv p_{\text {exit }}=p_{x 9}, x_{M 5} \equiv \mathrm{D}, \mathrm{x}_{\mathrm{M} 6} \equiv \mathrm{L}\right\}$. The errors $\Delta \mathrm{x}_{\mathrm{Mi}}$ have been calculated by in house calibration experiments and/or values reconfirmed by the vendor of the instrument involved. These error values are: $\left\{\Delta \mathrm{x}_{\mathrm{M} 1}= \pm 0.05 \mathrm{~g} / \mathrm{s}, \Delta \mathrm{x}_{\mathrm{M} 2}= \pm 0.15 \mathrm{kPa}, \Delta \mathrm{x}_{\mathrm{M} 3}= \pm 0.9 \mathrm{oC}\right.$, $\left.\Delta \mathrm{x}_{\mathrm{M} 4}= \pm 0.27 \mathrm{kPa}, \Delta \mathrm{x}_{\mathrm{M} 5} \equiv \pm 0.5 \mathrm{~mm}, \Delta \mathrm{x}_{\mathrm{M} 6} \equiv \pm 0.001 \mathrm{~m}\right\}$. For the handbook variables in Tables 5.1 to 8.1, we have N1 = 7 with $\left\{\mathrm{x}_{\mathrm{H} 1} \equiv \rho_{1}, \mathrm{x}_{\mathrm{H} 2} \equiv \rho_{2}, \mathrm{x}_{\mathrm{H} 3} \equiv \mu_{1}, \mathrm{x}_{\mathrm{H} 4} \equiv \mathrm{C}_{\mathrm{p} 1}, \mathrm{x}_{\mathrm{H} 5} \equiv \mathrm{k}_{1}\right.$, $\left.\mathrm{x}_{\mathrm{H} 6} \equiv \mathrm{h}_{\mathrm{fg}}\left(\mathrm{p}_{\mathrm{ref}}\right), \mathrm{x}_{\mathrm{H} 7} \equiv \mathrm{T}_{\mathrm{sat}}\left(\mathrm{p}_{\mathrm{ref}}\right)\right\}$. For these variables, a nominal experimental error of $2 \%$ is assumed. That is the error $\Delta \mathrm{x}_{\mathrm{Hi}}= \pm 0.02 * \mathrm{x}_{\mathrm{Hi}}(\mathrm{i}=1$ to M1). For the calculated variables (some of them are reported in Table 5.1), we have $\mathrm{N} 2=13$ with $\left\{\mathrm{x}_{\mathrm{C} 1} \equiv \mathrm{T}_{\text {sat }}\left(\left.\mathrm{p}_{\text {in }}\right|_{\text {measured }}\right.\right.$ ), $\mathrm{x}_{\mathrm{C} 2} \equiv \mathrm{h}_{\mathrm{fg}}\left(\mathrm{p}_{\mathrm{in}}\right), \mathrm{x}_{\mathrm{C} 3} \equiv \Delta \mathrm{T}, \mathrm{x}_{\mathrm{C} 4} \equiv \Delta \mathrm{p}, \mathrm{x}_{\mathrm{C} 5} \equiv \rho_{2} / \rho_{1}, \mathrm{x}_{\mathrm{C} 6} \equiv \mu_{2} / \mu_{1}, \mathrm{x}_{\mathrm{C} 7} \equiv \mathrm{G}, \mathrm{x}_{\mathrm{C} 8} \equiv \mathrm{Re}, \mathrm{x}_{\mathrm{C} 9} \equiv \mathrm{Ja} / \operatorname{Pr}_{1}$, $\left.\mathrm{x}_{\mathrm{C} 10} \equiv \dot{\mathrm{Q}}_{\mathrm{out}},\left.\mathrm{x}_{\mathrm{C} 11} \equiv \overline{\mathrm{h}}\right|_{\mathrm{Expt}}, \mathrm{x}_{\mathrm{C} 12} \equiv \overline{\mathrm{q}^{\prime \prime}},\left.\mathrm{x}_{\mathrm{C} 13} \equiv \mathrm{x}_{\mathrm{FC}}\right|_{\text {Expt }}\right\}$. For all these calculated variables $\mathrm{x}_{\mathrm{Ci}}$, the defining equations are such that they can be reassembled to express their dependence only on the measured and handbook variables. As a result, one can express the dependences and errors for $\mathrm{x}_{\mathrm{Ci}}$ (assuming a random Gaussian variation in errors) as per the well known (Holman [35]) expressions:

$$
\mathrm{x}_{\mathrm{Ci}}=\mathrm{f}_{\mathrm{i}}\left(\mathrm{x}_{\mathrm{M} 1}, \mathrm{x}_{\mathrm{M} 2}, \ldots, \mathrm{x}_{\mathrm{MN} 0}, \mathrm{x}_{\mathrm{H} 1}, \mathrm{x}_{\mathrm{H} 2}, \ldots . ., \mathrm{x}_{\mathrm{HN} 1}\right)
$$

and

$$
\mathrm{x}_{\mathrm{Ci}}=\sqrt{\sum_{\mathrm{i}=1}^{\mathrm{N} 0}\left\{\left(\frac{\partial \mathrm{f}_{\mathrm{i}}}{\partial \mathrm{x}_{\mathrm{Mi}}}\right) \cdot \Delta \mathrm{x}_{\mathrm{Mi}}\right\}^{2}+\sum_{\mathrm{i}=1}^{\mathrm{N} 1}\left\{\left(\frac{\partial \mathrm{f}_{\mathrm{i}}}{\partial \mathrm{x}_{\mathrm{Hi}}}\right) \cdot \Delta \mathrm{x}_{\mathrm{Hi}}\right\}^{2}},
$$


where, $\mathrm{i}=1$ to $\mathrm{N} 2$, and each function $\mathrm{f}_{\mathrm{i}}$ is known as a single explicit function or a function given by a set of nested explicit functions. Because of these explicit forms of $f_{i}$, (unlike situations where $f_{i}$ itself is approximately known with some statistical uncertainty), their derivatives and their values in Equation (A.2) are easily calculated for each $\mathrm{x}_{\mathrm{Ci}}$ for any given run in Table 5.1. 


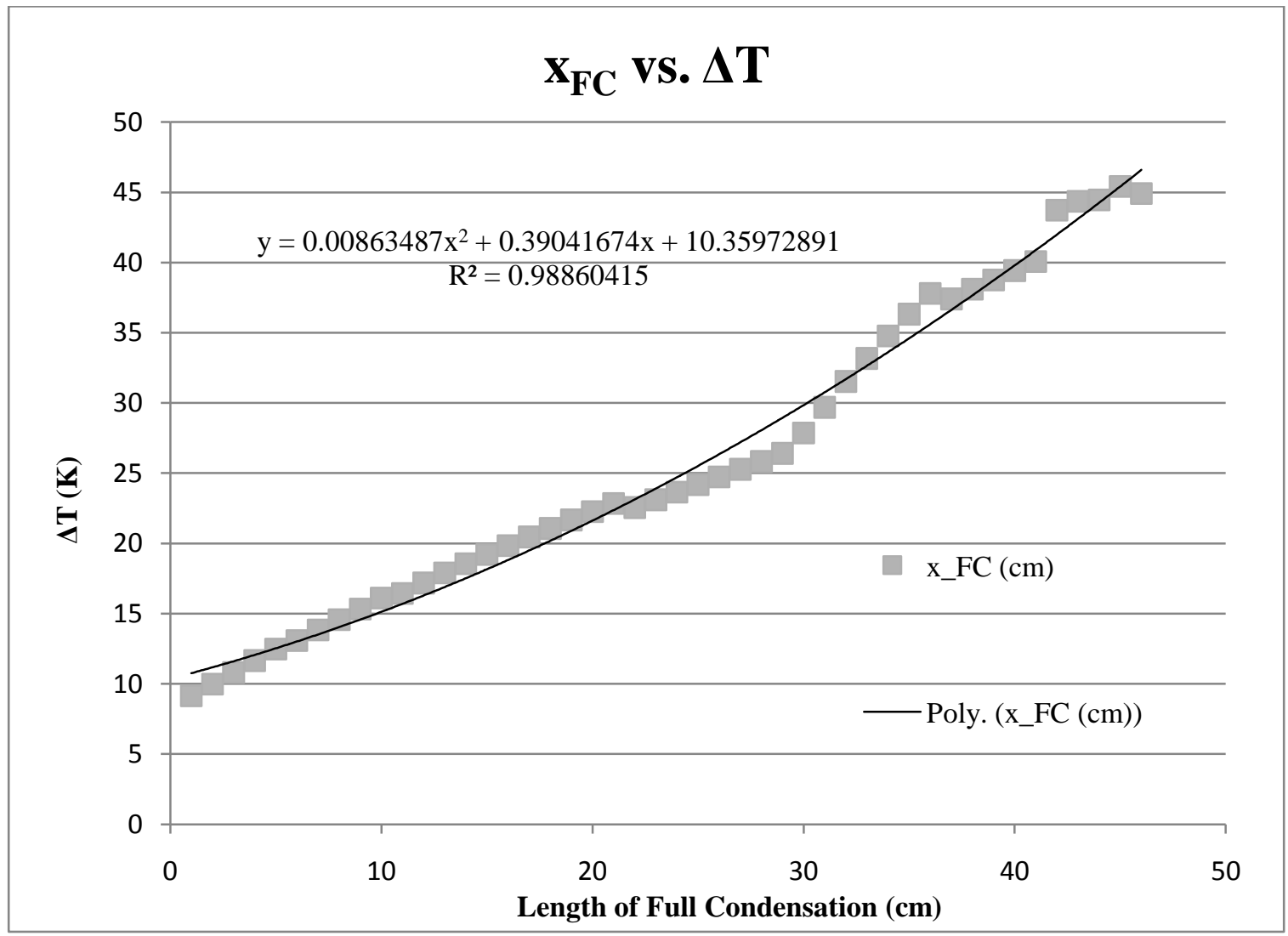

Figure A.1: In this chart, data from a particular full or complete condensation case is shown. Having the inlet mass flow rate actively fixed at 1.0 gram per second the inlet pressure was actively changed through a range of values. These changes of pressures effectively were describing different temperature differences or $\Delta T$. 


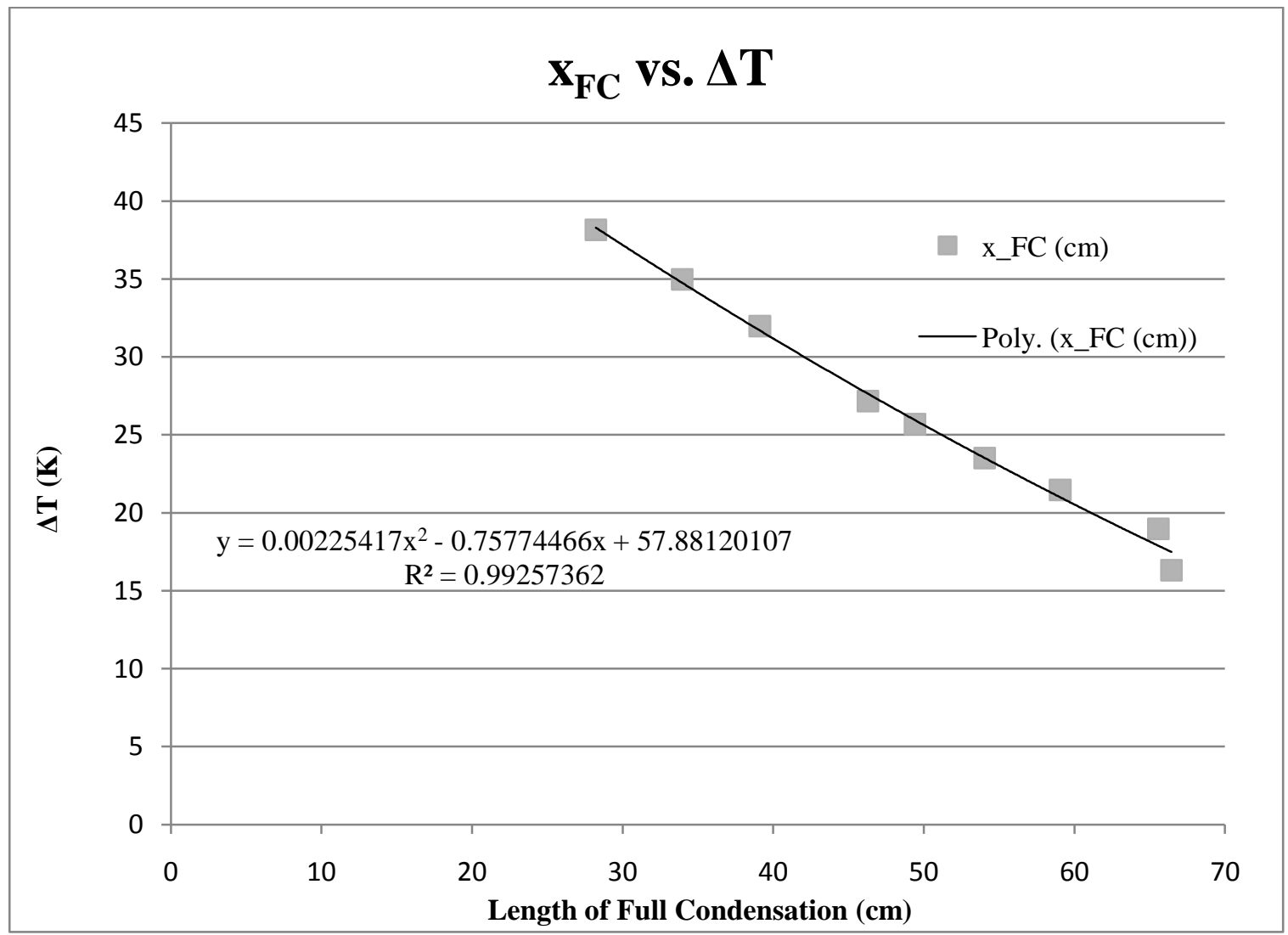

Figure A.2: In this chart, data from a particular full or complete condensation case is shown. Having the inlet mass flow rate actively fixed at 1.75 grams per second the inlet pressure was actively changed through a range of values. These changes of pressures effectively were describing different temperature differences or $\Delta T$. 


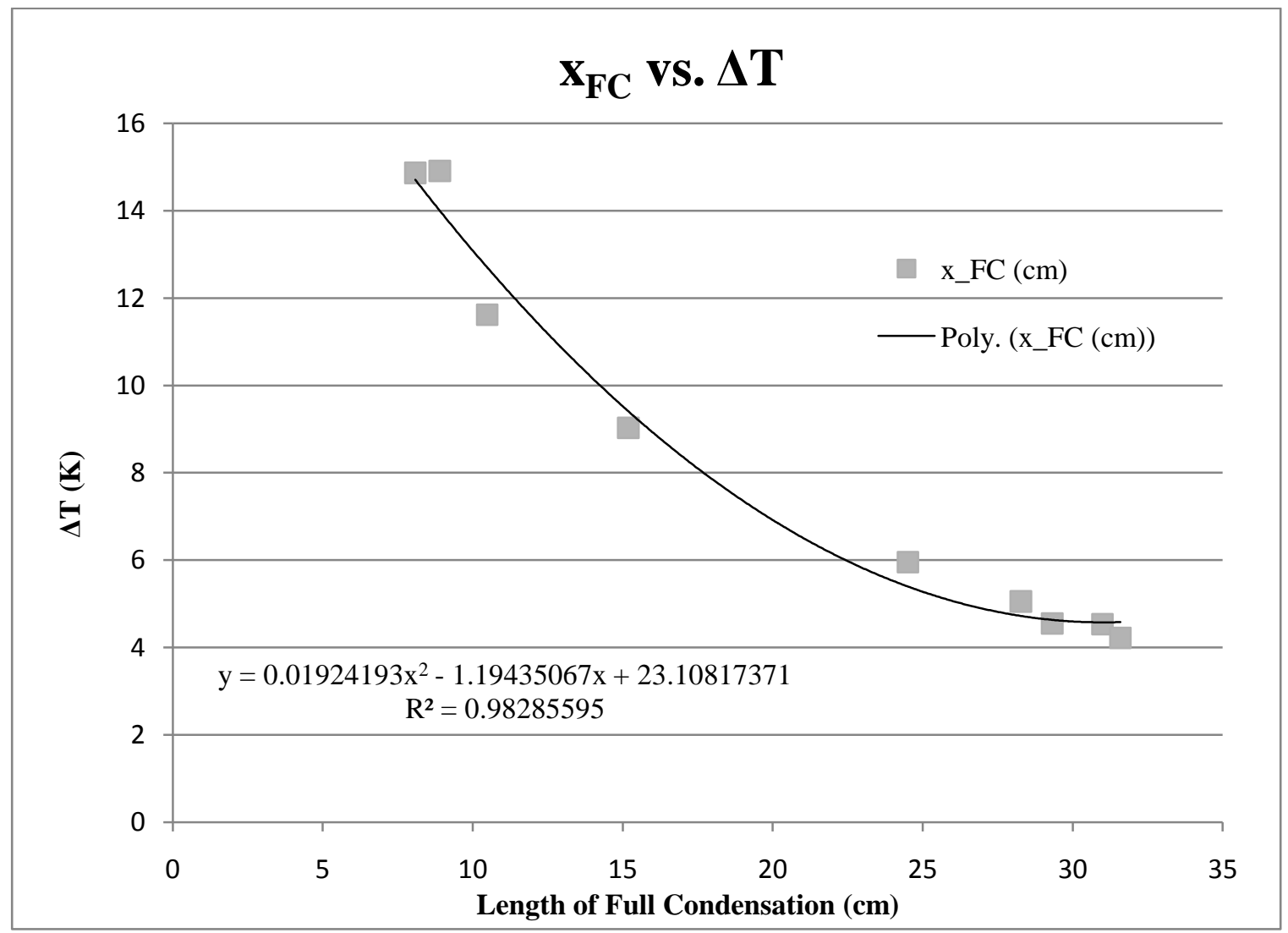

Figure A.3: In this chart, data from a particular full or complete condensation case is shown. Having the inlet mass flow rate actively fixed at 0.25 grams per second the inlet pressure was actively changed through a range of values. These changes of pressures effectively were describing different temperature differences or $\Delta T$. 


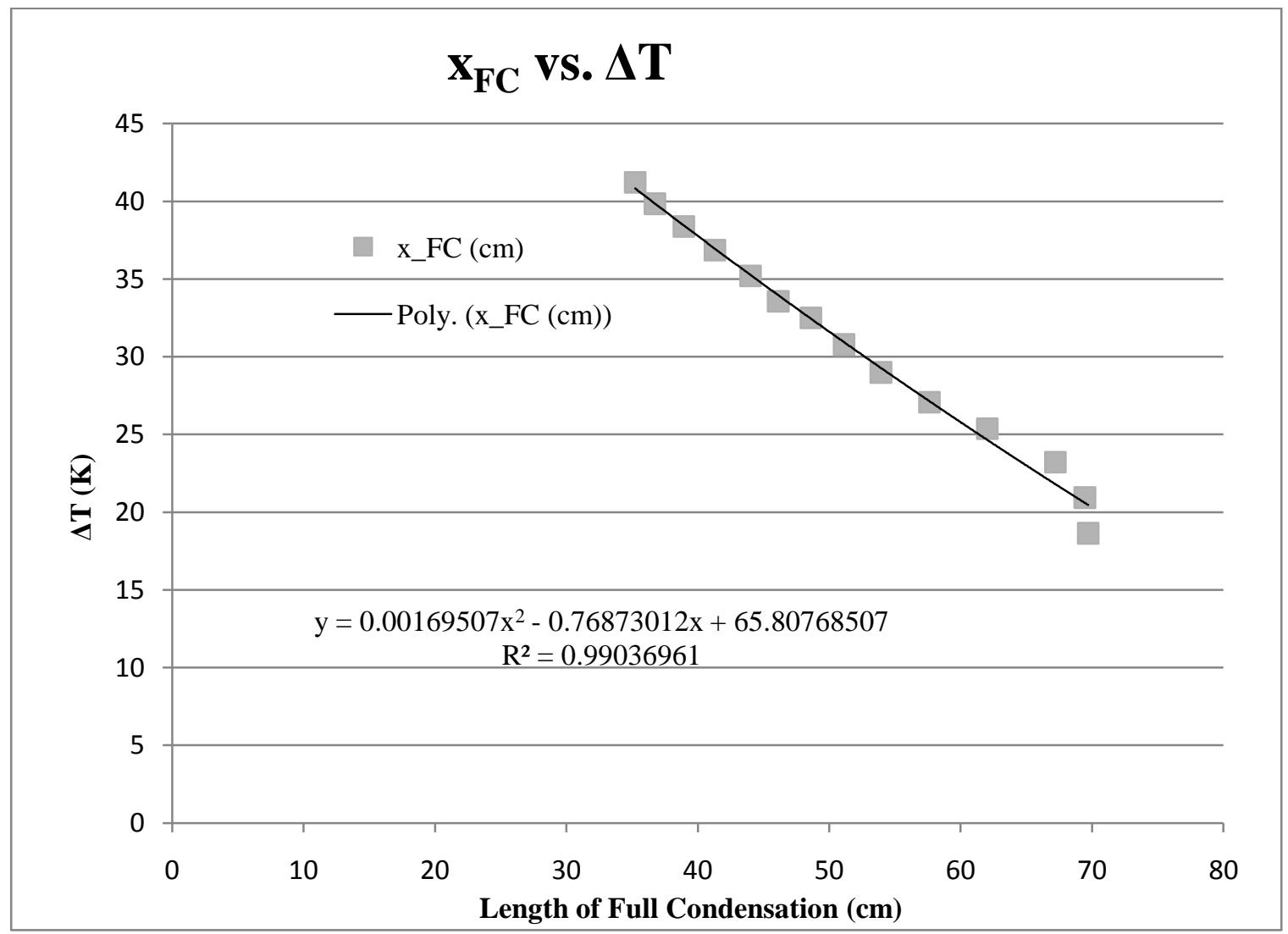

Figure A. 4: In this chart, data from a particular full or complete condensation case is shown. Having the inlet mass flow rate actively fixed at 2.0 grams per second the inlet pressure was actively changed through a range of values. These changes of pressures effectively were describing different temperature differences or $\Delta T$. 


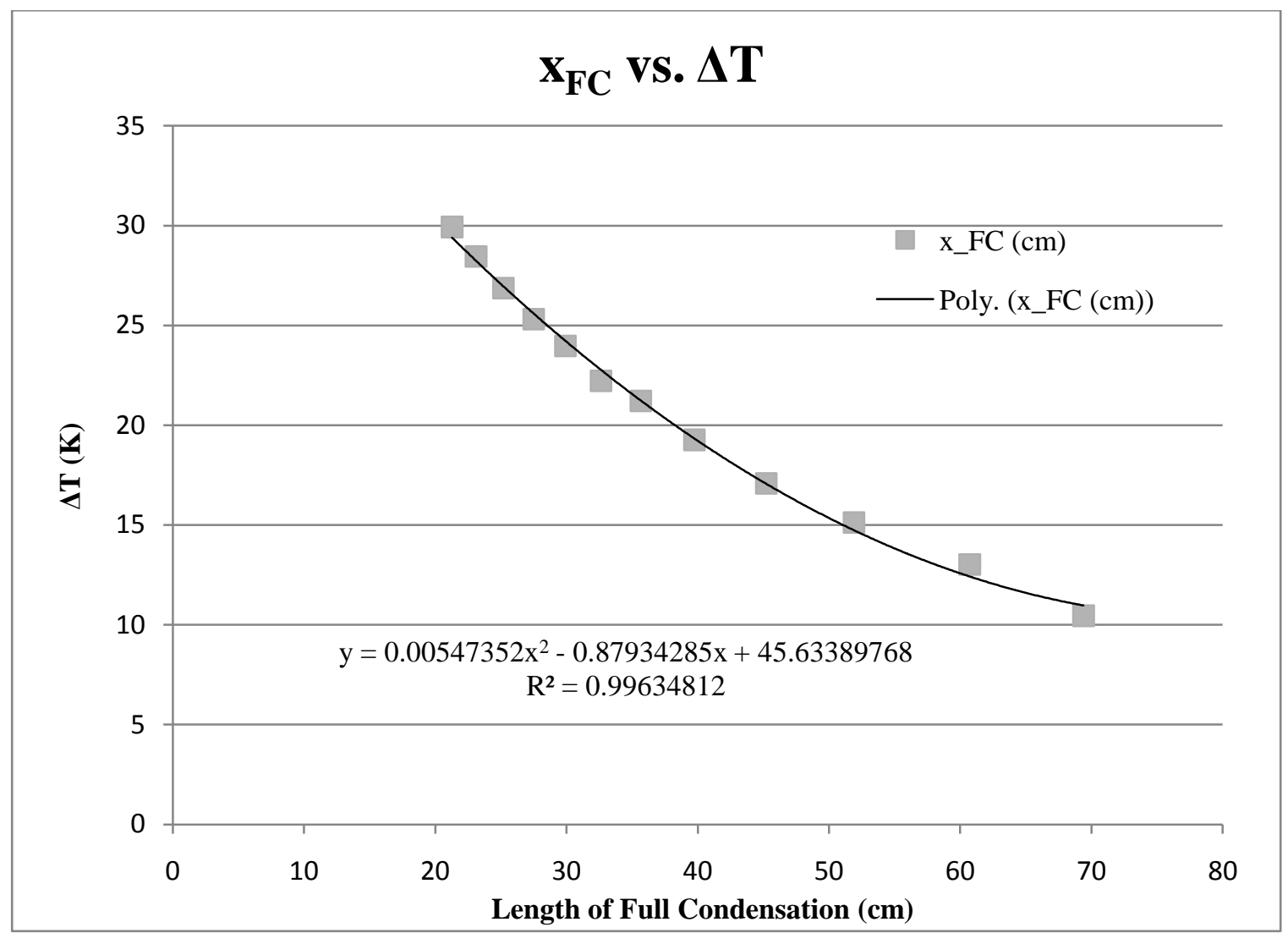

Figure A.5: In this chart, data from a particular full or complete condensation case is shown. Having the inlet mass flow rate actively fixed at $\mathbf{1 . 0}$ gram per second the inlet pressure was actively changed through a range of values. These changes of pressures effectively were describing different temperature differences or $\Delta T$. 


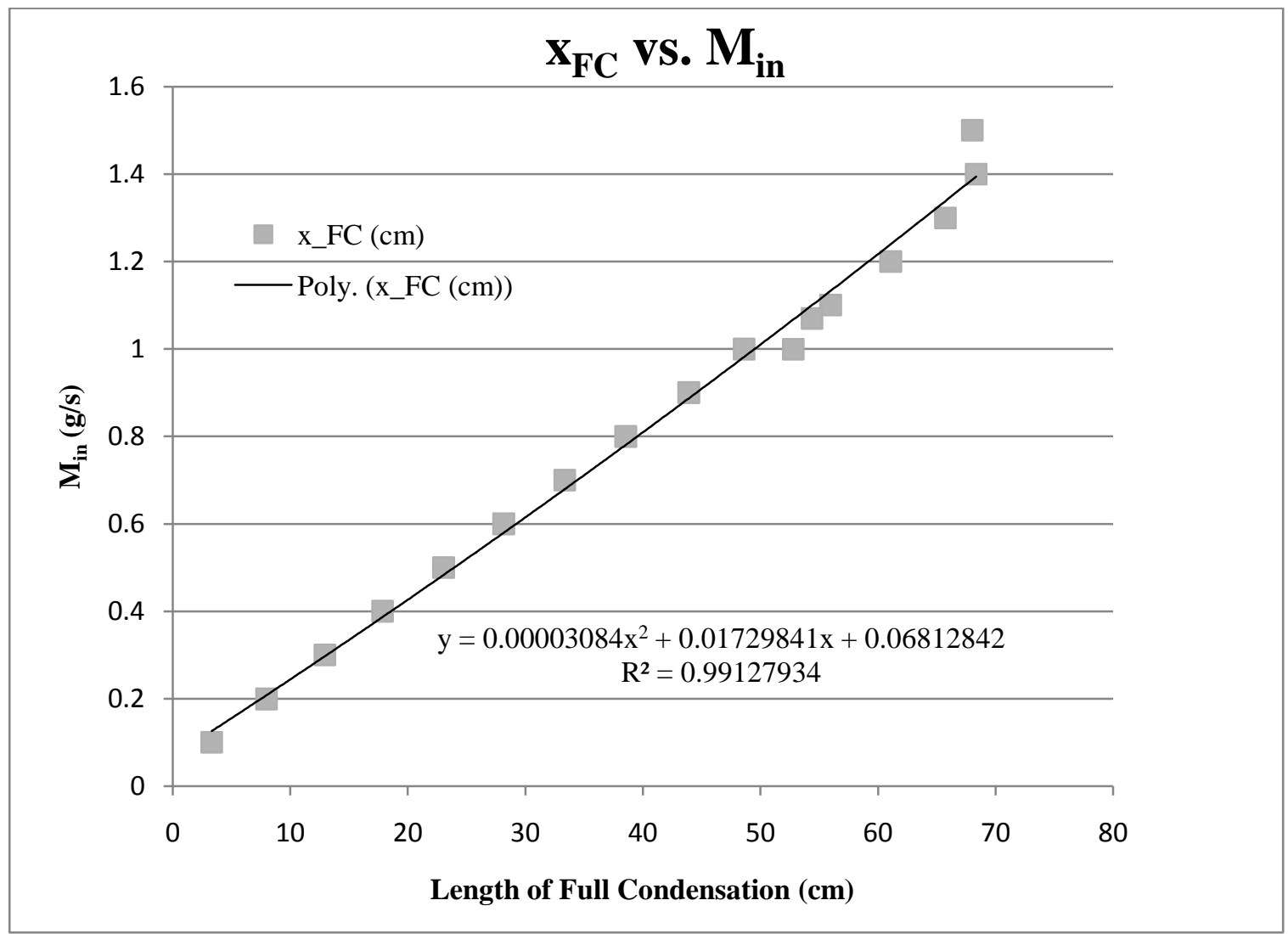

Figure A.6: In this chart, data from a particular full or complete condensation case is shown. Having the inlet vapor pressure actively fixed at $55 \mathrm{kPa}(8 \mathrm{psi})$ the inlet mass flow rate was actively changed through a range of values. 


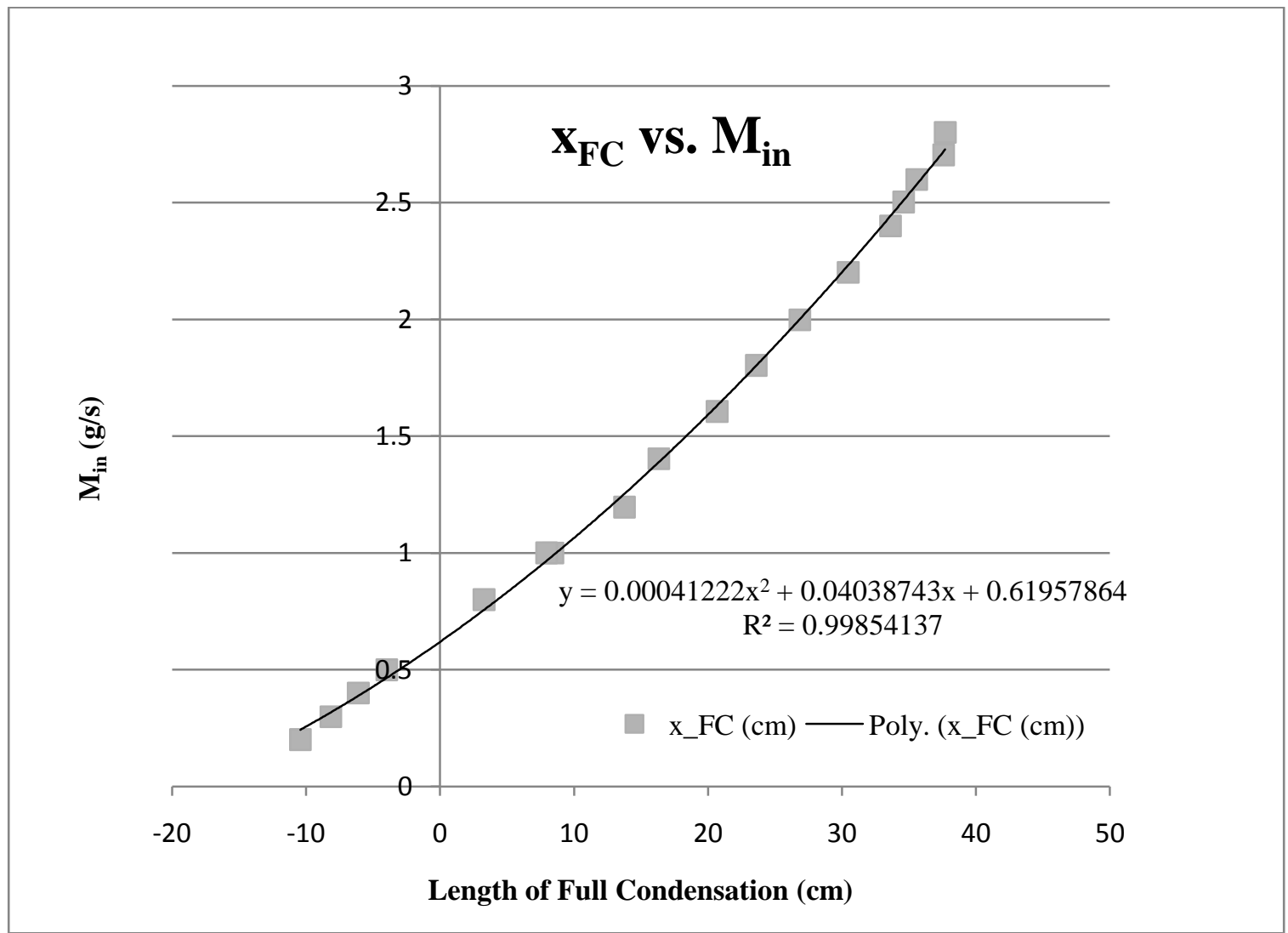

Figure A.7: In this chart, data from a particular full or complete condensation case is shown. Having the inlet vapor pressure actively fixed at $172 \mathrm{kPa}(25 \mathrm{psi})$ the inlet mass flow rate was actively changed through a range of values. 


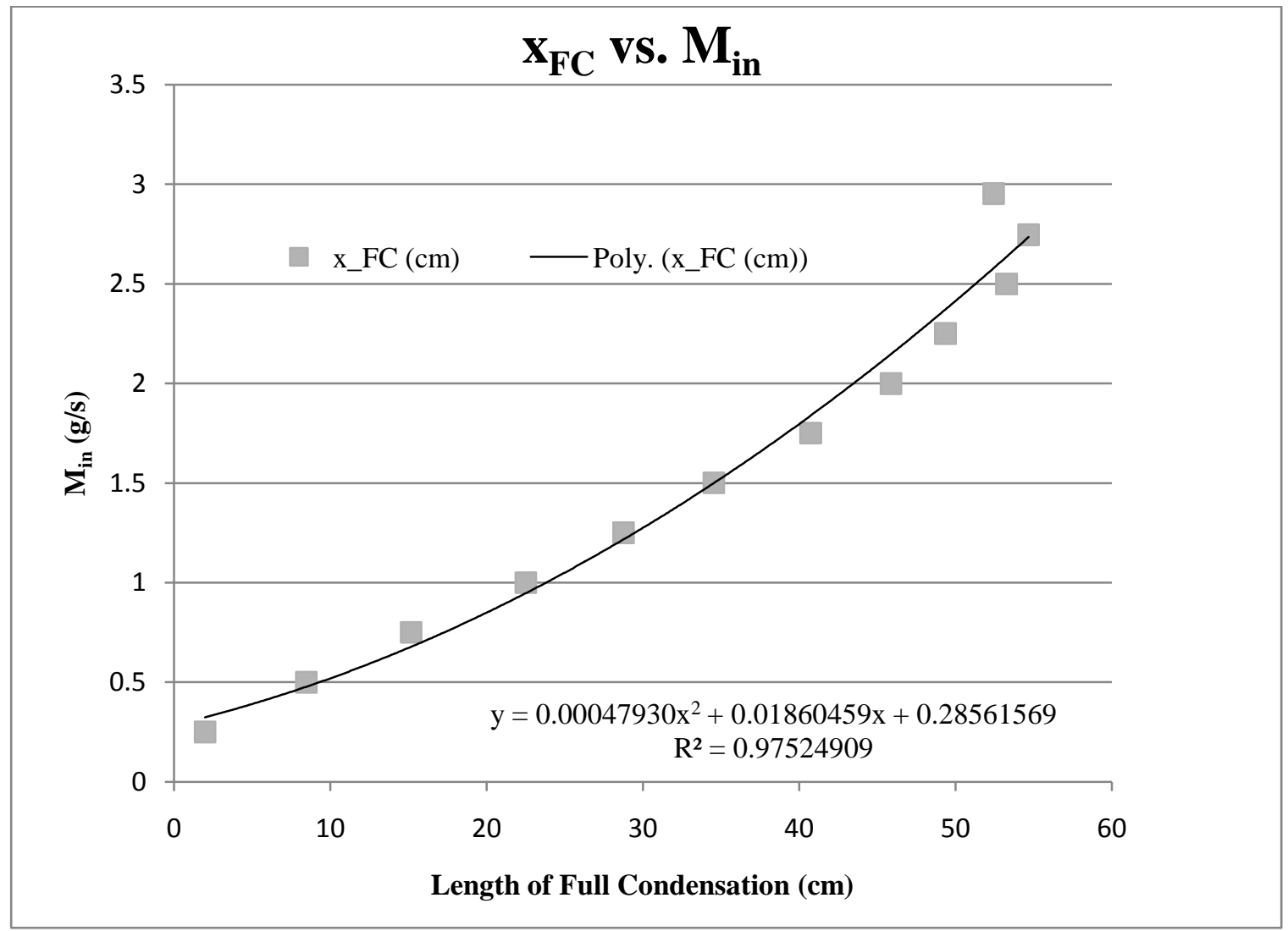

Figure A.8: In this chart, data from a particular full or complete condensation case is shown. Having the inlet vapor pressure actively fixed at $117 \mathrm{kPa}(17 \mathrm{psi})$ the inlet mass flow rate was actively changed through a range of values. 


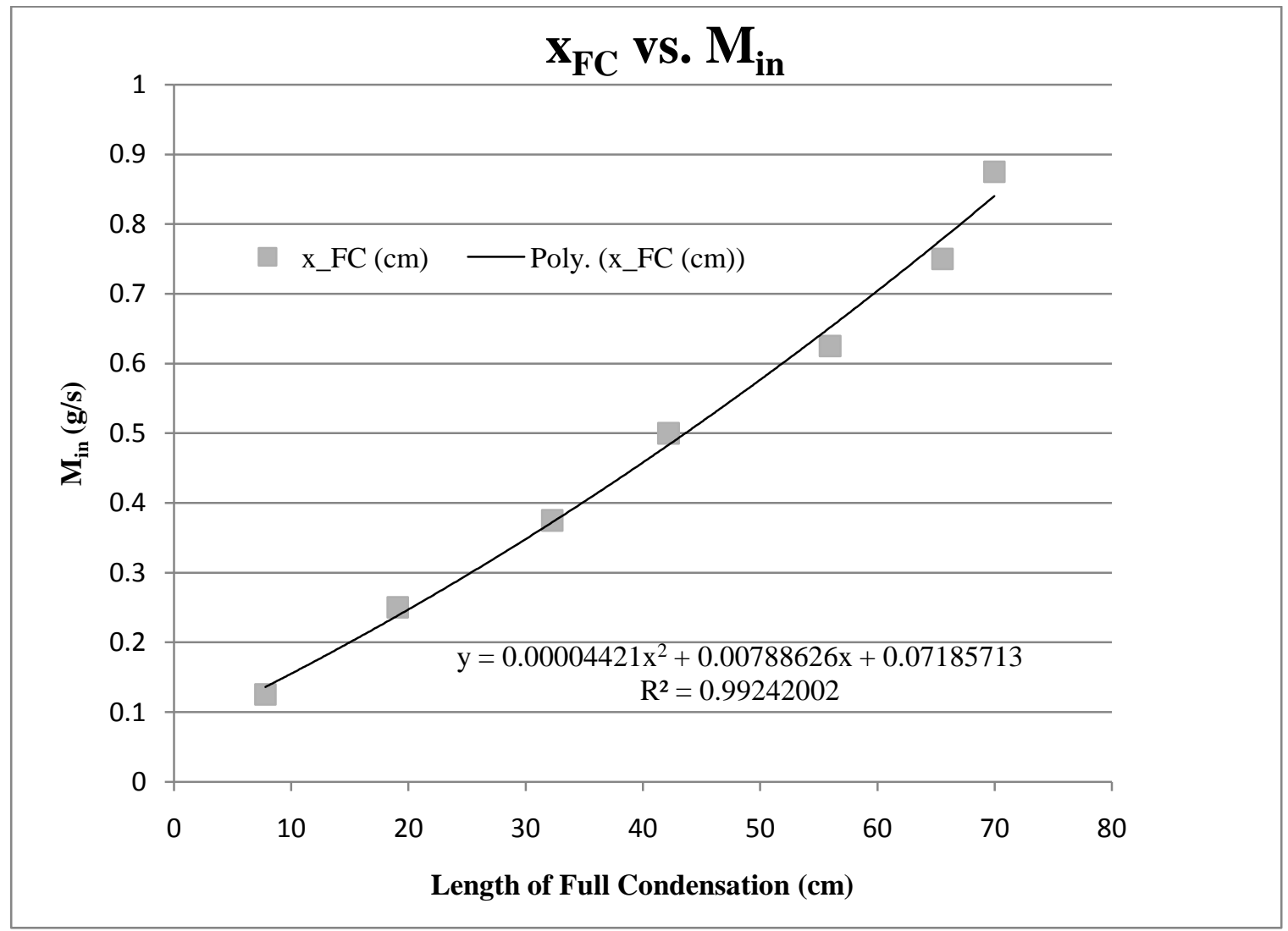

Figure A.9: In this chart, data from a particular full or complete condensation case is shown. Having the inlet vapor pressure actively fixed at $41 \mathrm{kPa}(6 \mathrm{psi})$ the inlet mass flow rate was actively changed through a range of values. 


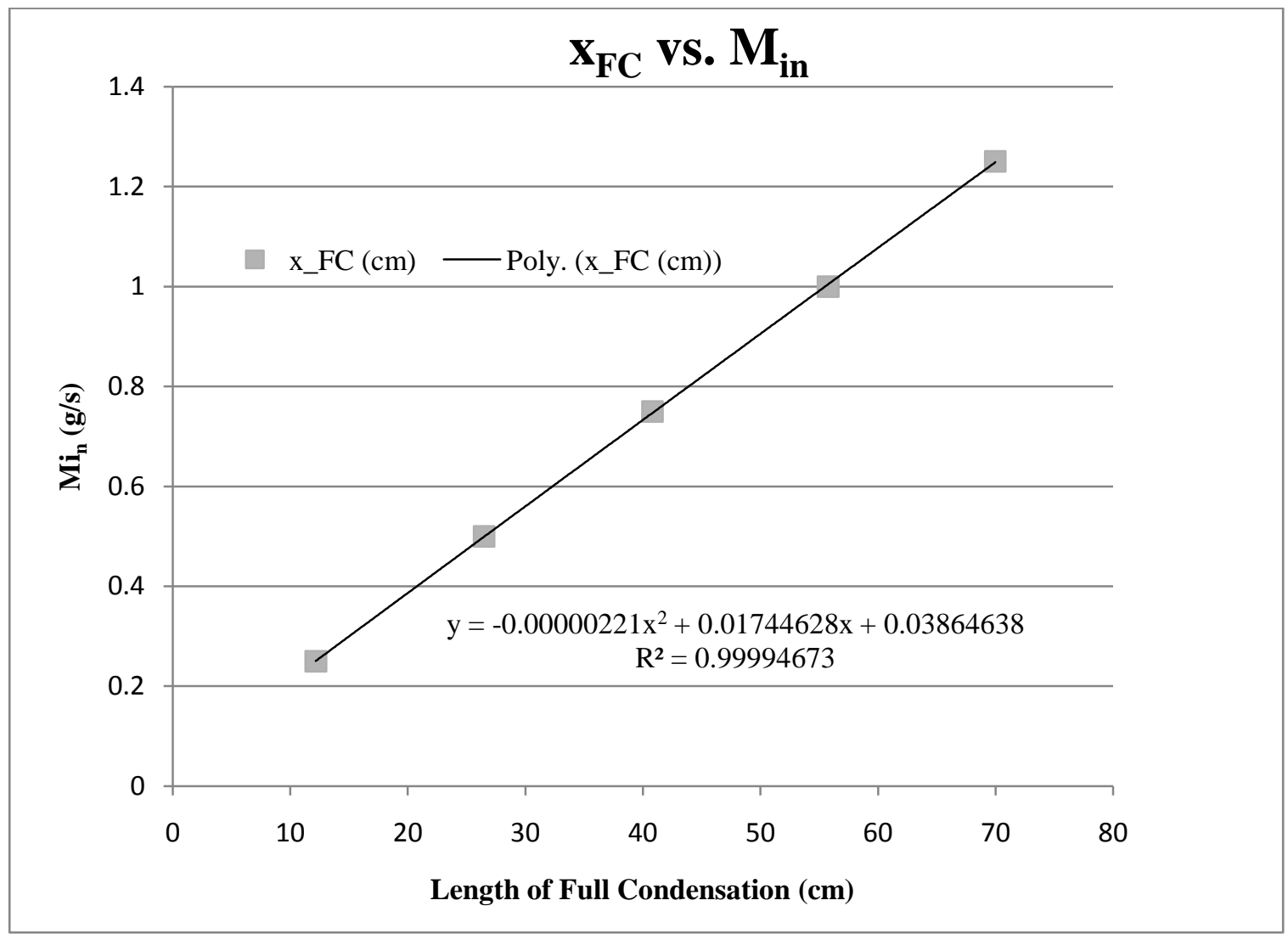

Figure A.10: In this chart, data from a particular full or complete condensation case is shown. Having the inlet vapor pressure actively fixed at $72 \mathrm{kPa}(10 \mathrm{psi})$ the inlet mass flow rate was actively changed through a range of values. 


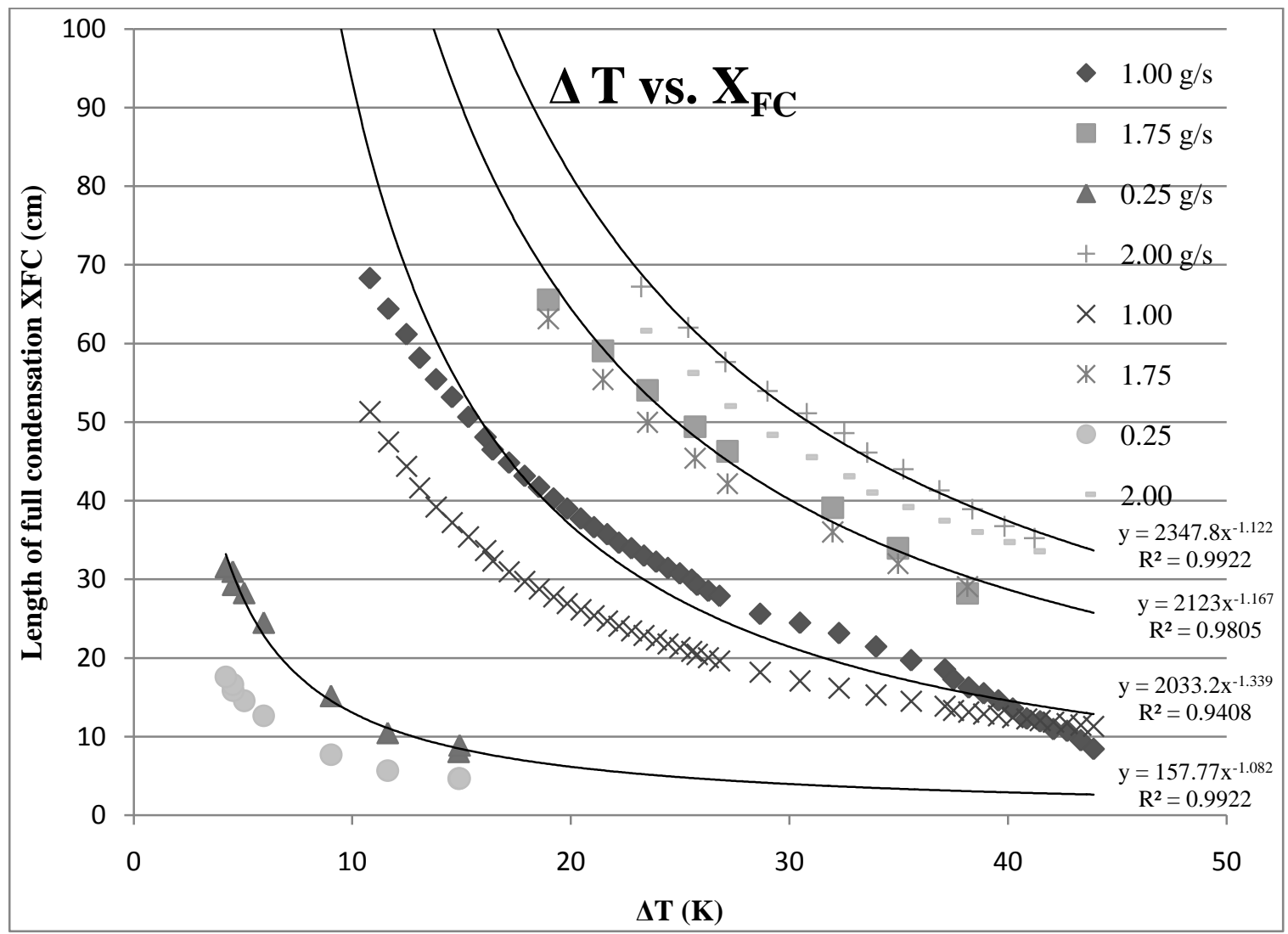

Figure A.11: In this chart, data from a specific set of full or complete condensation cases are shown. Having the inlet mass flow rate actively fixed from 0.25 to 2.0 grams per second, the inlet vapor pressure was actively changed from $30 \mathrm{kPa}$ to 155 kPa (4 psia to 22 psia). 


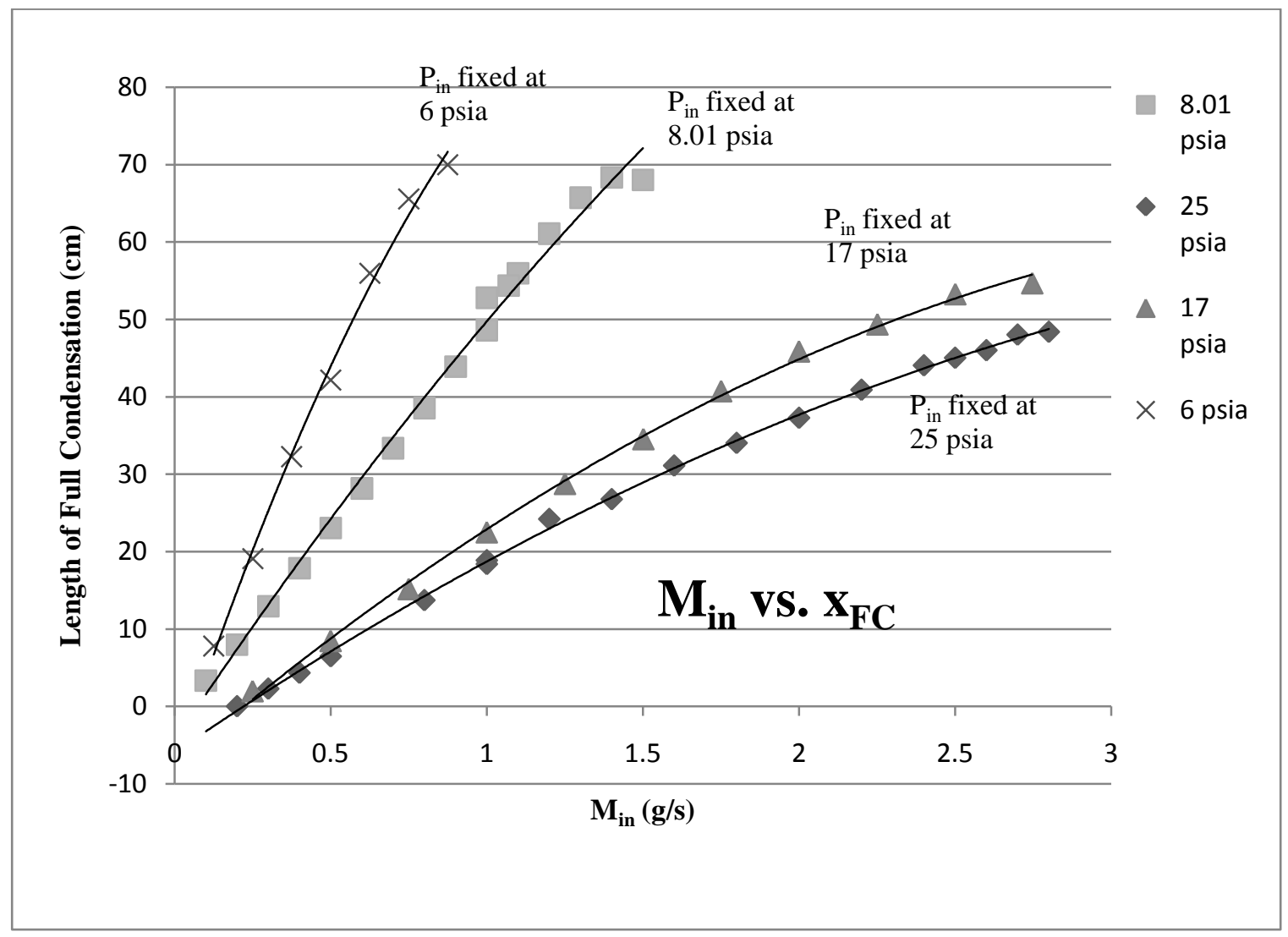

Figure A.12: In this chart, data from a specific set of full or complete condensation cases are shown. Having the inlet vapor pressure actively fixed from 6 to 25 psia (41 to $172 \mathrm{kPa}$ ) the inlet mass flow rates were actively changed from 0.25 to 2.75 grams per second. 